\title{
INVESTIGATION OF BIT HYDRAULICS FOR GASIFIED DRILLING FLUIDS
}

\author{
A THESIS SUBMITTED TO \\ THE GRADUATE SCHOOL OF NATURAL AND APPLIED SCIENCES \\ OF \\ THE MIDDLE EAST TECHNICAL UNIVERSITY
}

BY

HÜSEYIN ALİ DOĞAN

IN PARTIAL FULLFILMENT OF THE REQUIREMENTS FOR THE DEGREE $\mathrm{OF}$ MASTER OF SCIENCE IN

THE DEPARTMENT OF PETROLEUM AND NATURAL GAS ENGINEERING

APRIL 2004 
Approval of the Graduate School of Natural and Applied Sciences

\section{Prof. Dr. Canan Özgen Director}

I certify that this thesis satisfies all the requirements as a thesis for the degree of Master of Science.

\section{Prof. Dr. Birol Demiral Head of Department}

This is to certify that we have read this thesis and that in our opinion it is fully adequate, in scope and quality, as a thesis for the degree of Master of Science.

Assoc. Prof. Dr. İ. Hakk1

Gücüyener

Co-Supervisor
Assist. Prof. Dr. M. Evren

Özbayoğlu

Supervisor

Examining Committee Members

Prof. Dr. Birol Demiral (Chair Person)

Prof. Dr. Mahmut Parlaktuna

Assoc. Prof. Dr. İ. Hakkı Gücüyener

Assoc. Prof. Dr. Serhat Akın

Assist. Prof. Dr. M. Evren Özbayoğlu 


\author{
ABSTRACT \\ INVESTIGATION OF BIT HYDRAULICS FOR \\ GASIFIED DRILLING FLUIDS \\ Doğan, Hüseyin Ali \\ M.S., Department of Petroleum and Natural Gas Engineering \\ Supervisor: Assist. Prof. Dr. M. Evren Özbayoğlu \\ Co-Supervisor: Assoc. Prof. Dr. İ. Hakkı Gücüyener
}

April 2004, 96 pages

Accurate determination of the pressure losses at the bit is very important for drilling practices in petroleum industry. In the literature, there are several studies on determination of the pressure losses. Major focus is concentrated on single phase drilling fluids, which is far from accurate estimation of pressure losses for multiphase fluids, i.e., fluids including a liquid and a gas phase, at the bit. Some of 
these models are valid for multiphase fluids, however, they are either valid for very high gas flow rates, or developed using very strong assumptions.

This study presents a mathematical model for calculating bit hydraulics for gasified drilling fluids. The theory, which is valid for both sonic (critical) and subsonic (sub-critical) regimes, is based on the solution of the general energy equation for compressible fluid flow. The model is sensitive to changes in internal energy, temperature and compressibility. In addition, the model uses "mixture sound velocity" approach.

A computer program is developed based on the proposed mathematical model. The program calculates pressure drop through a nozzle in subsonic flow region, and suggest flow rate if the calculated pressure drop values is in the sonic flow pressure ranges.

The program has been run at reasonable field data. The results of the models have been compared with the results of existing models in the literature. The results show that the pressure losses through the bit can be estimated with a variation less than 9\%. Also, it has been observed that bottom hole pressure, velocity of the liquid phase and nozzle size have a strong influence on bit pressure drop.

Keywords: Gasified Drilling Fluids, Bit Hydraulics, Sonic (Critical) and Subsonic (Sub-critical) Regimes, Multiphase Flow, and Sound Wave Transmission. 


\title{
Öz
}

\section{GAZ KARIŞIMLI SONDAJ SIVILARI İÇİN MATKAP HIDROLİGININ İNCELENMESİ}

\author{
Doğan, Hüseyin Ali \\ Yüksek Lisans Tezi, Petrol ve Doğal Gaz Mühendisliği \\ Tez Yöneticisi: Yard. Doç. Dr. M. Evren Özbayoğlu \\ Yardımcı Tez Yöneticisi: Doç. Dr. İ. Hakkı Gücüyener
}

Nisan 2004, 96 sayfa

Petrol sektöründe yapılan sondaj operasyonlarında, matkaplardaki basınç kayıplarının kesin olarak belirlenmesi çok önemlidir. Literatürde, basınç kayıplarının hesaplanması üzerine yapılmış çalışmalar mevcuttur. Bunlardan birçoğu, tek fazlı sondaj akışkanları için kullanılan bağıntı ve yöntemler içermekte olup, çok fazlı sondaj akışkanları, bir başka deyişle sıvı gaz karışımları için, basınç düşümlerinin başarılı bir şekilde hesaplanmasını sağlamaktan çok uzaktır. Varolan 
çalışmalardan birkaçı ise, ya yüksek gaz akış hızlarında uygun sonuçlar ya da veren birçok varsayıma dayanarak meydana getirilen çalışmalardır.

$\mathrm{Bu}$ çalışma, gazlı sondaj akışkanları hidroliğini hesaplayacak bir matematiksel model sunmaktadır. Kritik ve kritik altı akış rejimlerine uygun olan bu model, sıkıştırılabilir akış için olan temel enerji denkleminden elde edilmiştir. Model, iç enerji, sıkıştırılabilme çarpanı ve sıcaklık değişimlerini dikkate almaktadır. Buna ek olarak, "karışımların ses hızları" yaklaşımı bu modelde kullanılmıştır.

Geliştirilen matematiksel model kullanılarak bir bilgisayar programı oluşturulmuştur. Bu program, matkap basınç kayıplarını ses altı bölgesinde hesaplamakta ve eğer akış ses üstü bölgede ise ses, altı bölgesine uygun akış hızları önermektedir.

Bilgisayar programı, saha değerlerine uygun verilerle çalıştırılmıştır. Elde edilen sonuçlar, literatürde olan modellerden elde edilen sonuçlarla karşılaştırılmış ve geliştirilen modelin sonuçlarının \%9'dan az bir fark gösterdiği görülmüştür. Ayrıca, kuyu dibi basıncının, sıvı faz hızlının ve nozul çapının matkap basınç kaybı değerleri üzerinde çok etkili oldukları gözlenmiştir.

Anahtar Kelimeler: Gaz Karışımlı Sondaj Sıvıları, Matkap Hidroliği, Ses Altı (Kritik Altı) ve Ses Üstü (Kritik) Rejimleri, Çok Fazlı Akış, Ses Dalgası Aktarımı. 


\section{ACKNOWLEDGEMENTS}

I strongly believe that the presented work is a product of combined efforts, in terms of inspiration, encouragement, support and help, contributed by a number of people. I would like to express my gratitude towards my Co-Supervisor Assoc. Prof. Dr. İ. Hakkı Gücüyener and Supervisor, Assist. Prof. Dr. M. Evren Özbayoğlu for their continuous support, advice and encouragement throughout this M.Sc. work.

My appreciation also goes to Prof. Dr. Birol Demiral, Prof. Dr. Mahmut Parlaktuna, Prof. Dr. Tanju Mehmetoğlu and Assoc. Prof. Dr. Serhat Akın for their participation in my thesis committee and for their continued support throughout this work.

I would like to thank Ms. Başak Ballı and Mr. Ilker Cankara, for their valued support, help and friendship.

I would like to express my sincere thanks to my boss and friends in my offices for their support, comments and patience. 


\section{TABLE OF CONTENTS}

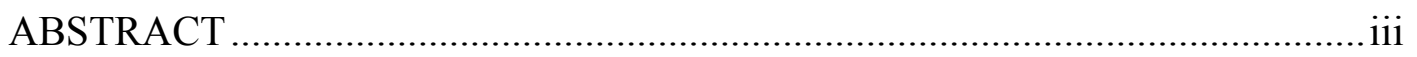

ÖZ

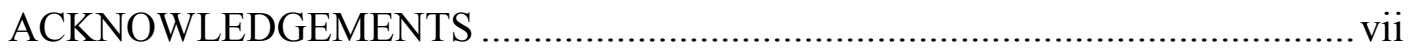

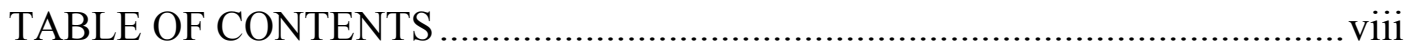

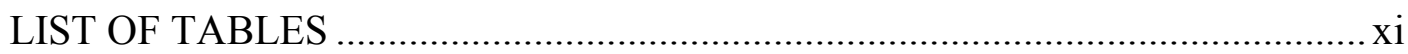

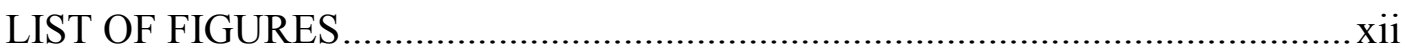

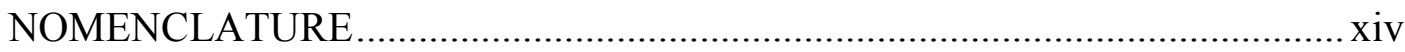

\section{CHAPTER}

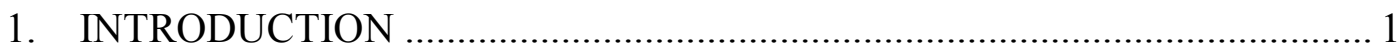

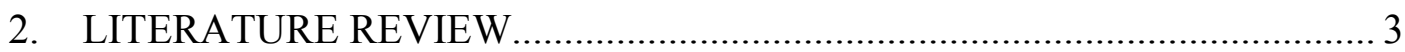

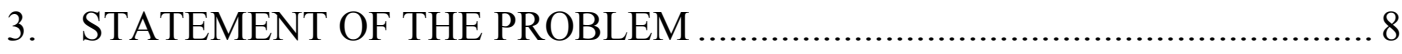

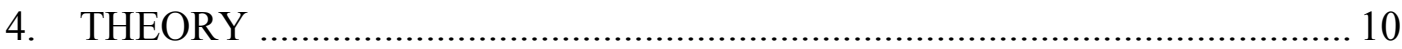

4.1. The General Energy Equation For Sonic And Sub-Sonic Flow .............. 15

4.2. Introduction to The General Energy Equation .................................... 16

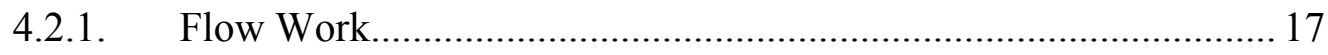

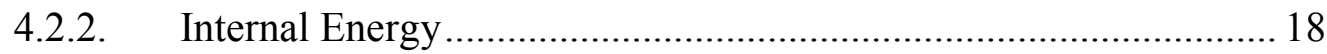

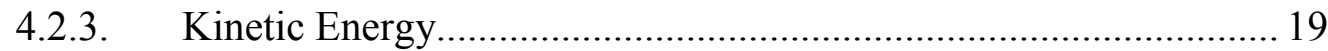




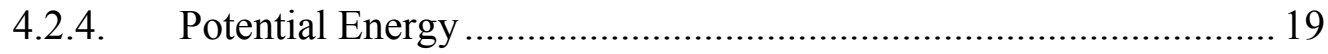

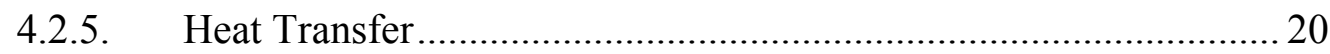

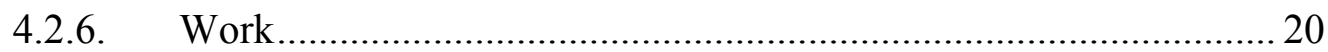

4.3. Derivation of The General Energy Equation........................................ 21

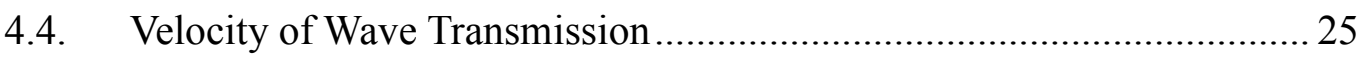

4.5. Flow Diagram of The Model............................................................... 30

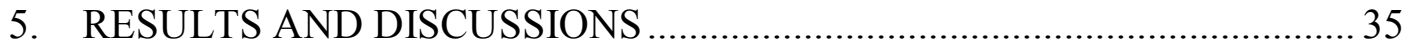

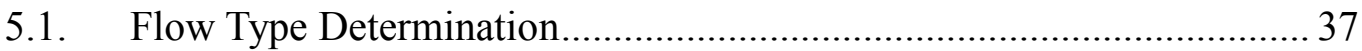

5.2. Sensitivity Analysis of Hydraulic Parameters ......................................... 39

5.2.1. Effect of Bottom Hole Pressure on Bit Pressure Drop.................... 39

5.2.2. Effect of Flow Rate on Bit Pressure Drop................................... 42

5.2.3. Effect of Bottom Hole Temperature on Bit Pressure Drop ............. 44

5.2.4. Effect of Nozzle Size on Bit Pressure Drop.................................. 46

5.2.5. Effect of Bit Size on Bit Pressure Drop ...................................... 47

5.2.6. Effect of Sonic Pressure on Bit Pressure Drop ............................ 48

5.3. Comparison of The Proposed Model with Previously Dvl. Models ....... 50

5.3.1. Effect of Bottom Hole Pressure on Bit Pressure ............................ 51

5.3.2. Effect of Liquid Flow Rate on Pressure Drop................................ 55

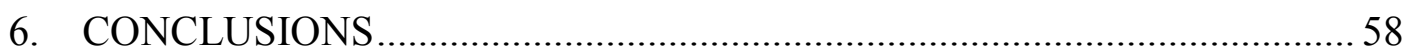

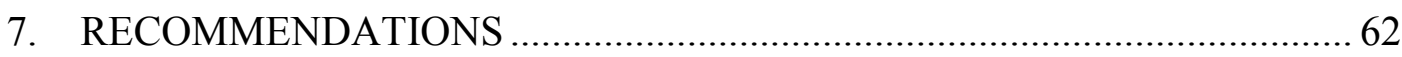

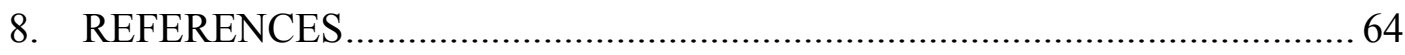




\section{APPENDICES}

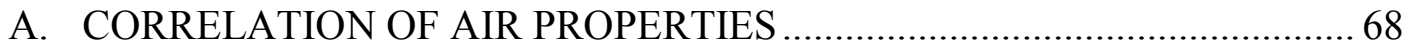

A.1. Correlation for Air Heat Capacity at Constant Pressure Values.............. 68

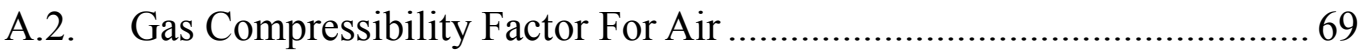

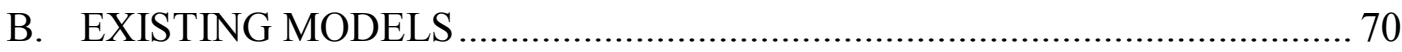

B.1. Gücüyener and Liu Model............................................................... 70

B.2. Bit Pressure Drop Determination Equation By Guo ............................ 72

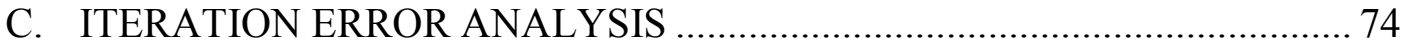

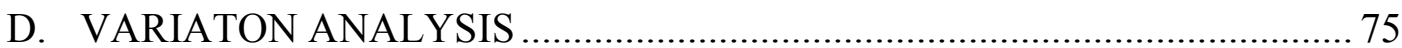

E. CALCULATED PRESSURE DROP VALUES AND VARIATION

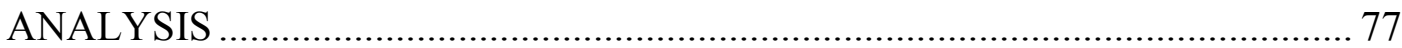




\section{LIST OF TABLES}

TABLE

1. Selected Parameters for Sample Run …............................................................ 36

2. Constant Pressure Heat Capacity Values ...................................................... 68

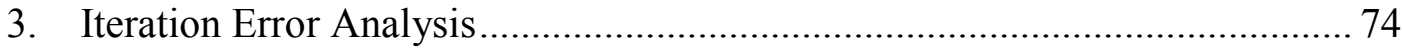

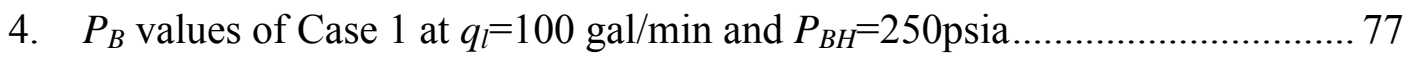

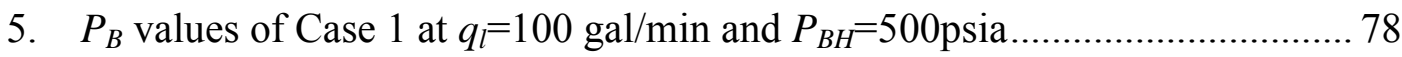

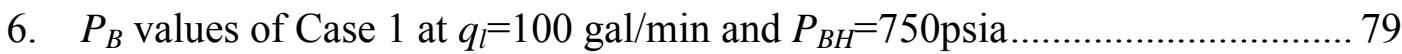

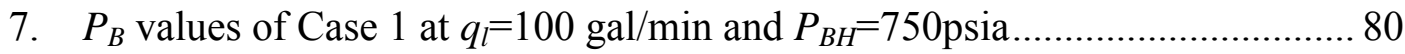

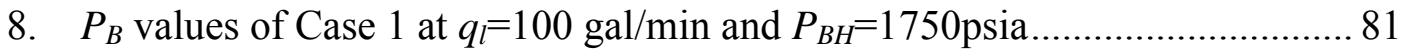

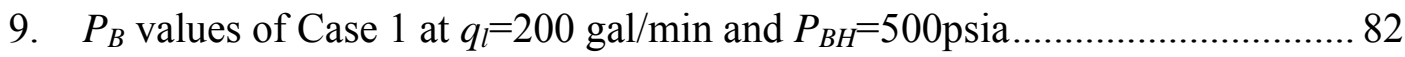

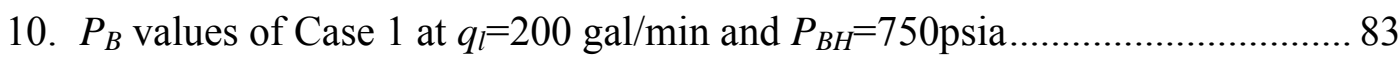

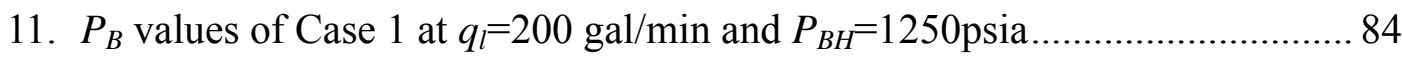

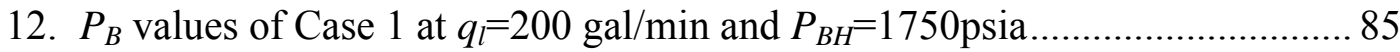

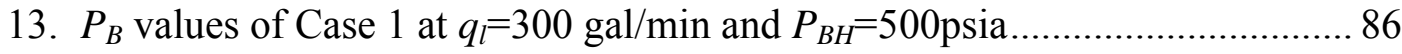

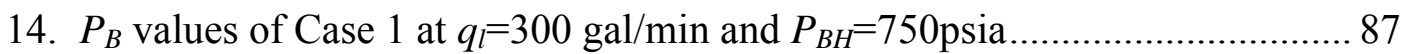

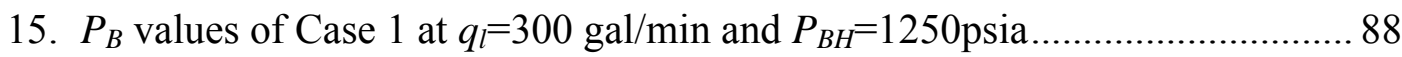

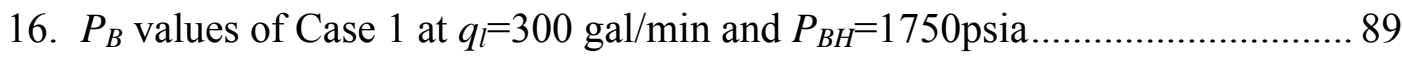




\section{LIST OF FIGURES}

\section{FIGURE}

1. Pressures vs. Flow Rate Relations At a Nozzle .............................................. 11

2. Diagram of Flow Through a Nozzle ......................................................... 14

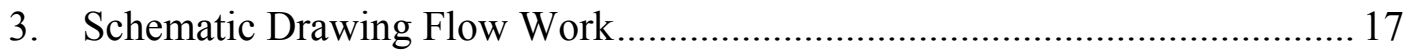

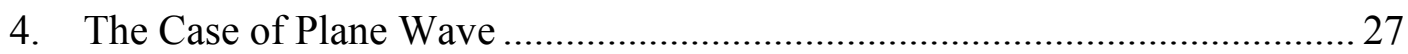

5. Two Phase Flow Map For Vertical Flow, Kaya et. al. [20] ............................. 37

6. Froude Number and Fluid Velocity Through Nozzle .................................... 39

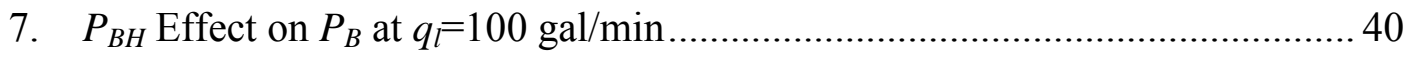

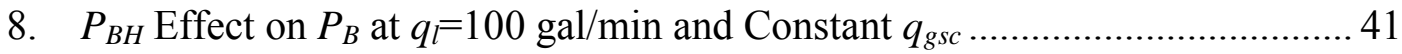

9. Liquid Flow Rate Effect on $P_{B}$ at $P_{B H}=1250$ psia and Constant $q_{l} \ldots \ldots \ldots \ldots \ldots . . . . . .42$

10. Gas Flow Rate Effect on $P_{B}$ at $P_{B H}=750$ psia and Constant $q_{g s c} \ldots \ldots \ldots \ldots \ldots \ldots . . . . . . . . . . .43$

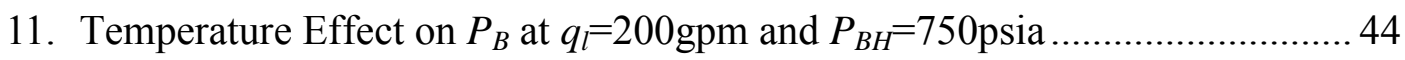

12. Temperature Effect on $P_{B}$ at $q_{g s c}=750 \mathrm{scft} / \mathrm{min}$ and $P_{B H}=750 \mathrm{psia} \ldots \ldots \ldots \ldots \ldots \ldots . . . . . .45$

13. Nozzle Size Effect on $P_{B}$ at $q_{l}=200$ gpm and $P_{B H}=750 \mathrm{psia} \ldots \ldots \ldots \ldots \ldots \ldots \ldots \ldots . . . . . . . . . . . . .46$

14. Nozzle Size Effect on $P_{B}$ at $q_{g s c}=750 \mathrm{scft} / \mathrm{min}$ and $P_{B H}=750 \mathrm{psia} \ldots \ldots \ldots \ldots \ldots \ldots . . . . . .47$

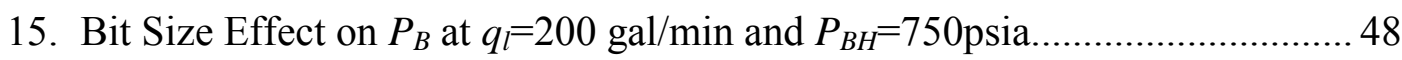

16. Sonic Pressure Effect on $P_{B}$ at $q_{l}=100 \mathrm{gal} / \mathrm{min}$ and $P_{B H}=750 \mathrm{psia} . \ldots \ldots \ldots \ldots \ldots . . . . . . . .49$

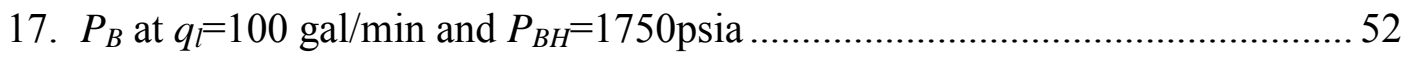

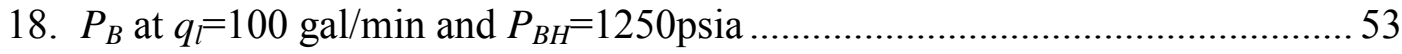




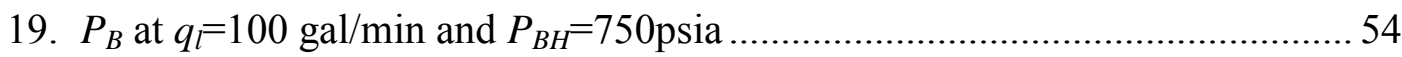

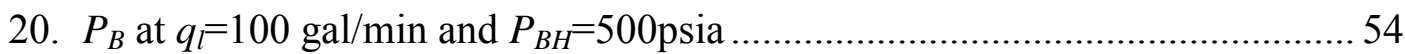

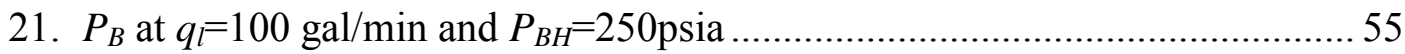

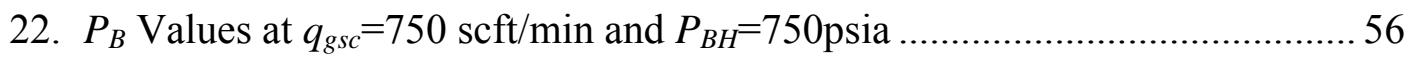

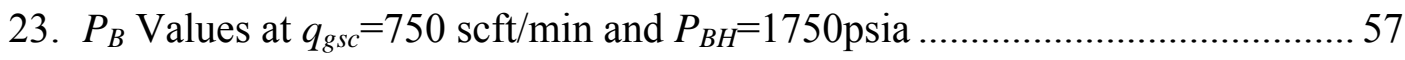

24. Variation Analysis of $P_{B H}$ at $q_{l}=100 \mathrm{gal} / \mathrm{min}$ and $P_{B H}=250 \mathrm{psi} \ldots \ldots \ldots \ldots \ldots \ldots . . . . . . . . .90$

25. Variation Analysis of $P_{B H}$ at $q_{l}=100 \mathrm{gal} / \mathrm{min}$ and $P_{B H}=500 \mathrm{psi}$..................... 90

26. Variation Analysis of $P_{B}$ at $q_{l}=100 \mathrm{gal} / \mathrm{min}$ and $P_{B H}=750 \mathrm{psi}$..................... 91

27. Variation Analysis of $P_{B}$ at $q_{l}=100 \mathrm{gal} / \mathrm{min}$ and $P_{B H}=1250 \mathrm{psi}$.................... 91

28. Variation Analysis of $P_{B}$ at $q_{l}=100 \mathrm{gal} / \mathrm{min}$ and $P_{B H}=1750 \mathrm{psi}$..................... 92

29. Variation Analysis of $P_{B}$ at $q_{l}=200 \mathrm{gal} / \mathrm{min}$ and $P_{B H}=500 \mathrm{psi} \ldots \ldots \ldots \ldots \ldots \ldots \ldots . . . . . . . . . .92$

30. Variation Analysis of $P_{B}$ at $q_{l}=200 \mathrm{gal} / \mathrm{min}$ and $P_{B H}=750 \mathrm{psi}$...................... 93

31. Variation Analysis of $P_{B}$ at $q_{l}=200 \mathrm{gal} / \mathrm{min}$ and $P_{B H}=1250 \mathrm{psi}$.................... 93

32. Variation Analysis of $P_{B}$ at $q_{l}=200 \mathrm{gal} / \mathrm{min}$ and $P_{B H}=1750 \mathrm{psi}$..................... 94

33. Variation Analysis of $P_{B}$ at $q_{l}=300 \mathrm{gal} / \mathrm{min}$ and $P_{B H}=500 \mathrm{psi} \ldots \ldots \ldots \ldots \ldots \ldots \ldots . . . . . . . . . . .94$

34. Variation Analysis of $P_{B}$ at $q_{l}=300 \mathrm{gal} / \mathrm{min}$ and $P_{B H}=750 \mathrm{psi}$..................... 95

35. Variation Analysis of $P_{B}$ at $q_{l}=300 \mathrm{gal} / \mathrm{min}$ and $P_{B H}=1250 \mathrm{psi}$.................... 95

36. Variation Analysis of $P_{B}$ at $q_{l}=300 \mathrm{gal} / \mathrm{min}$ and $P_{B H}=1750 \mathrm{psi} \ldots \ldots \ldots \ldots \ldots \ldots . . . . . . . . . .96$ 


\section{NOMENCLATURE}

\begin{tabular}{|c|c|}
\hline$a$ & Acceleration, $\mathrm{ft} / \mathrm{sec}^{2}$ \\
\hline$A$ & Area, $\mathrm{ft}$ \\
\hline$C_{p}$ & Isobaric heat capacity, $(\mathrm{ft}-\mathrm{lbf}) /\left(\mathrm{lbm}-{ }^{\circ} \mathrm{F}\right)$ \\
\hline$C_{v}$ & Isotropic heat capacity, $(\mathrm{ft}-\mathrm{lbf}) /\left(\mathrm{lbm}-{ }^{\circ} \mathrm{F}\right)$ \\
\hline$C$ & Medium compressibility, $\mathrm{psi}^{-1}$ \\
\hline$C_{N}$ & Nozzle discharge coefficient, dimensionless \\
\hline$d_{c}$ & Nozzle diameter, $\mathrm{ft}$ \\
\hline$d_{c-e q}$ & Equivalent diameter of nozzles, $\mathrm{ft}$ \\
\hline$d_{d}$ & Pipe diameter downstream of the nozzle, $\mathrm{ft}$ \\
\hline$D$ & Dilation, dimensionless \\
\hline$E$ & Internal energy of one pound fluid, $\mathrm{ft}-\mathrm{lbf} / \mathrm{lbm}$ \\
\hline$f$ & Weight fraction in the flowing fluid, dimensionless \\
\hline$F$ & Heat capacity ratio, dimensionless \\
\hline$g$ & Acceleration of gravity, $\mathrm{ft} / \mathrm{sec}^{2}$ \\
\hline$g_{c}$ & $32.2(\mathrm{lbm}-\mathrm{ft}) /\left(\mathrm{lbf}-\mathrm{sec}^{2}\right)$ \\
\hline$k$ & Heat capacity ratio \\
\hline$k e$ & Kinetic energy of one pound fluid, (ft-lbf)/lbm \\
\hline$M$ & Molecular weight, lbm/mol \\
\hline$m$ & Mass, lbm \\
\hline
\end{tabular}




\begin{tabular}{|c|c|}
\hline$\dot{m}_{c}$ & Calculated mass flow rate, $\mathrm{lbm} / \mathrm{sec}$ \\
\hline$\dot{m}_{a}$ & Actual mass flow rate, $1 \mathrm{bm} / \mathrm{sec}$ \\
\hline$N N$ & Number of nozzles, dimensionless \\
\hline$n$ & Polytropic expansion exponent, dimensionless \\
\hline$P$ & Pressure, psi \\
\hline $\bar{P}$ & Average pressure, psi \\
\hline$P_{B}$ & Bit Pressure Drop across the bit, psi \\
\hline$P_{r}$ & Reduced pressure, dimensionless \\
\hline$P_{R}$ & Pressure drop ratio, dimensionless \\
\hline pe & Potential energy of one pound fluid, (ft-lbf)/lbm \\
\hline$P E$ & Potential energy, ft-lbf \\
\hline$Q$ & Heat transferred to one pound of the flowing fluid, $(\mathrm{ft}-\mathrm{lbm}) / \mathrm{lbm}$ \\
\hline$q$ & Flow rate, cuft/sec \\
\hline$q_{g s c}$ & Flow rate at standard conditions, $\mathrm{scft} / \mathrm{sec}$ \\
\hline$R$ & Universal gas constant $\left(\mathrm{psi}-\mathrm{ft}^{3}\right) /\left(\mathrm{lbm}-\mathrm{mol}-{ }^{\circ} \mathrm{R}\right)$ \\
\hline$s$ & Condensation \\
\hline$T$ & Temperature, ${ }^{\circ} \mathrm{F}$ \\
\hline $\bar{T}$ & Average temperature, ${ }^{\circ} \mathrm{F}$ \\
\hline$T_{r}$ & Reduced temperature \\
\hline$W$ & Work, ft-lbf \\
\hline$w$ & Work of one pound fluid, (ft-lbf)/lbm \\
\hline$V$ & Volume, cuft \\
\hline$z$ & Gas compressibility factor, dimensionless \\
\hline
\end{tabular}


Z Elevation, $\mathrm{ft}$

\section{Greek Letters}

$\vartheta \quad$ Velocity, $\mathrm{ft} / \mathrm{sec}$

$\kappa \quad$ Elasticity, psi

$\beta \quad$ Volumetric fraction, dimensionless

$v \quad$ Specific volume, $\mathrm{ft}^{3} / \mathrm{lbm}$

$\rho \quad$ Density, $1 \mathrm{lbm} / \mathrm{ft}^{3}$

\section{Subscripts}
$f \quad$ fluid
$g \quad$ gas
$l \quad$ liquid
$m \quad$ mixture
BH bottom hole
$0 \quad$ initial
1 upstream of the nozzle
2 at the nozzle throat
3 condition just downstream of the nozzle throat if flow is subsonic
4 recovered condition downstream of polytropic compression. 


\section{CHAPTER 1}

\section{INTRODUCTION}

Involved with highly fractured low pressure formations and depleted reservoirs, low pressure drilling, having several distinct advantages over conventional drilling, eliminates problems such as partial or total loss of circulation, formation damage, differential sticking, etc. In addition, it is proven that the low weighted drilling fluids increase the penetration rate and extend bit life.

Gasified drilling fluids have been increasingly used for drilling depleted reservoirs and highly fractured formations. Injecting gas and liquid through the drillstring generates the mixture drilling fluid. Gasification of the fluid through the drillstring leads to compressible two-phase flow in the drillstring, at the bit and at the annulus. It must be pointed out that, the effectiveness of bit could be improved by increasing in hydraulic power. The penetration rate would increase with increasing hydraulic horsepower until the cuttings were removed as fast as they were generated. In fact, the hydraulic power depends on pressure drop across the bit. Therefore, major focus has to be on the pressure drop at the bit. 
The compressible two-phase fluid has a different flow behavior than widespread single phase drilling liquids. Flow patterns, compressibility factors and temperature dependence properties differentiate the two-phase fluids from single phase incompressible fluids. There have been many attempts to define gasified drilling fluid hydraulics. Flow of two phase fluids has been expressed using either empirical correlations or using mechanistic modeling approached. Like the proposed model in this study, almost the entire mathematical models presented in the literature are based on the general energy equation. Yet, some of those models have been developed for wellhead chokes. These models have been used to guide throughout this study. In deed, in the literature, developed mathematical models exist for estimating pressure drop at the drilling bits and those are simple forms of general energy equation. The proposed model has been compared with those mathematical models. 


\section{CHAPTER 2}

\section{LITERATURE REVIEW}

Two-phase flow through a restriction may be either sonic (critical) or subsonic (sub-critical). Most of the models were developed for wellhead chokes and take sonic flow into consideration. A group of those models are comprised of empirical relationships (Omana [1], Ros [2, 3], Pilehvari [4], Osman and Dokla [5, 6]). These investigators used field data to propose a relationship to predict flow rate in the sonic region. The relationships basically consist of a three-parameter equation in which the flow rate is linearly proportional to the upstream pressure of the choke. These empirical models generally are valid over a range where experimental data were available, but they give poor results when extrapolated out of range.

The other models are theoretical relationships that have been derived from the basic fluid flow principles and they are given below.

As early as 1949, Tangren, et. al. [7] conducted the first significant study on two-phase flow through a restriction. They derived expressions for velocity of sound, equation of motion for two-phase flow and sonic flow through a choke. The 
procedure, used in their analysis, was based on the basic laws of continuity, momentum, energy and ideal gas equation of state applied for a mixture.

Many years later, Ashford [8], and Ashford and Fierce [9], using a similar approach with Tangren et. al. [7], derived the general energy equation to predict the sonic limit pressure. The model of Ashford and Fierce [9] assumed that the derivative of mass flow rate with respect to the pressure ratio is zero at sonic flow. However, the model has an uncertainty and deficiency, those are, downstream pressure cannot be easily determined and the model fails in subsonic flow.

Sachdeva, et. al. [10] extended the analysis of Ashford and Fierce [9] and proposed an equation to predict the sonic pressure ratio through a choke. It was assumed that the gas phase at the entrance of the restriction is contracted isentropically, but at downstream of the restriction, the gaseous fraction of the fluid expands polytropically. Therefore, their equations of pressure drop need only one input pressure (upstream or downstream pressure).

Fortunati [11] used a new approach, and developed correlations for sound velocity, sonic and subsonic flow, and sonic and subsonic transition. He has introduced a sound velocity equation. The developed sound velocity equation, yet, cannot be applied for low gas/liquid ratio. Gould [12] pointed out that, for mass fraction of gas less than 0.4 are not applicable for Fortunati's work. 
Perkins [13] and Clark and Perkins [14] reviewed the thermodynamic basis, and developed a theoretical framework, which is valid for both subsonic and sonic flow through a choke. In these studies, the framework constructed based on the general energy equation and sonic flow boundary could also be calculated in addition to sonic flow rate. Since the majority of these works are focused on correlating the available flow values at subsonic flow, their model is used as the major guide of the proposed model in this study. The model of Perkins' $[13,14]$ can determine variables at any point in the flowing system based on the following assumptions:

- Temperature varies with position,

- Velocity varies with position,

- The gas compressibility factor is constant,

- The liquids have a negligible compressibility compared to gas phase,

- Elevation changes are negligible,

- The flow process is adiabatic and frictionless,

- Internal energy changes are negligible

According to Perkins' $[13,14]$ study, the compressible two-phase fluid runs into a sudden expansion just at the throat of the choke. They developed an approximated relation, which depends on downstream pressure, and choke and downstream medium size. The relation is explained in detail in Chapter 4.

There are major differences between the proposed model in this study and Perkins' work [13, 14], which are factor of internal energy factor and changes in 
gas compressibility factor. The proposed model is derived from the general energy equation including the effect of internal energy and compressibility factor changes. Moreover, in Perkins' work [13, 14], the reversible adiabatic expansion of an ideal gas (polytropic expansion) is inserted into those of compressible two-phase fluid. In the proposed model, in this study the polytropic expansion is applied to only gas phase.

Guo, Harelend and Rajtar [15] used a thermodynamics based approach, and explained the pressure drop equations for whole drill string and bit. In their work, aerated mud is used. As the other models, their model was also based on generalized energy equation. Moreover, they made common assumptions, such as elimination of energy losses due to friction and that of elevation changes. However, according to Lyons, Guo and Seidel [16], the application of this model is limited with high gas volume fractions. The developed equation of Guo et. al. [15] is presented in Appendix B.

Gücüyener [17], and Liu and Medley [18] obtained an implicit equation for the pressure drop through bit nozzles. The equation is applicable for gal/liquid mixtures. The equation was based on common equation, i.e., the general energy equation. In their studies, the upstream velocity of the fluid was assumed to be zero. Actually, the difference between the velocities of upstream and nozzle was significantly large. Grounded on that fact, the assumption is logical for low gas flow rates or small nozzle sizes. In addition to this assumption, their equation 
ignores the internal energy term in the general energy equation. The development of their equation is presented in Appendix B. 


\section{CHAPTER 3}

\section{STATEMENT OF THE PROBLEM}

In drilling operations, when gasified drilling fluids are used very little is known about the, estimation of the pressure drop through the bit nozzles.

In the literature, there are a few researches focusing on this problem. Most of the existing studies have developed models for wellhead chokes; indeed, many of them are not suitable for describing flow behavior of gasified drilling fluids through nozzles. Moreover, most of these models are valid for only sonic flow, where in drilling practices, the flow is subsonic. The applicable works for pressure drop and the bit are based on many strong assumptions. Although these approximations facilitate the development and usage of the developed equations, the results of those equations are not giving exact values.

This study is aimed to improve a model suitable for the flow behavior at the bit for gasified fluids which has been derived from the general energy equation by using fewer approximations. A mathematical model is developed for determining

pressure drop at the bit, and estimating the appropriate flow rates for both liquid and gas phase to keep the mixture velocity at sub-sonic conditions. Basic 
conservation equations, i.e., momentum and energy, are used. Several other hydraulics calculations, which are used to optimise the drilling performance, are conducted, such as, hydraulic horsepower, impact force and jet velocity. The calculated pressure data are compared with other models' results available in the literature. Also, a sensitivity analysis is conducted to understand the impact of several drilling parameters on pressure drop at the bit. 


\section{CHAPTER 4}

\section{THEORY}

A bit nozzle can be treated as a restriction in a pipe "space". There may exist both sonic and subsonic flow in the restriction. During sonic flow, the flow rate through the restriction reaches a maximum value with respect to the prevailing upstream conditions. The velocity of the fluids flowing through the restriction reaches sonic (pressure wave propagation) velocity [10]. Indeed, the value of sonic velocity depends on the fluid properties. In the case of sonic flow, large turbulent energy losses are ultimately possible because of shock front [13]. This shock front is the same as the sonic wall. As a result, even if the downstream pressure is decreased, the flow rate does not increase or increase in the upstream. Pressure does not affect the flow rate, so does the downstream pressure, see Figure 1. If the upstream pressure is decreased, the flow rate does not change until the sonic subsonic boundary is reached. If the decrease in the upstream pressure continues and the pressure is lower than the sonic pressure limit, the flow rate will start to be affected. 


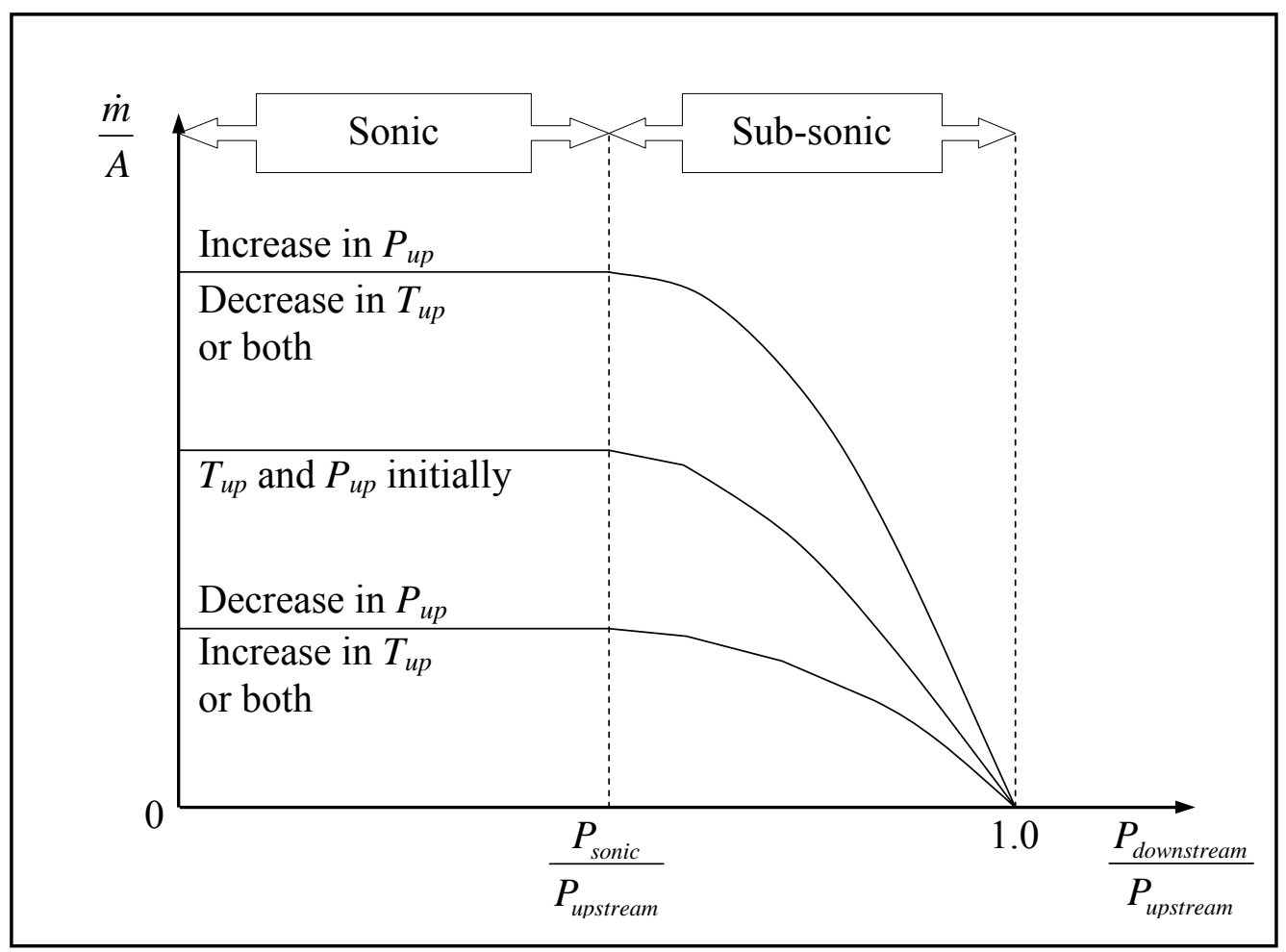

Figure 1 Pressures vs. Flow Rate Relations At a Nozzle

According to Perkins [13], the general energy equation is valid for both sonic and subsonic flow. For subsonic flow, the general energy equation shows that a polytropic expansion (reversible adiabatic expansion) occurs as the fluid accelerates downstream of the restriction. Sachdeva et. al. [10] stated that during gas expansion at the throat, a temperature gradient develops between the phases, resulting in fast heat transfer between them. This process is in-between the extremes of isothermal and adiabatic processes. Thus, a polytropic process approximates the heat flow in the gas-liquid mixtures.

In an adiabatic process, there is no heat transfer with the surroundings. Therefore, for an adiabatic process, the energy takes the form as 
$d U=-P d V$

If the system is closed and the volume is kept constant, the energy equation can also be expressed as,

$d U=C_{v} d T$

Since the system is adiabatic, substituting eq. (4.1) into (4.2) gives

$-P d V=C_{v} d T$

If the gas phase of the fluid is assumed to be ideal gas, eq. (4.3) takes the form

$$
P V=R T=\left(C_{p}-C_{v}\right) d T \Rightarrow C_{v} d T=\left(C_{v}+C_{p}\right) \frac{T}{V} d V
$$

Separateing the variables and writing $k$ representing $C_{p} / C_{v}$ gives

$$
\frac{d T}{T}+(k-1) \frac{d V}{V}=0
$$

Integration of eq. (4.5) yields

$T V^{k-1}=$ constant 
Equation (4.6) implies how temperature and volume of an ideal gas vary during an adiabatic expansion. If the gas expands, the temperature goes up. Indeed, the pressure varies also, and the ideal gas conforms to the relation given below

$\frac{P V}{T}=$ constant

Eliminating the temperature term and expressing eq. (4.6) and on the basis of one pound of flowing gas yields

$P v_{g}^{k}=$ constant

As mentioned before, polytropic expansion occurs at downstream conditions. Therefore, the variables in eq. (4.8) are properties of gas inside the nozzle. Since the system has two phases, which include liquid and gas, the heat capacity ratio of the fluid is

$n=\frac{\left(f_{g} C_{p g}+f_{l} C_{p l}\right)}{\left(f_{g} C_{v g}+f_{l} C_{v l}\right)}$

So, for two-phase fluids eq. (4.8) takes the form

$P v_{g}^{n}=$ constant 
Perkins [13] defined the sonic - subsonic flow. To determine the sonic boundary, it is required to know the magnitude of the discharge pressure in the restriction throat, $P_{2}$, as presented in Figure 2. The pressure at this point is not normally measured directly. On the other hand, pressure at the outlet of the nozzle throat, $P_{3}$, can be estimated by a pressure measurement device. For subsonic flow, Perkins [13] has developed an approximate relationship,

$$
P_{3}=P_{1}-\frac{P_{1}-P_{4}}{1-\left(d_{c} / d_{d}\right)^{1.85}}
$$

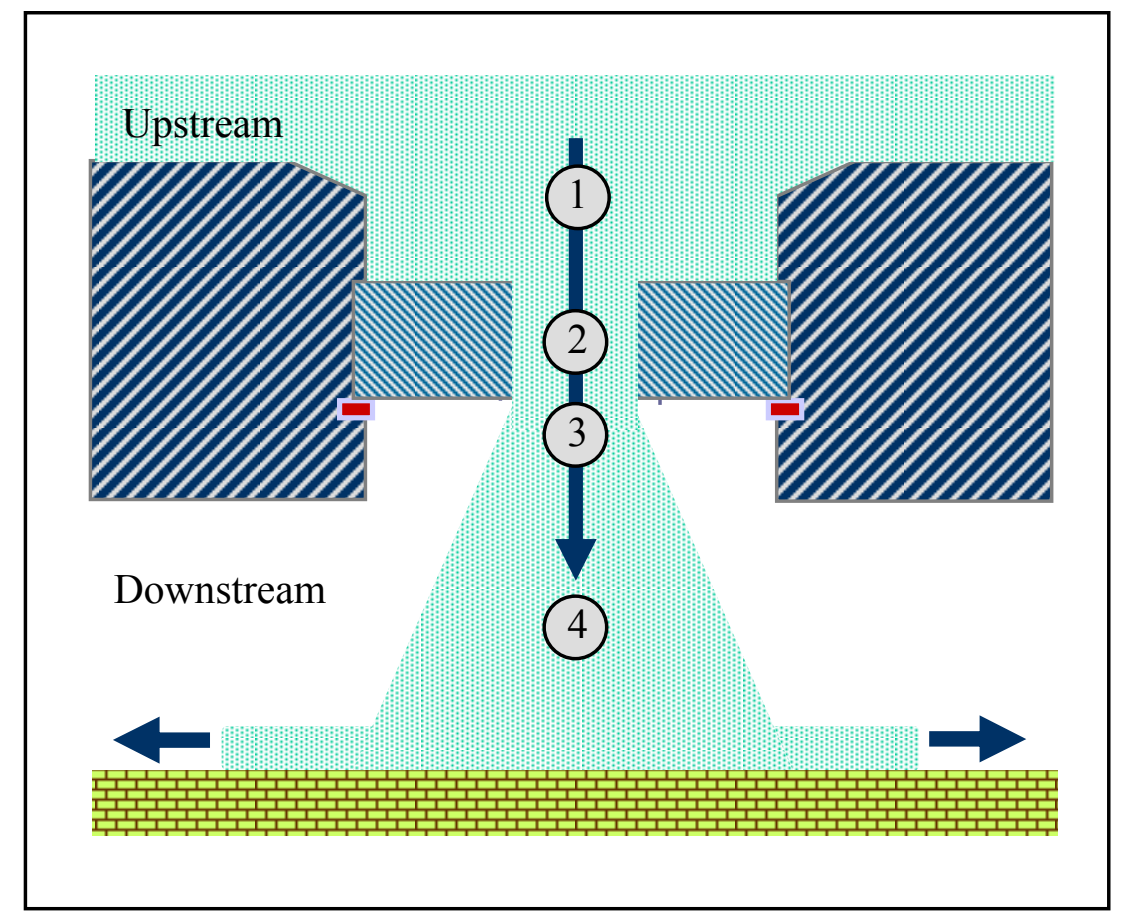

Figure 2 Diagram of Flow Through a Nozzle 


\subsection{The General Energy Equation For Sonic And Sub-Sonic Flow}

The thermodynamic framework for multiphase sonic flow is based on the principles of conservation of energy. As a gasified fluid mixture approaches to a restriction, its velocity will increase due to the reduction in the pressure. For any point in the flowing system, the following assumptions are made:

1. Velocity varies with axial (flow) direction, but for a particular arbitrary point, all components are moving with the same velocity. According to Fortunati [11], when dealing with the two-phase flow flow, all the researchers found that both phases will have the same velocity, if these conditions are satisfied;

- Velocity is greater than $32.8 \mathrm{ft} / \mathrm{sec}$

- $\quad$ Froude Number, $\mathrm{Fr}>600$, where

$$
F r=\left(\frac{\vartheta^{2}}{g_{c} d}\right)
$$

Moreover, Ros $[2,3]$ showed that there is practically no slippage at between the phase the throat. Hence, it is reasonable to assume same velocity for each phase at the nozzle.

2. The gas compressibility factor is constant. 
3. The liquid has a negligible compressibility when compared with gas.

4. Elevation changes are ignored.

5. The flow is adiabatic. Even the nozzle is not insulated; the process is so fast that the rate of heat transfer between the fluid flowing in the nozzle and the surroundings is zero. Besides, the fluid does not have enough time for any significant heat transfer inside the nozzle.

6. The flow is frictionless. According to Ros [2, 3], the wall shear forces can be neglected. Moreover, in the Omana's [1] experimental work, viscosity has a negligible effect on the pressure drop.

7. Temperature varies in the axial direction, but for an arbitrary point, all components are moving with the same temperature.

\subsection{Introduction to The General Energy Equation}

One of the fundamental laws of nature is the conservation of energy principle. It states that during an interaction, energy can change from one form to another, but the total amount of energy remains constant. That is, energy can neither be created nor destroyed; it can only change form. The first law of thermodynamics is simply an expression of the conservation of energy principle. 


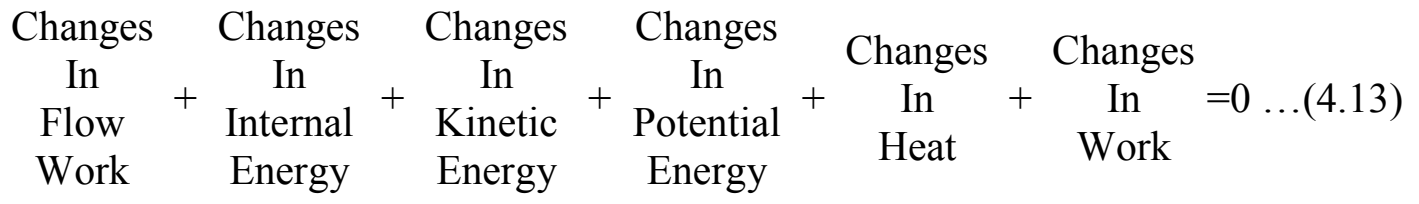

\subsubsection{Flow Work}

Control volumes involve mass flow across their boundaries and some work is required to force the mass go into or out of control volume, as seen in Figure 3.

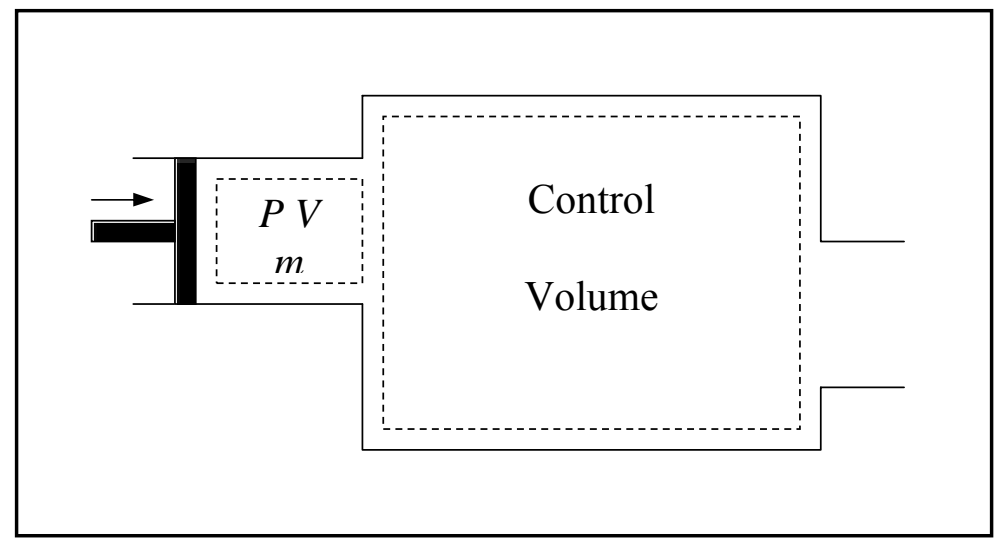

Figure 3 Schematic Drawing Flow Work

It is necessary to maintain a continuous flow through a control volume. The pressure acting on the control volume is

$W_{\text {flow }}=F L=(P A) L=P V$

On the basis of unit mass of flowing fluid, eq. (4.14) can be written as 
$w_{\text {flow }}=P v=W_{\text {flow }} / m$

In field units, eq. (4.15) can be expressed as

$w_{\text {flow }}=P v[\mathrm{psia}]\left[\mathrm{ft}^{3} / \mathrm{lbm}\right] \Rightarrow\left[\mathrm{lbf} / \mathrm{in}^{2}\right]\left[\mathrm{ft}^{3} / \mathrm{lbm}\right] \Rightarrow 144\left[\mathrm{lbf} / \mathrm{ft}^{2}\right]\left[\mathrm{ft}^{3} / \mathrm{lbm}\right]$

which reduces to

$w_{\text {flow }}=144 P v[\mathrm{ft}-\mathrm{lbf} / \mathrm{lbm}]$

\subsubsection{Internal Energy}

It is related to the molecular structure of a system and the degree of the molecular activity, and they are independent of outside reference boundary on the control volume in Figure 2. The individual molecules in a system move with same velocity, vibrate, and rotate about an axis during their random motion. The internal energy of a system is determined by

$E=C_{v} T\left[\mathrm{ft}-\mathrm{lbf} / \mathrm{lbm}-{ }^{\circ} \mathrm{F}\right]\left[{ }^{\circ} \mathrm{F}\right] \Rightarrow[\mathrm{ft}-\mathrm{lbf} / \mathrm{lbm}]$ 


\subsubsection{Kinetic Energy}

Basically, it is the energy that the system possesses as a result of its motion relative to a reference boundary on the control volume, as seen in Figure 2. From the point of view of macroscopic scale, the kinetic energy of flowing fluids is significant. On the basis of one pound of flowing fluid, this can be written as

$$
k e=\frac{0.5 m \vartheta^{2}}{g_{c}}\left[(\mathrm{ft} / \mathrm{sec})^{2}\right]\left[1 /\left(\mathrm{lbm}-\mathrm{ft} / \mathrm{lbf}-\mathrm{sec}^{2}\right)\right] \Rightarrow[\mathrm{ft}-\mathrm{lbf} / \mathrm{lbm}]
$$

\subsubsection{Potential Energy}

It is the energy that the system possesses as a result of its elevation in a gravitational field. In this study, potential energy is ignored. When compared with the other energy components, it is too small to take into consideration.

$$
P E=m g Z
$$

On the basis of unit mass of flowing fluid, eq. (4.20) can be written as

$$
p e=\frac{g Z}{g_{c}}\left[\mathrm{ft} / \mathrm{sec}^{2}\right][\mathrm{ft}]\left[1 /\left(\mathrm{lbm}-\mathrm{ft} / \mathrm{lbf}-\mathrm{sec}^{2}\right)\right] \Rightarrow[\mathrm{ft}-\mathrm{lbf} / \mathrm{lbm}]
$$




\subsubsection{Heat Transfer}

Heat is defined as the form of energy that is transferred between two systems by virtue of a temperature. It only takes place, if there is a temperature difference. As stated before, in this study, the process is so fast that the fluid does not have sufficient time for any heat transfer, thus, it is negligible.

$Q=C_{v} \Delta T$

\subsubsection{Work}

Work is the energy transfer associated with force acting through a distance. The energy can cross the boundary of the closed system only in the form of heat or work. Actually, a rising piston, a rotating shaft, and an electrical wire cross having current on the system boundaries are all associated with work interactions. In the system, in which the drilling fluid flowing through a nozzle, there is no work done by the system. Therefore, in the proposed model, the work equals to zero. 


\subsection{Derivation of The General Energy Equation}

The mathematical modelling of two - phase flow can be developed on the bases of the general energy equation. The system used, in this model, consists of a restriction. In the flow direction, there are four important points, as presented in Figure 2.

In Figure 2, the upstream of the nozzle is signed as point 1. At that point, velocity is low when compared with velocity at point 2 . At point 1 , although the pressure value is an unknown at this moment, kinetic and internal energies can be used to determine $P_{1}$. The fluid passes to point 2 , i.e. flows through the nozzles. Since the fluid accelerates, there is kinetic energy increase through the nozzle. The energy changes form from flow work to kinetic energy, and the flow work term decreases. This means that, the fluid is decompressed and polytropic expansion occurs. Because the process is fast, there is no heat transfer to and from the surroundings. Therefore, at point 2 , the temperature reduces due to the sudden adiabatic expansion. Unfortunately, pressure cannot be measured at point 2 . Actually, pressure at the outlet of the nozzle throat, $P_{3}$, can be estimated by a pressure measurement device. During the flow of fluid, for subsonic flow, there is no change in pressure at this stage, i.e., $P_{3}$ equals to $P_{2}$.

The fluid, finally, reaches to point 4 , where the fluid has the final state of energy, pressure and temperature values. Since a portion of kinetic energy is lost at 
the discharge of the nozzle due to the geometrical expansion, the pressure difference at point 4 and point 3 is small. The relation between $P_{3}$ and $P_{4}$ is expressed by eq. (4.11)

The energy changes of the fluid are explained, before the fluid pass from point 1 to point 2 . On the basis of one pound flowing fluid, the general energy equation can be written as

Initially, because of the small size of the nozzle, the difference in elevation is negligible, i.e., $Z_{1} \cong Z_{2}$. Then, since, there is neither external work done on the system nor internal work done by the system, work equals to zero. Moreover, the heat transfer is assumed to be negligible, thus $W=0$ and $Q \cong 0$.

The change in the internal energy can be expressed as

$$
d E=d\left(C_{v} T\right)
$$

where the heat capacity of the fluid constant volume is a function of temperature. Thus, the general energy, eq. (4.23) equation reduces to

$$
144(P d v+v d P)+d\left(C_{v f} T\right)+\frac{1}{2 g_{c}} 2 \vartheta d \vartheta=0
$$

For a control volume, $d v$ in eq. (4.25) equals to 0 . Then eq. (4.25) simplifies to 
$144(v d P)+d\left(C_{v f} T\right)+\frac{\vartheta d \vartheta}{g_{c}}=0$

Integrating the equation (4.26), with respect to $P, V$ and $\vartheta$ yields

$144 \int_{P_{1}}^{P_{2}} v d P+\int_{T_{1}}^{T_{2}} C_{v f} d T+\frac{1}{g_{c}} \int_{\vartheta_{1}}^{\vartheta_{2}} \vartheta d \vartheta=0$

The first term of equation (4.27), specific volume of fluid, $v$, is a function of pressure. As mentioned above, the polytropic expansion occurs as the fluid accelerates through the nozzle. The polytropic expansion equation in terms of the specific volume of gas, confining pressure, $P$, polytropic expansion constant, $b$, and ratio of specific heat constant $n$, is given below.

$P v_{g}^{n}=P\left(v_{f}-v_{l}\right)^{n}=b$

where $n$ is expressed as in eq. (4.9)

As the heat capacity of incompressible liquid at constant pressure is constant and equals to that at constant volume, eq. (4.9) takes the form

$$
n=\frac{\left(f_{g} C_{p g}+f_{l} C_{v l}\right)}{\left(f_{g} C_{v g}+f_{l} C_{v l}\right)}
$$

Specific volume of the fluid is defined as 
$v_{f}=(b / P)^{1 / n}+v_{l}$

The polytropic expansion equality for between point 1 and point 2 can be written as

$P_{1}\left(v_{m 1}-v_{l}\right)^{n}=P_{2}\left(v_{m 2}-v_{l}\right)^{n}$

So, the first term of eq. (4.27) becomes

$$
\begin{aligned}
& 144 \int_{P_{1}}^{P_{2}} v_{f} d P \Rightarrow 144 \int_{P_{1}}^{P_{2}}\left[\left(b^{1 / n} P^{-1 / n}\right)+v_{l}\right] d P \\
& \Rightarrow 144 b^{1 / n}\left(\frac{n}{n-1}\right)\left(P_{2}^{\frac{n-1}{n}}-P_{1}^{\frac{n-1}{n}}\right)+144 v_{l}\left(P_{2}-P_{1}\right)
\end{aligned}
$$

The third term of eq. (4.25) is integrated.

$$
\frac{1}{g_{c}} \int_{\vartheta_{1}}^{\vartheta_{2}} \vartheta d \vartheta=\frac{\vartheta_{2}^{2}-\vartheta_{1}^{2}}{2 g_{c}}
$$

Integrating eq. (4.32) and eq. (4.33) into eq. (4.27) yields

$$
144 b^{1 / n}\left(\frac{n}{n-1}\right)\left(P_{2}^{\frac{n-1}{n}}-P_{1}^{\frac{n-1}{n}}\right)+144 v_{l}\left(P_{2}-P_{1}\right)+\left(\int_{T_{1}}^{T_{2}} C_{v f} d T\right)+\frac{\vartheta_{2}^{2}-\vartheta_{1}^{2}}{2 g_{c}}=0
$$

Combining eq. (4.30) and (4.34) gives 


$$
\begin{array}{r}
144\left(P_{2}\left(v_{f 2}-v_{l}\right)^{n}\right)^{1 / n}\left(\frac{n}{n-1}\right)\left(P_{2}^{\frac{n-1}{n}}-P_{1}^{\frac{n-1}{n}}\right)+144 v_{l}\left(P_{2}-P_{1}\right) \\
+\frac{\vartheta_{2}^{2}-\vartheta_{1}^{2}}{2 g_{c}}+\left(\int_{T_{1}}^{T_{2}} C_{v f} d T\right)=0
\end{array}
$$

After simplifying eq. (4.35) the final form of general energy equation becomes

$$
\begin{array}{r}
144\left(v_{f 2}-v_{l}\right)\left(\frac{n}{n-1}\right)\left(P_{2}^{\frac{n-1}{n}} P_{1}^{1 / n}\right)+144 P_{2}\left(v_{f 2}-v_{l}\right)\left(\frac{n}{n-1}\right) \\
+144 v_{l}\left(P_{2}-P_{1}\right)+\frac{\vartheta_{2}^{2}-\vartheta_{1}^{2}}{2 g_{c}}+\left(\int_{T_{1}}^{T_{2}} C_{v f} d T\right)=0
\end{array}
$$

In eq. (4.36), the mass flow rate term is isentropic and at all cases, the isentropic value is equal to the ratio of actual flow rate and nozzle discharge coefficient. According to Perkins [13], after a compilation of 1,432 data sets obtained from the literature, comprising both sonic and subsonic flows, the best overall average value of the discharge coefficient, $\mathrm{C}_{N}$, is found to be 0.826 .

\subsection{Velocity of Wave Transmission}

The sound velocity is influenced by the physical properties of the medium, such as density and elasticity, which are equivalent to the mass as stiffness factor in the case of vibration of a particle, as stated by Wood [19]. While a wave of compression and rarefaction moves through a medium, the density (the volume) 
fluctuates locally. The value of these fluctuations depends on the properties mentioned above as well as the applied force (power of sound). To clarify the behaviour of sound wave, the dilation, condensation, elasticity and density of the medium are examined.

- Dilation, $D$ : It is the ratio of the increment of the volume to the original volume.

$D=\frac{\Delta V}{V_{0}} \Rightarrow V=V_{0}(1+D)$

- Condensation, $s$ : It is the ratio of the increment of density to the original density.

$s=\frac{\Delta \rho}{\rho_{0}} \Rightarrow \rho=\rho_{0}(1+s)$

Conservation of mass is expressed as, $\rho V=\rho_{0} V_{0} \Rightarrow(1+s)(1+D)=1$, so, condensation term, $s$, equals to $-D$. Here, $s D$ is so small that the value is neglected.

- Volume elasticity, $\kappa$. The elasticity is the change in the volume of a compressible fluid, when the fluid is exposed to a pressure. The value of the initial volume is taken into consideration. 
$\kappa=-V_{0} \frac{\partial P}{\partial V} \Rightarrow \kappa=-\frac{\partial P}{D}=\frac{\partial P}{s}$

- Compressibility, $c$ : The compressibility is the reciprocal of elasticity.

$c=-\frac{1}{V_{0}} \frac{\partial V}{\partial P} \Rightarrow c=\frac{1}{\kappa}$

Consider the case of plane waves travelling along the x-axis, as shown in Figure 4.

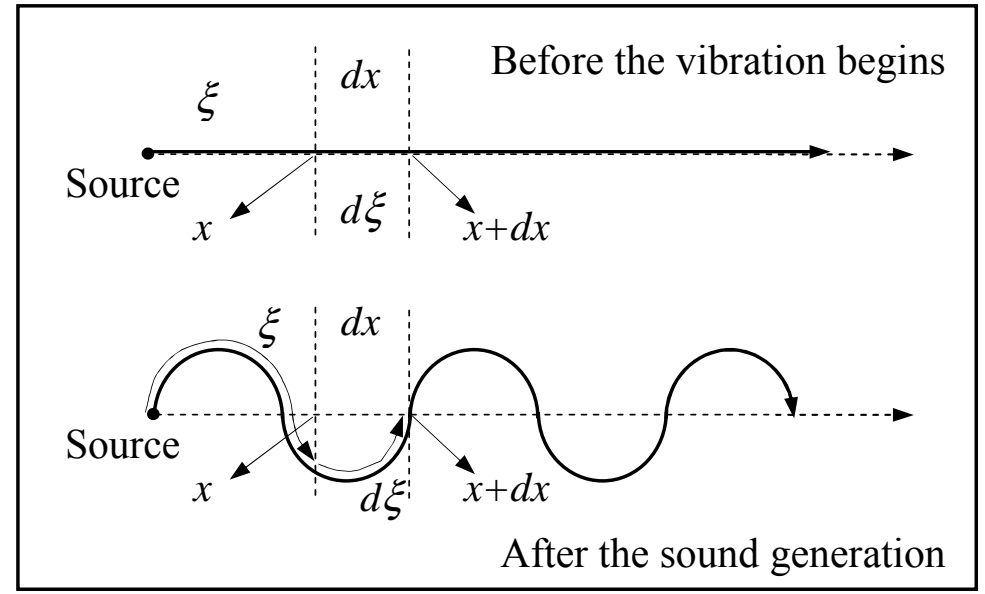

Figure 4 The Case of Plane Wave

Displacement of the planes normally at $x$ and $(x+d x)$ will be $\xi$ and $\left(\xi+\frac{d \xi}{d x} \partial x\right)$.

When the source generates sound, the thickness of the imaginary layer changes between the plane $x$ and plane $x+d x$. Before the generation of the round, 
change of the thickness equals to $d x$, but then, the sound leads to an oscillation where the thickness is $d x+d \xi$. In other words, the difference is $d \xi$. So, the dilation becomes,

$$
D=\frac{d \xi}{d x}=-s
$$

If the excess pressure on the $x+d x$ plane is $d P$ (change in the force of the wave due to friction), there is a velocity decrease and the force is equal to

$$
F=m a \Rightarrow d P=-\left(\rho_{0} d x\right) \frac{d^{2} \xi}{d t^{2}}
$$

where $\rho_{0} . d x$ is the mass of the unit area of the medium, and $\frac{d^{2} \xi}{d t^{2}}$ is the deceleration term.

Using eq. (4.40) and (4.42), one can derive

$$
\frac{d^{2} \xi}{d t^{2}}=-\rho_{0} \frac{d P}{d x} \Rightarrow \frac{d^{2} \xi}{d t^{2}}=\frac{\kappa}{\rho} \frac{d^{2} \xi}{d x^{2}} \Rightarrow \vartheta_{s}=\sqrt{\frac{\kappa}{\rho_{0}}}
$$

Eq. (4.43) can be applied for all cases of transmission of small amplitude plane wave in solid, liquid or gaseous media. In the gaseous - liquid medium, it can be assumed that $P \rho_{0}=\rho P_{0}=$ constant for a constant temperature. So, the elasticity is reduced to 


$$
\kappa=-V_{0} \frac{\partial P}{\partial V} \Rightarrow \kappa=\rho_{0} \frac{\partial P}{\partial \rho}=\rho_{0} \frac{P_{0}}{\rho_{0}}=P_{0}
$$

This, from eq. (4.43), the sound velocity becomes

$$
\vartheta_{s}=\sqrt{\frac{P_{0}}{\rho_{0}}}
$$

If the system is are not isothermal, but adiabatic, Using eq. (4.10), eq. (4.44) becomes

$$
P v^{n}=P_{0} v_{0}^{n} \Rightarrow P=\rho^{n} \frac{P_{0}}{\rho_{0}^{n}} \Rightarrow \frac{d P}{d \rho}=n \rho_{0}^{n-1}\left(\frac{P_{0}}{\rho_{0}^{n}}\right) \Rightarrow \kappa=n P_{0}
$$

Thus, from eq. (4.43), the sound velocity for compressible fluid mixtures can be written as

$$
\vartheta_{s}=\sqrt{n \frac{P_{0}}{\rho_{0}}}
$$




\subsection{Flow Diagram of The Model}

1. The model requires the following inputs.

- Bit inside and outside diameters used in equation (4.11),

- Nozzle amount and nozzle size to calculated equivalent size of the nozzles,

- Gas flow rate, in standard conditions, and liquid flow rate to estimate mass flow rates and mass fraction of the phases.

- Bottom hole temperature and pressure.

The fluid inside drill string gains heat from the surroundings and when the fluid reaches to bit it is assumed that the temperature of the fluid is equal to the bottom hole temperature. Thus, bottom hole temperature is referred as $T_{1}$.

2. If the bit has more than one nozzle, the model estimates an equivalent nozzle diameter, as given in eq. (4.48).

$d_{c-e q}=\sqrt{\sum_{i=1}^{N N} d_{c}^{2}}$

3. As a first iteration, the value of downstream pressure, $P_{1}$ is equalised to $P_{4}$.

4. Calculate $P_{3}$, by using eq (4.11) (Perry Relationship [14]) and at subsonic velocity. Calculated pressure value is assumed to be equal to nozzle pressure, i.e., $P_{2}=P_{3}$, 
5. In order to determine the mass fraction, mass flow rates and specific volume of liquid and gas phases, physical properties of gas phase and liquid phase and mixtures of these phases should be well defined. The proposed model requires gas compressibility. The compressibility factor of air can be calculated by using eq. (A.1). Then, using $z_{1}$ value obtained from eq. (A.1), $v_{f 1}$ and $\rho_{g 1}$ can be calculated as

$$
P_{1} V_{g 1}=n_{g 1} R T_{1} z_{1} \Rightarrow \rho_{g 1}=\frac{P_{1} M_{g}}{R T_{1} z_{1}}
$$

and

$$
\rho_{f}=\frac{m_{f}}{V_{1}}=\frac{m_{f}}{m_{f}\left(\frac{f_{g}}{\rho_{g}}+\frac{f_{l}}{\rho_{l}}\right)}=\frac{1}{\left(\frac{f_{g}}{\rho_{g}}+\frac{f_{l}}{\rho_{l}}\right)}=\frac{1}{v_{f}}
$$

respectively.

6. Calculate the polytropic expansion exponent, $n$, by using eq. (4.29). In this equation the mass fractions and constant volume heat capacities of gas and liquid fraction of the fluid are desired. The model needs air and water heat capacity values. The specific heat capacity values for air are listed in Appendix A. The estimated values of air are used for correlating heat capacity at desired 
$P$ and $T$. For water, Perkins [13] suggested $778 \mathrm{ft}-\mathrm{lbf} / \mathrm{lbm}-{ }^{\circ} \mathrm{F}$ or constant volume heat capacity.

7. Calculate $T_{2}$ at the nozzle using eq. (4.51). As mentioned in earlier, a polytropic expansion (reversible adiabatic expansion) occurs as the fluid accelerates downstream of the nozzle. Expansion causes the temperature through the nozzles to drop. Equation (4.6) implies how temperature and volume of an ideal gas vary during an adiabatic expansion. For fluid flow across a bit, equation (4.6) takes for, as seen in equation (4.51). Using the equation (4.51), the temperature in the nozzle can be calculated as

$\left(T_{2}+460\right)=\left(T_{1}+460\right) P_{R}^{(n-1) / n}$

8. Calculate $z_{2}, v_{f 2}$ and $\rho_{g 2}$ as mentioned in step 5 .

9. Calculate the estimated mass flow rate. Due to the conservation of mass, at all points in and out of the bit, the mass flow rate should be constant. Mass flow rate can be calculated using

$$
\dot{m}_{c}=\dot{m}_{a} / C_{N}
$$

where, the actual mass flow rate is proportional to volumetric fluid flow rate and it calculated by eq. (4.53), 
$m_{a}=\left(q_{l} \times \rho_{l}\right)+\left(q_{g} \times \rho_{g}\right)$

Thus, velocity of the fluid at any point of the bit could be calculated as shown in eq. (4.54)

$\vartheta=\frac{m_{c}}{A}\left(\frac{f_{g}}{\rho_{g}}+\frac{f_{l}}{\rho_{l}}\right)$.

10. Determine the average pressure and temperature values, and recalculate the polytropic expansion exponent, $n$, as mentioned in step 6 . In the final form of general energy equation, eq. (4.36), polytropic expansion exponent is important. Although it varies with the temperature and the pressure of the fluid, it is assumed as constant for flow through the bit. Therefore, an average value of the exponent is required and is estimated by using average temperature and pressure values, such that

$\bar{P}=0.5\left(P_{1}+P_{2}\right)$.

and

$\bar{T}=0.5\left(T_{1}+T_{2}\right)$

respectively.

11. Use the general energy equation eq. (4.36) for calculating $P_{1}$. 
12. Go back to step 4 and iterate the $P_{1}$ values until the results converge. If the percent difference between the values of $P_{1}$ from values is less than $1.0 \times 10^{-6}$, the model gives the best $P_{1}$ values. The error analysis presents in Appendix C.

13. Check $\vartheta_{2}$ value, whether the system is in subsonic flow range or not. If $\vartheta_{\text {sonic }}>\vartheta_{2}$ than the flow is subsonic.

$\vartheta_{\text {sonic }}=\sqrt{n \frac{P_{2}}{\rho_{f 2}}}$

14. If the velocity is greater than sonic velocity, the program reduces the gas and liquid flow rates at the same proportion till the velocity go below the sonic velocity. 


\section{CHAPTER 5}

\section{RESULTS AND DISCUSSIONS}

In this study, a mathematical model for estimating the pressure drop of the bit for two-phase fluids is presented. In the literature, there are some similar applications, however the diversity of the proposed model is to be more sensitive to flow conditions and inner forces. The algorithm and related calculated process gives more accurate results than the models previously developed.

The developed model could work in the subsonic - sonic flow conditions. Since sonic flow is not convenient with drilling operations, the model obtains pressure drop results across the bit only in subsonic flow. If the flow is sonic, the proposed model suggests a change in liquid or gas flow rates, so that the flow is kept in subsonic flow ranges.

For making calculations of the pressure drop faster, a computer program is developed based on the proposed model. Using the developed program, runs are performed at widely encountered field conditions for various air-water mixture flow rates. These values were used for comparison of the performance of the 
proposed model with the previously developed models and determination of the influences of flow parameters on pressure drop. The conditions are listed in Table 2, where Case 1 is assigned as a base condition. The conditions were selected to explain the effects of nozzle size, diameter of the bit, liquid and gas flow rates, bottom hole pressure and bottom hole temperatures. The influences of these factors have been discussed in the further section.

Table 1 Selected Parameters for Sample Run

\begin{tabular}{|c|c|c|c|c|}
\hline & Case 1 & Case 2 & Case 3 & Case 4 \\
\hline Gas Phase & Air & Air & Air & Air \\
\hline Liquid Phase & Water & Water & Water & Water \\
\hline$C_{N}$ & 0.826 & 0.826 & 0.826 & 0.826 \\
\hline Num. Of Nozzle & 3 & 3 & 3 & 3 \\
\hline Nozzle Size, in & $13 / 32$ & $13 / 32$ & $15 / 32$ & $13 / 32$ \\
\hline $\begin{array}{l}\text { Diameter of } \\
\text { downstream, in }\end{array}$ & $121 / 4$ & $121 / 4$ & $121 / 4$ & $81 / 2$ \\
\hline $\begin{array}{l}\text { Diameter of } \\
\text { upstream, in }\end{array}$ & $21 / 4$ & $21 / 4$ & $21 / 4$ & $13 / 4$ \\
\hline$Q_{G S C}, \mathrm{scft} / \mathrm{min}$. & $\begin{array}{l}200,500,750, \\
1000 \text { and } 1500\end{array}$ & $\begin{array}{l}200,500,750, \\
1000 \text { and } 1500\end{array}$ & $\begin{array}{l}200,500,750, \\
1000 \text { and } 1500\end{array}$ & $\begin{array}{l}200,500,750 \\
1000 \text { and } 1500\end{array}$ \\
\hline$Q_{l i q}, \mathrm{gal} / \mathrm{min}$ & 100,200 and 300 & 100,200 and 300 & 100,200 and 300 & 100,200 and 300 \\
\hline$P_{B H}$, psia & $\begin{array}{l}250,500,750, \\
1250 \text { and } 1750\end{array}$ & $\begin{array}{l}250,500,750, \\
1250 \text { and } 1750\end{array}$ & $\begin{array}{l}250,500,750, \\
1250 \text { and } 1750\end{array}$ & $\begin{array}{l}250,500,750 \\
1250 \text { and } 1750\end{array}$ \\
\hline$T_{B H},{ }^{\circ} \mathrm{F}$ & $100^{\circ} \mathrm{F}$ & $150^{\circ} \mathrm{F}$ & $100^{\circ} \mathrm{F}$ & $100^{\circ} \mathrm{F}$ \\
\hline
\end{tabular}




\subsection{Flow Type Determination}

As mentioned in theory, the proposed model initially assumes that, the flow pattern of two-phase fluids through the bit nozzles is dispersed bubbly. In the literature, some experiments were conducted to identify five distinct flow patterns for vertical upward flow: bubbly, dispersed bubble, slug, churn and annular flow, and two phase flow pattern type map for vertical flow were obtained, as presented Figure 5. The flow pattern of a gasified fluid can be estimated by calculating the superficial liquid and gas velocities. For this study, the calculated superficial values of liquids and gas phase flowing through bit nozzle were checked on that map, and it was observed that, for all cases, the flow is in the disperse flow area.

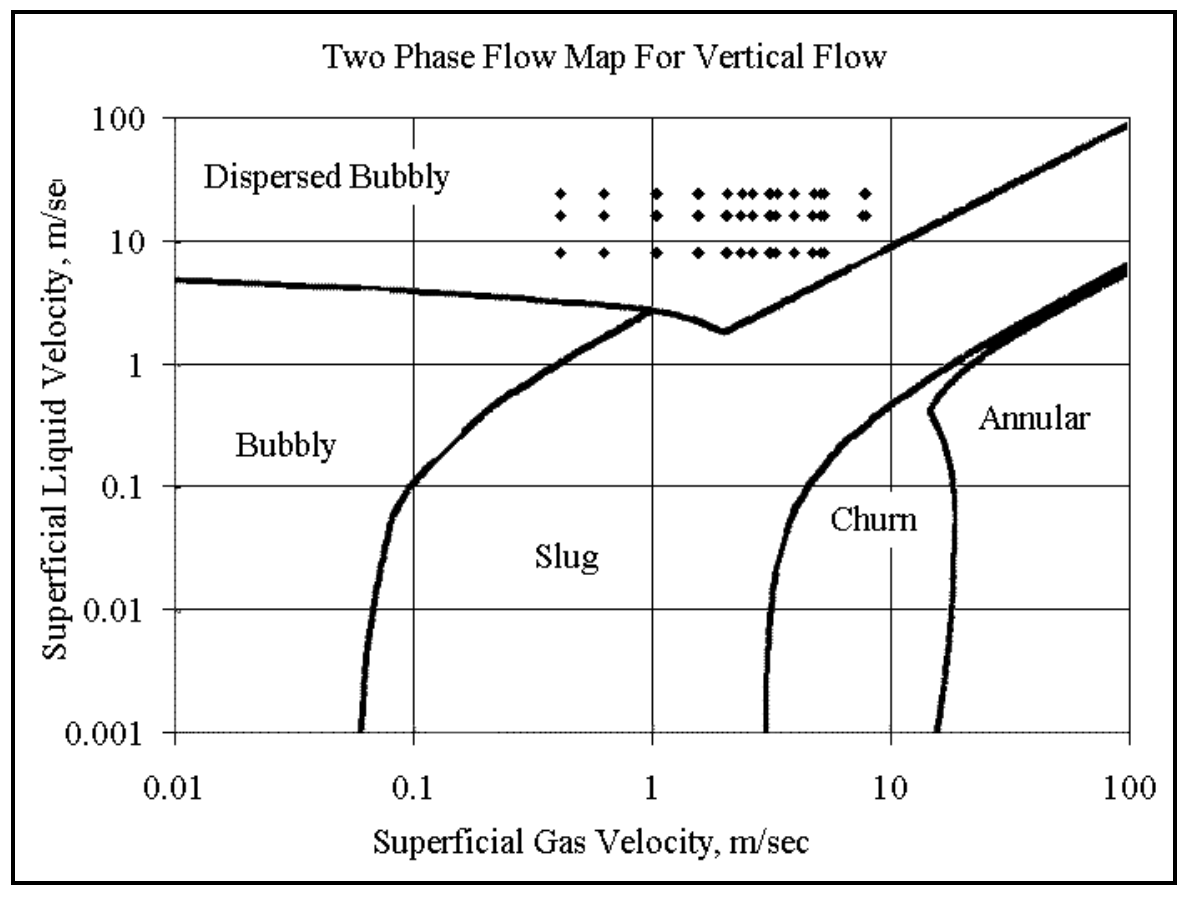

Figure 5 Two Phase Flow Map For Vertical Flow, Kaya et. al. [20] 
The results satisfy the assumption, the flow of two-phase fluid across the bit nozzles is disperse bubbly flow. In Figure 5, the points in the dispersed flow area show the results obtained in this study.

As mentioned before, it is assumed that, velocity varies with axial (flow) direction, but for a particular arbitrary point, all components are moving with the same velocity. Moreover, it is also assumed that, no slippage occurs between the phases at the nozzle throat. Two boundaries are specified to confirm these assumptions. These boundaries are Froude limit, eq. (4.12), and $32.8 \mathrm{ft} / \mathrm{sec}$ velocity of fluid limit at the nozzle throat ([11] and $[2,3])$. For this study, the calculated velocity through the bit nozzle and Froude number were checked, as seen in Figure 6 , and it is observed that calculated values are greater than these limits. Thus, for all cases, there is no slippage between the phases at the throat, i.e., air and water fractions are moving with same velocity. 


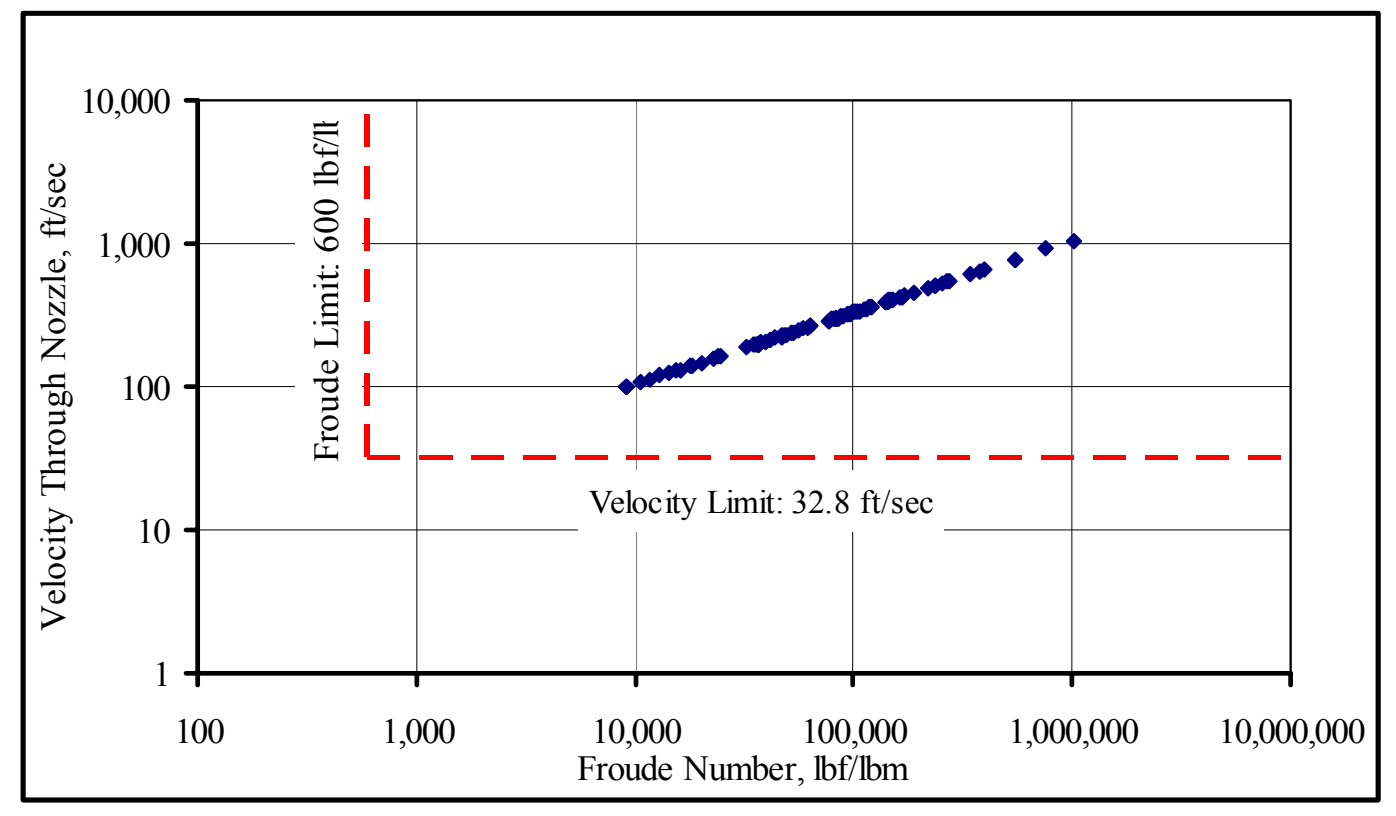

Figure 6 Froude Number and Fluid Velocity Through Nozzle

\subsection{Sensitivity Analysis of Hydraulic Parameters}

Effects of bottom hole pressure and temperature, liquid flow rate, gas flow rate, and nozzle and bit sizes on bit pressure drop were investigated. The effective two-phase drilling fluid hydraulic parameters, i.e., nozzles size, flow rates, etc., could change the efficiency of the bit and lead to obtain more efficient bit horsepower.

\subsubsection{Effect of Bottom Hole Pressure on Bit Pressure Drop}

The bottom hole pressure has a significant effect on pressure drop at the bit. As the pressure difference between upstream and down stream of the nozzles 
increases, the fluid tends to move faster while passing through the nozzle, yet, the nozzle does not let high velocity through itself. Then, inside the bit, the fluid accumulates, which leads an increase in the upstream pressure. The proposed model values, which were obtained for different bottom hole pressures, were plotted on pressure drop vs. gas flow rate (Figure 7) and pressure drop vs. bottom hole pressure graphs (Figure 8). As seen from Figure 7, as the bottom hole pressure decreases, the pressure drop values increase. The bottom hole pressure could rise until the upstream pressure of the nozzle reaches to sonic pressure boundary.

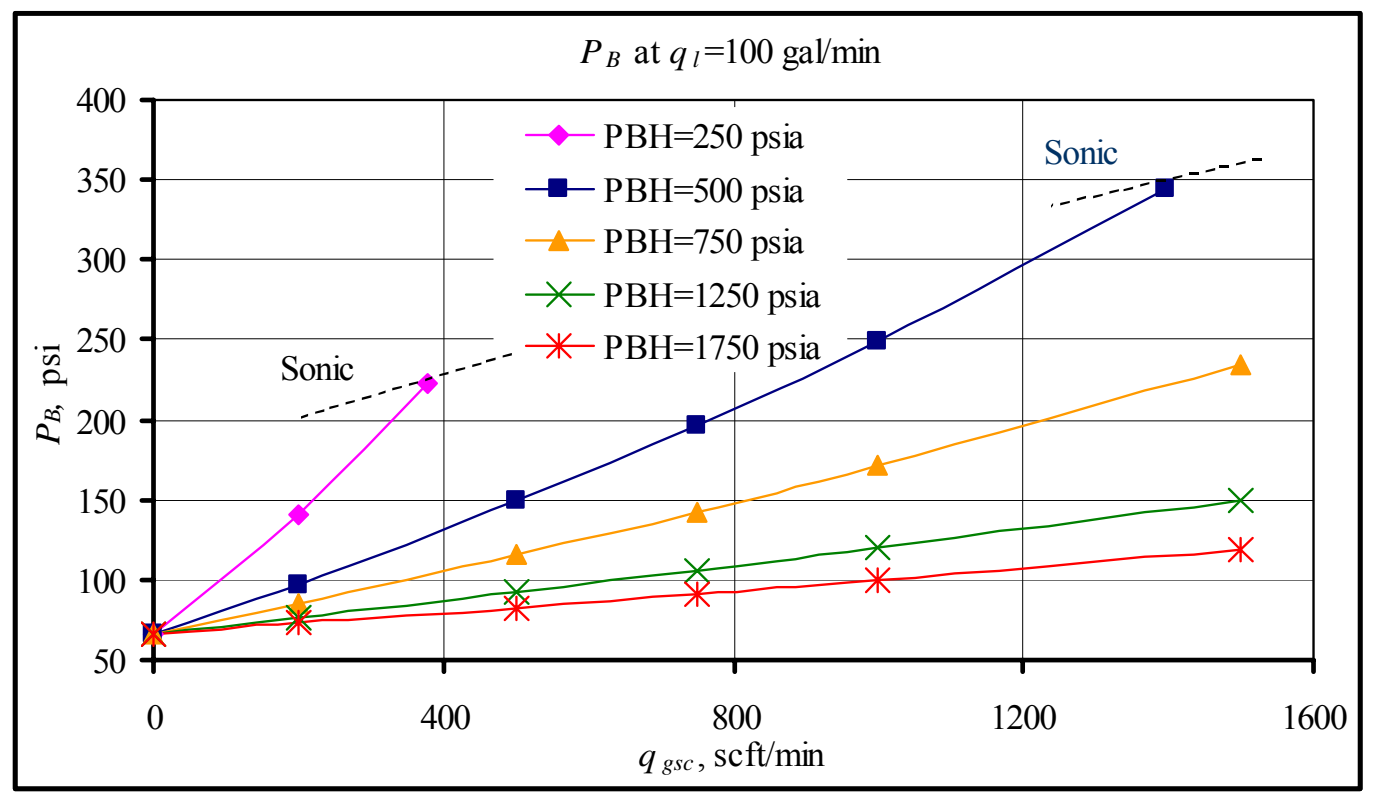

Figure $7 P_{B H}$ Effect on $P_{B}$ at $q_{l}=100 \mathrm{gal} / \mathrm{min}$

At higher-pressure values, the flow is sonic. At that region, the flow pressure behaviour depends on the compressibility of the fluid. The detailed information is given in section 5.2.6. 
The effect of bottom hole pressure on pressure drop at the bit is significant as seen in Figure 8. At $200 \mathrm{scft} / \mathrm{min}$ gas flow rate, the bit pressure drop curve shows a steep increase, as the bottom hole pressure is started to reduce from 500 psia to 250 psia. At higher gas flow rate values, the effect of the $P_{B H}$ is more significant. As seen in Figure 8, $1000 \mathrm{scft} / \mathrm{min}$ curve shows more severe decrease in $P_{B}$ values with increasing bottom hole pressure. The difference between the curves increase as the gas flow rates increase. As a result, at higher gas flow rates, the bottom hole pressure has more considerable effect on $P_{B}$.

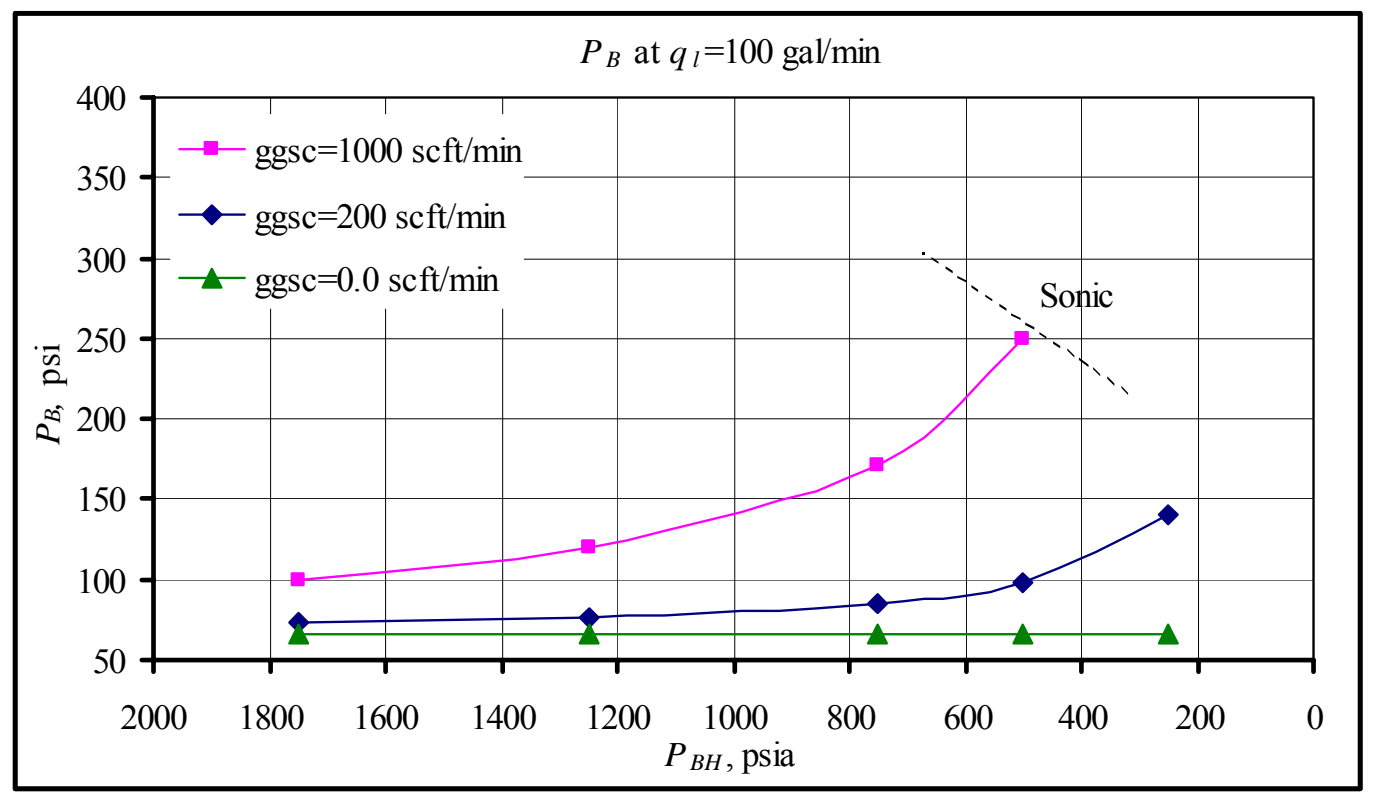

Figure $8 \quad P_{B H}$ Effect on $P_{B}$ at $q_{l}=100 \mathrm{gal} / \mathrm{min}$ and Constant $q_{g s c}$

In Figure 8, when there is no gas flow $(0.0 \mathrm{scft} / \mathrm{min})$, the curve is flat. Since only the gas phase in the system is assumed to be compressible, the bottom hole pressure is effective only on the compressible phase Thus, as gas flow rate approaches to $0.0 \mathrm{scft} / \mathrm{min}$, this effect disappears. Therefore, an increase in the gas 
concentration causes $P_{B H}$ to be more effective on $P_{B}$. If the fluid is incompressible, $P_{B H}$ has no effect on $P_{B}$.

\subsubsection{Effect of Flow Rate on Bit Pressure Drop}

The flow rates have a noticeable effect on bit pressure drop. For constant gas flow rates and bottom hole pressures, as the liquid rate is increased, a significant increase in bit pressure drop is observed, as seen in Figure 9.

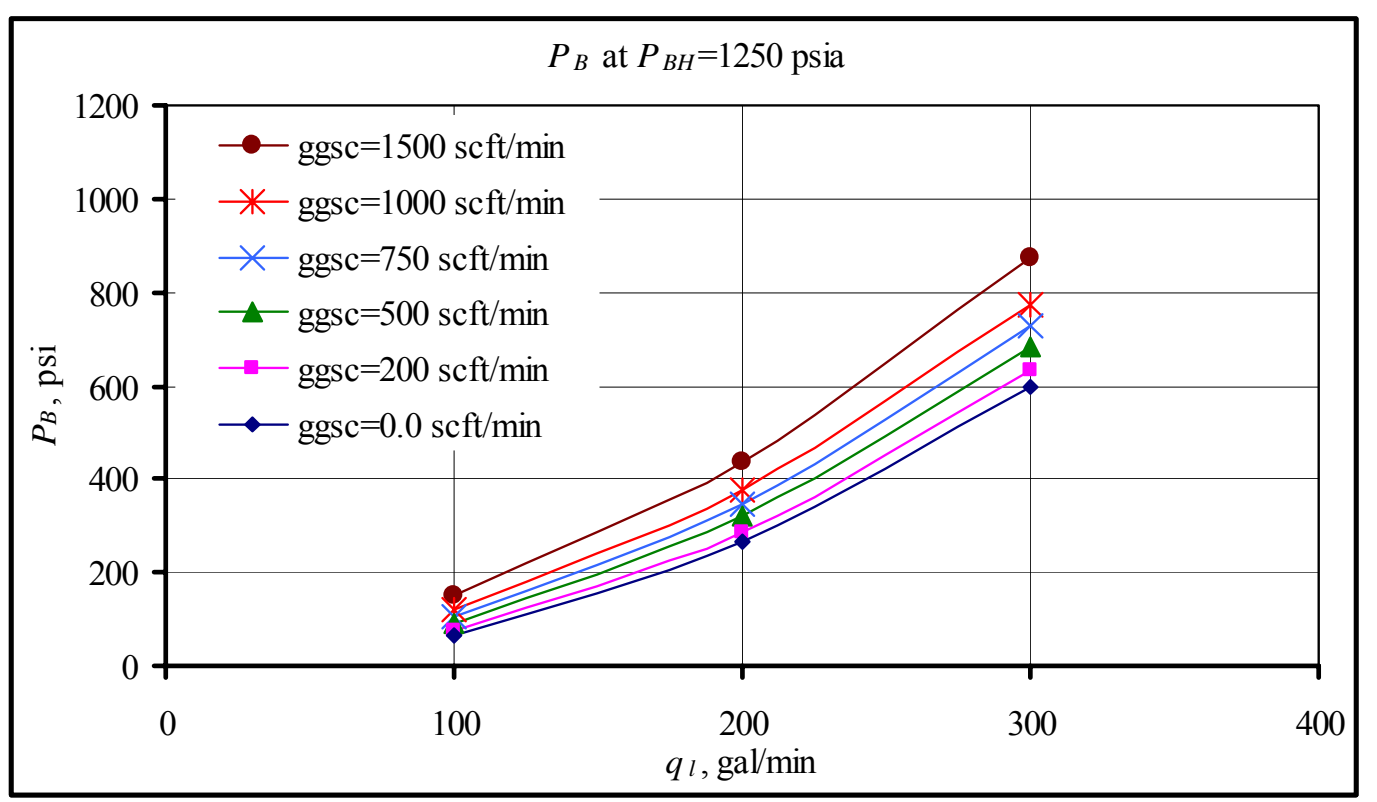

Figure 9 Liquid Flow Rate Effect on $P_{B}$ at $P_{B H}=1250$ psia and Constant $q_{l}$

The influence of gas flow rate on $P_{B}$ also is observed in Figure 10. Actually, change in the liquid flow rate has stronger influence on bit pressure drop than the change in gas flow rate. The compressibility of the gas leads to a reduction in the volume. Therefore, even the gas flow rate in the system is doubled, that does not 
result to a significant increase in the bit pressure drop. On the other hand, as seen in Figure 9, when the liquid flow rate is doubled, the bit pressure drop values are triplet.

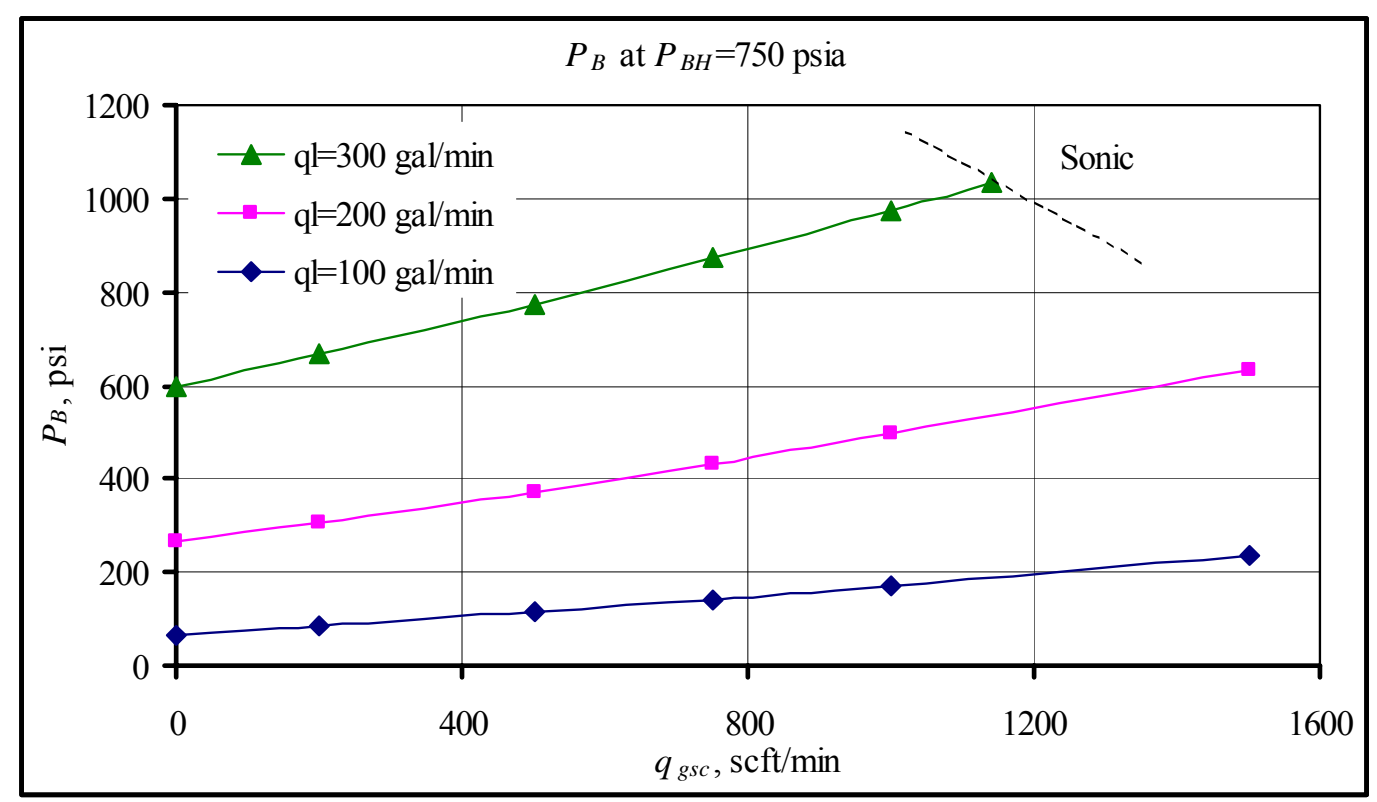

Figure 10 Gas Flow Rate Effect on $P_{B}$ at $P_{B H}=750$ psia and Constant $q_{g s c}$

In Figure 10, at higher values of gas flow rate, the pressure in the bit reaches the sonic limit. Since the total mass flow rate increases, in side the nozzle, the velocity of the fluid reaches the sonic velocity of that fluid. Indeed, since the sonic velocity limit is higher in liquid than in gas, the liquid concentration of the two-phase fluid rises, so the sonic velocity of the mixtures and the sonic pressure limit. However, if the total flow rate is high enough, the flow will reach to its sonic limit, even the sonic velocity of the fluid is increased. Therefore, mixture flow rate could be increased easily till the sonic pressure limit is reached 


\subsubsection{Effect of Bottom Hole Temperature on Bit Pressure Drop}

Temperature is a function of gas properties. Changes in temperature influence only the gas phase, provided that incompressible liquid assumption is defined. The density, compressibility and heat capacities of the gas depend on temperature. However, temperature effect is not as significant as the effect of bottom hole pressure or flow rates on bit pressure drop. The calculated values of the proposed model were plotted on bit pressure drop vs. gas flow rate (Figure 11) and bit pressure drop vs. liquid flow rate (Figure 12) graphs for a constant bottom hole pressure.

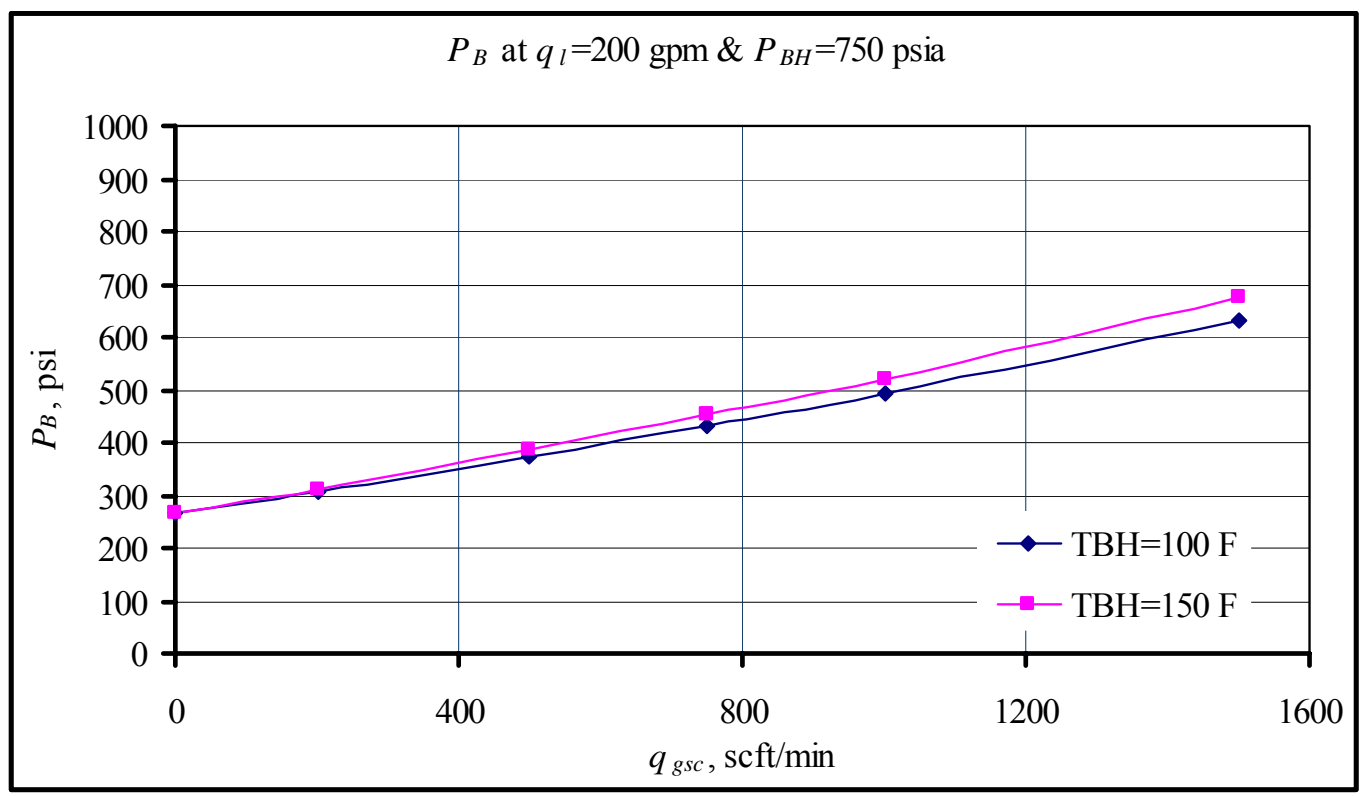

Figure 11 Temperature Effect on $P_{B}$ at $q_{l}=200 \mathrm{gpm}$ and $P_{B H}=750 \mathrm{psia}$ 


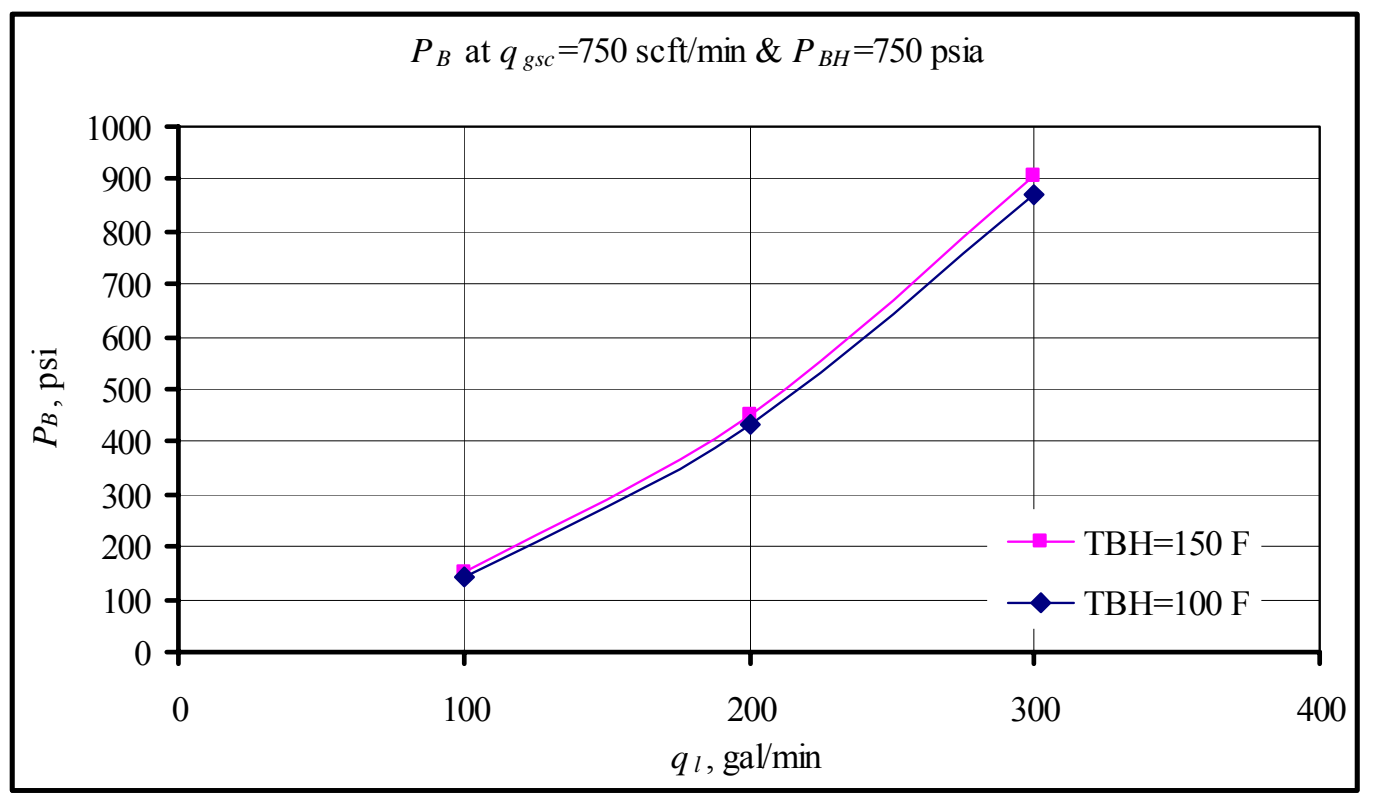

Figure 12 Temperature Effect on $P_{B}$ at $q_{g s c}=750 \mathrm{scft} / \mathrm{min}$ and $P_{B H}=750 \mathrm{psia}$

In Figure 11, at lower gas flow rates, i.e. low gas concentration, the curves are collapsing on each other. In other words, when the gas flow rate increases, the gas concentration rises in the mixture for a constant liquid flow rate, and the temperature changes affect $P_{B}$ more due to the increase the amount of gas.

As seen in Figure 12, temperature changes result in a slight change in pressure drop values. Increase in liquid flow rate does have a significant effect on bit pressure drop. As mentioned above, temperature is a function of gas properties, and changes in temperature do not affect the bit pressure drop for different liquid flow rate values. 


\subsubsection{Effect of Nozzle Size on Bit Pressure Drop}

Nozzle size leads to a considerable change in bit pressure drop. In fact, in theory, the nozzle size influences the velocity through the nozzle. For a smaller nozzle size, the fluid cannot pass easily through the nozzle. For this reason, the fluids begin to accumulate in the bit and cause an increase in the upstream pressure even smaller value of flow rates, as presented in Figure 13 and Figure 14. As seen in Figure 13, for a constant liquid flow rate and bottom hole pressure, as the nozzle size is increased, a significant decrease in pressure drop is observed for all gas flow rates. Moreover, as presented in Figure 14, when the gas flow rate is kept constant, bit pressure drop is even sharper for smaller nozzle size as the liquid rate is increased.

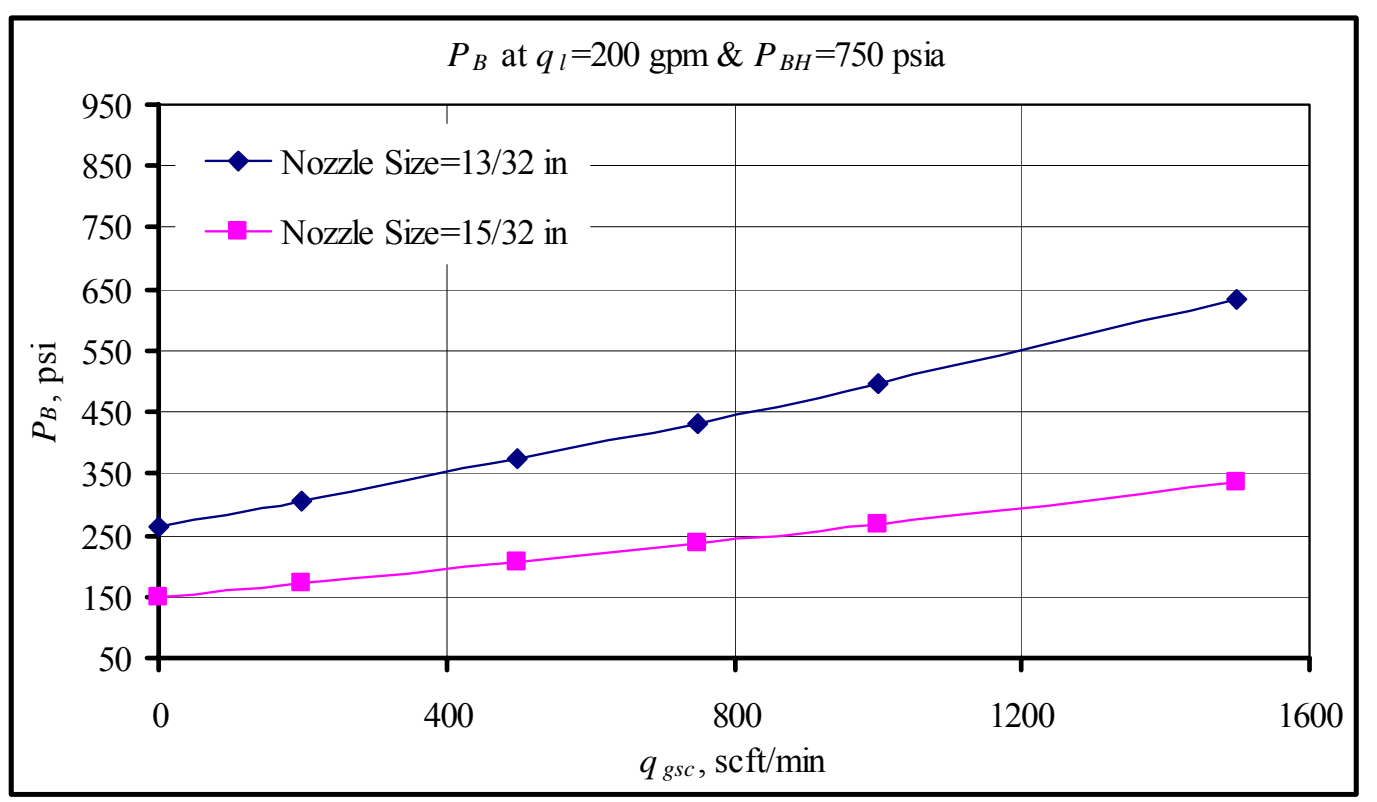

Figure 13 Nozzle Size Effect on $P_{B}$ at $q_{l}=200 \mathrm{gpm}$ and $P_{B H}=750 \mathrm{psia}$ 


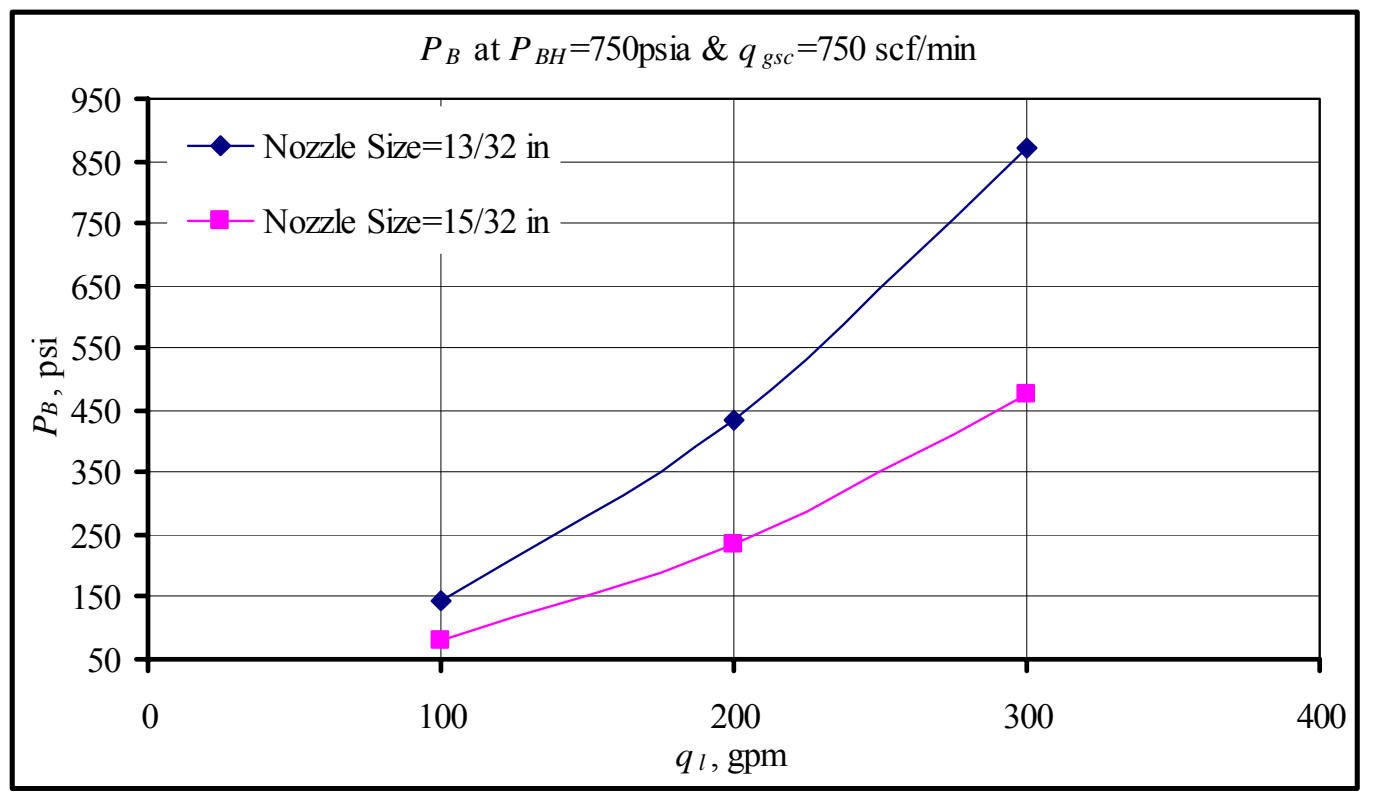

Figure 14 Nozzle Size Effect on $P_{B}$ at $q_{g s c}=750 \mathrm{scft} / \mathrm{min}$ and $P_{B H}=750 \mathrm{psia}$

\subsubsection{Effect of Bit Size on Bit Pressure Drop}

Bit size does not have any influence on the bit pressure drop values. Actually, the bit size value has to been taken into consideration during the estimation of annular hydraulic calculations, which is out of the scope of this work. Difference of the proposed model results for different bit sizes, is insignificant. From Figure 15, it can be seen that there is no change in the bit pressure drop when the bit size changes. As a result, it can be said that, the bit size does not have any effect on bit pressure drop. 


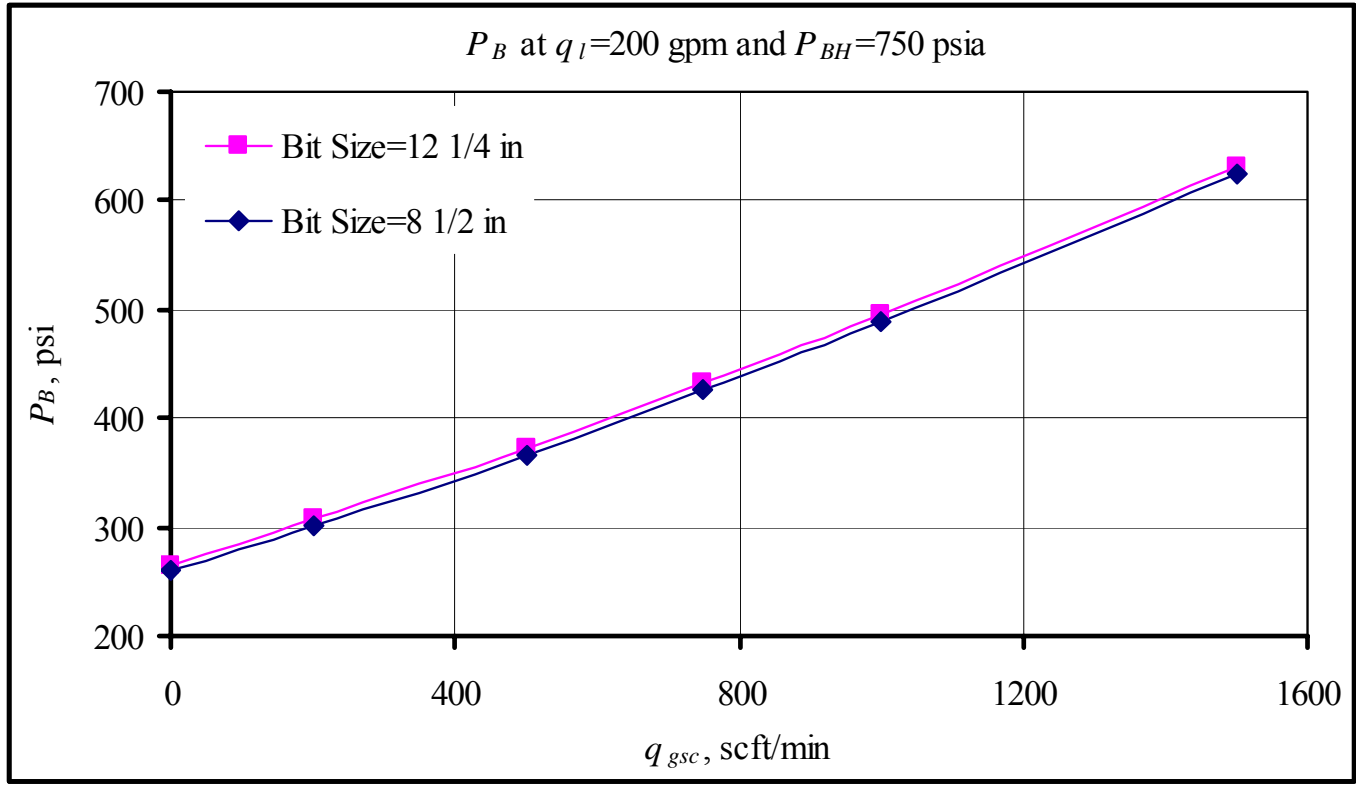

Figure 15 Bit Size Effect on $P_{B}$ at $q_{l}=200 \mathrm{gal} / \mathrm{min}$ and $P_{B H}=750 \mathrm{psia}$

\subsubsection{Effect of Sonic Pressure on Bit Pressure Drop}

The fluid flowing through a nozzle cannot have a higher velocity than the sonic velocity of that fluid. When the fluid velocity through the nozzle reaches to the sonic velocity, accumulation of the fluid in the bit increases. At such high velocities, there exists a sonic wall, which prevents the fluid to flow with very high velocities. This results a build up in the upstream pressure. In other words, the bit pressure values rise. For a two-phase fluid system, the pressure drop values increase rapidly as the flow rates are approaching to the sonic boundary. As presented in Figure 16, as the gas flow rate increases, the velocity in the nozzle rises and this leads an increase in upstream pressure. Since the bottom hole 
pressure is kept constant, the upstream pressure continues to increase with increasing gas flow rate.

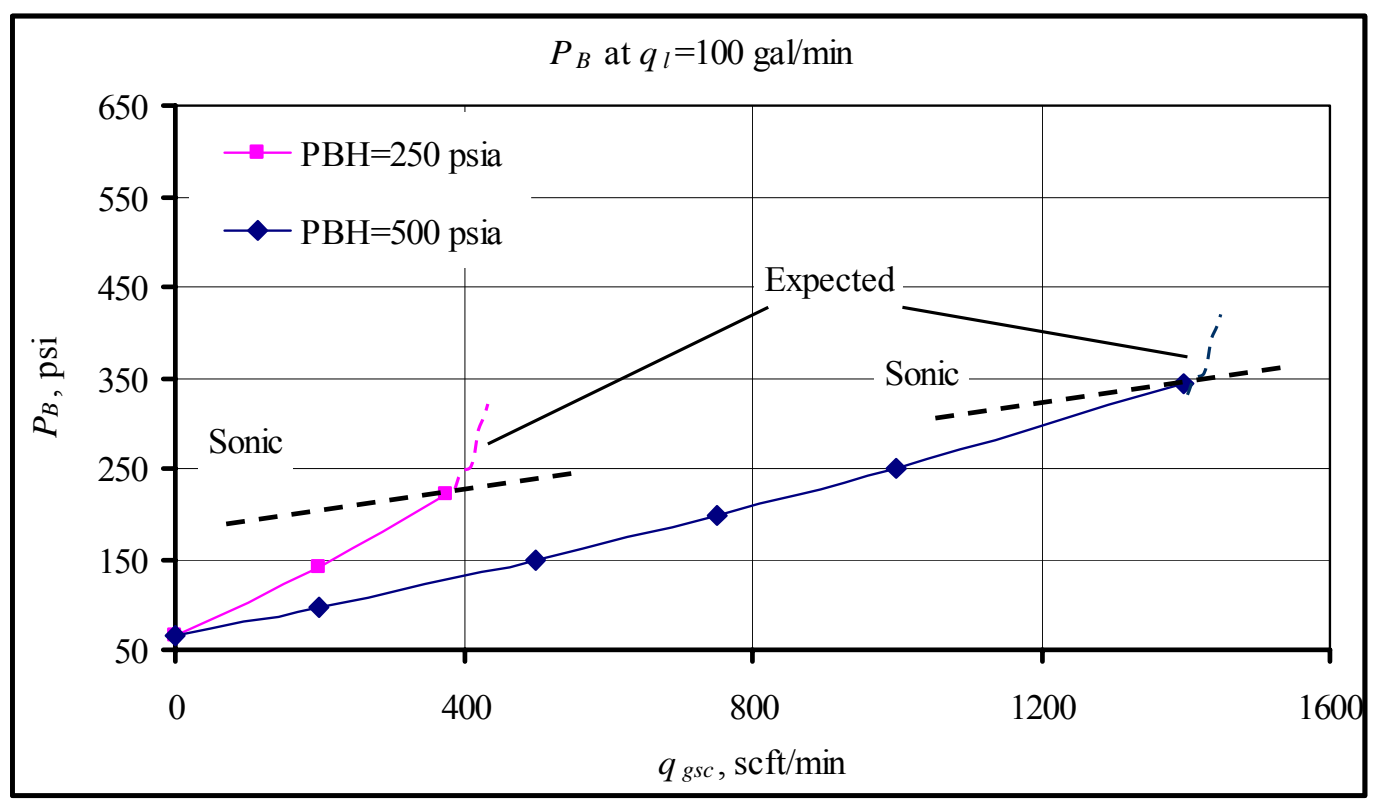

Figure 16 Sonic Pressure Effect on $P_{B}$ at $q_{l}=100 \mathrm{gal} / \mathrm{min}$ and $P_{B H}=750 \mathrm{psia}$

When the fluid velocity reaches to the sonic velocity, there is an excessive accumulation inside the bit. The accumulation leads to the upstream pressure to increase rapidly; so the gas is compressed and the velocity will decrease. The accumulation and compression changes are instant and vanish with the stabilization of the upstream pressure. In Figure 16, expected bit pressure drop curve for a twophase fluid at sonic conditions was plotted. For an incompressible fluid flowing trough a bit nozzle, as the flow velocity approaches to the sonic velocity, due to the incompressibility of the fluid, a sudden increase in the upstream pressure is observed. 
At lower bottom hole pressure values, the fluid can reach the sonic limit even at lower gas flow rates. If the sonic limits, in Figure 16, are compared, there is more than a 100 psi difference for lower and higher gas flow rates. At lower bottom hole pressure, the fluid has a higher volume than at high pressure due to compressibility of the gas phase. So, the volumetric flow rate of the fluid increases. Moreover, at low pressures, the sonic velocity of the fluid is low. As a result, at different bottom hole pressures, the reasons why the sonic pressure varies are the sonic velocity changes and compressibility of the gas phase.

\subsection{Comparison of The Proposed Model With Previously Developed Models}

Bit pressure drop predictions of the proposed model are compared with the existing ones, which are Gücüyener [17] and Liu [18] (eq. (A.4)) and Guo [15] (eq. (A.5)). This comparison was conducted in a range of practical values of bottom hole pressures, gas and liquid flow rates, as listed in Table 1. The comparison indicates that the differences between the models are very sensitive to changes in bottom hole pressure, gas and liquid flow rates.

Internal energy and temperature changes of flow of two-phase fluid, which flows across a bit, are not included in the previous models. The proposed model does not ignore those changes for the bit pressure drop calculations. The existence of those factors affects the pressure drop values. The variations due to those factors are also examined. 
Deviation of the existing models from the exact solutions obtained in this study is analyzed and variation analysis results are presented in tables 4 to 16 and figures $24-36$.

\subsubsection{Effect of Bottom Hole Pressure on Bit Pressure}

The comparison of the models in the literature and proposed model was conducted for a constant liquid rate $(100 \mathrm{gal} / \mathrm{min})$ and varying bottom hole pressure and gas flow rates. The results are plotted on graphs, as seen from Figure 17 to Figure 21.

In these figures, the proposed model does not present significant difference with Gücüyener [17] and Liu [18] curves. However, significant differences are observed with the results of Guo [15] Model. The results of the comparisons are presented in Appendix E. The proposed model has a maximum of $9 \%$ difference from the Gücüyener [17] and Liu [18] model results.

The effect of internal energy on bit pressure drop is not significant for lower bottom hole pressure, but higher bottom hole pressure values, variation becomes more significant. In Figure 17, the proposed model curves, one which does not include the internal energy, is different from the proposed model with the internal energy. The proposed model without internal energy is estimating closer results to Gücüyener [17] and Liu [18] model curves. Since, their model does not include the internal energy and it assumes that the velocity of the fluid at the bit, $\vartheta_{1}$, is zero, 
the predicted results of the proposed model without internal energy and Gücüyener [17] and Liu [18] model show a similar behavior. In the general energy equation, eq. (4.36), the kinetic energy change depends on the inlet and outlet velocities of the fluid at the bit. Due to Gücüyener [17] and Liu [18] assumption of zero inlet velocity of fluid at point 1 , the kinetic energy values at upstream condition are zero and calculated kinetic energy gain is higher for their model. This leads to a higher bit pressure drop value. In Figure 17, if Gücüyener [17] and Liu [18] model curve is compared with the proposeThe calculated values of the proposed model, which does not take the internal energy into consideration, are listed and analyzed in Appendix E. According to the variation analysis, the existence of internal energy and factor of temperature changes in the bit have a maximum $3.3 \%$ difference, as seen in Table 8 of Appendix E.

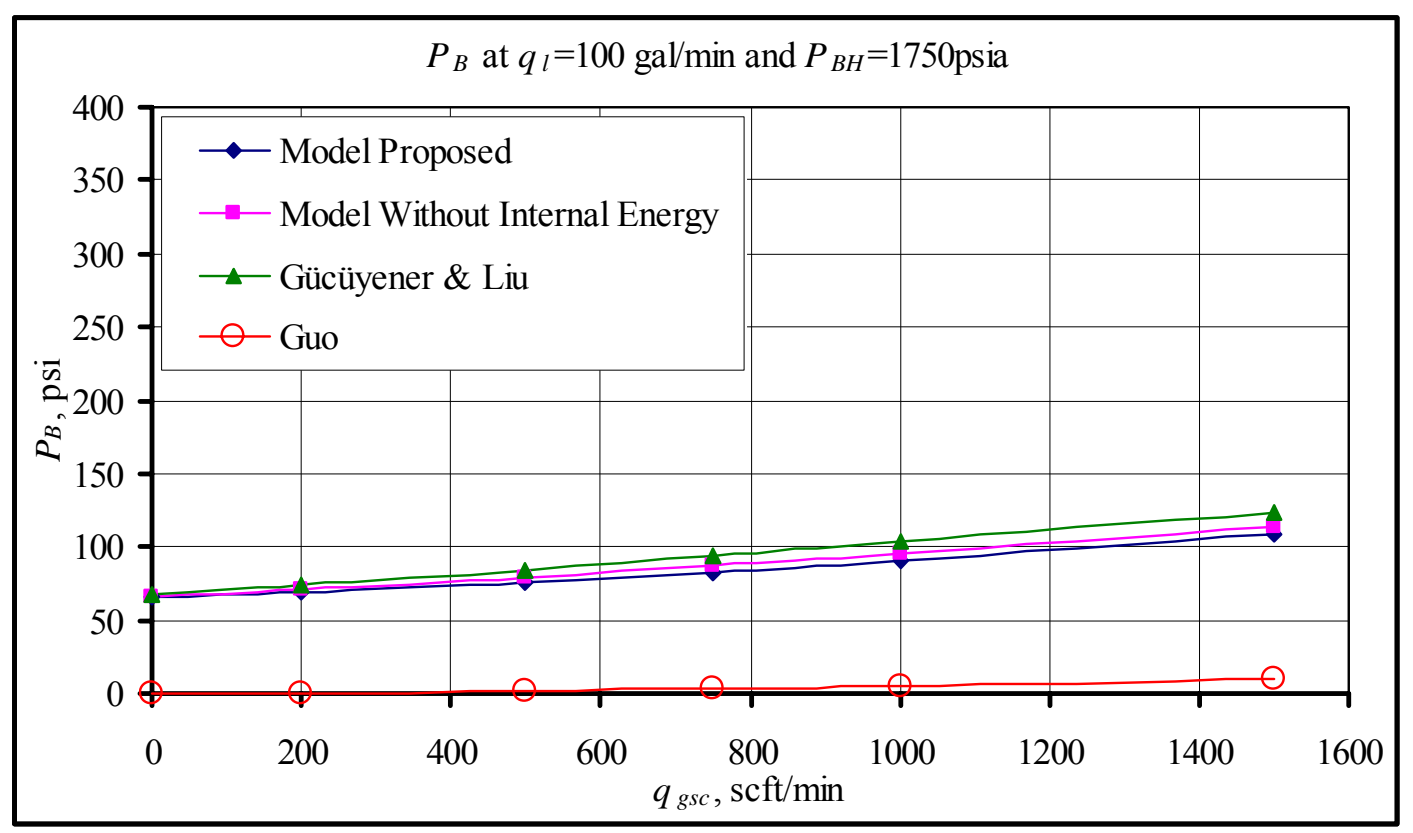

Figure $17 P_{B}$ at $q_{l}=100 \mathrm{gal} / \mathrm{min}$ and $P_{B H}=1750 \mathrm{psia}$ 
The curves are collapsing on each other with increasing bottom hole pressure as seen from Figure 18 to Figure 21. However, the predicted values of Guo [15] model are approaching to zero with an increase in bottom hole pressure, as presented in Figure 17. Actually, as mentioned in literature survey chapter, the Gou [15] model is valid for high gas concentrations. Therefore, the pressure drop values rise at high gas flow rates, as seen Figure from 18 to 21 . However, since the existing gas is compressed and the volume of the gas in the mixture is reduced, i.e., the gas concentration reduces, Guo [15] equation curves approach to zero.

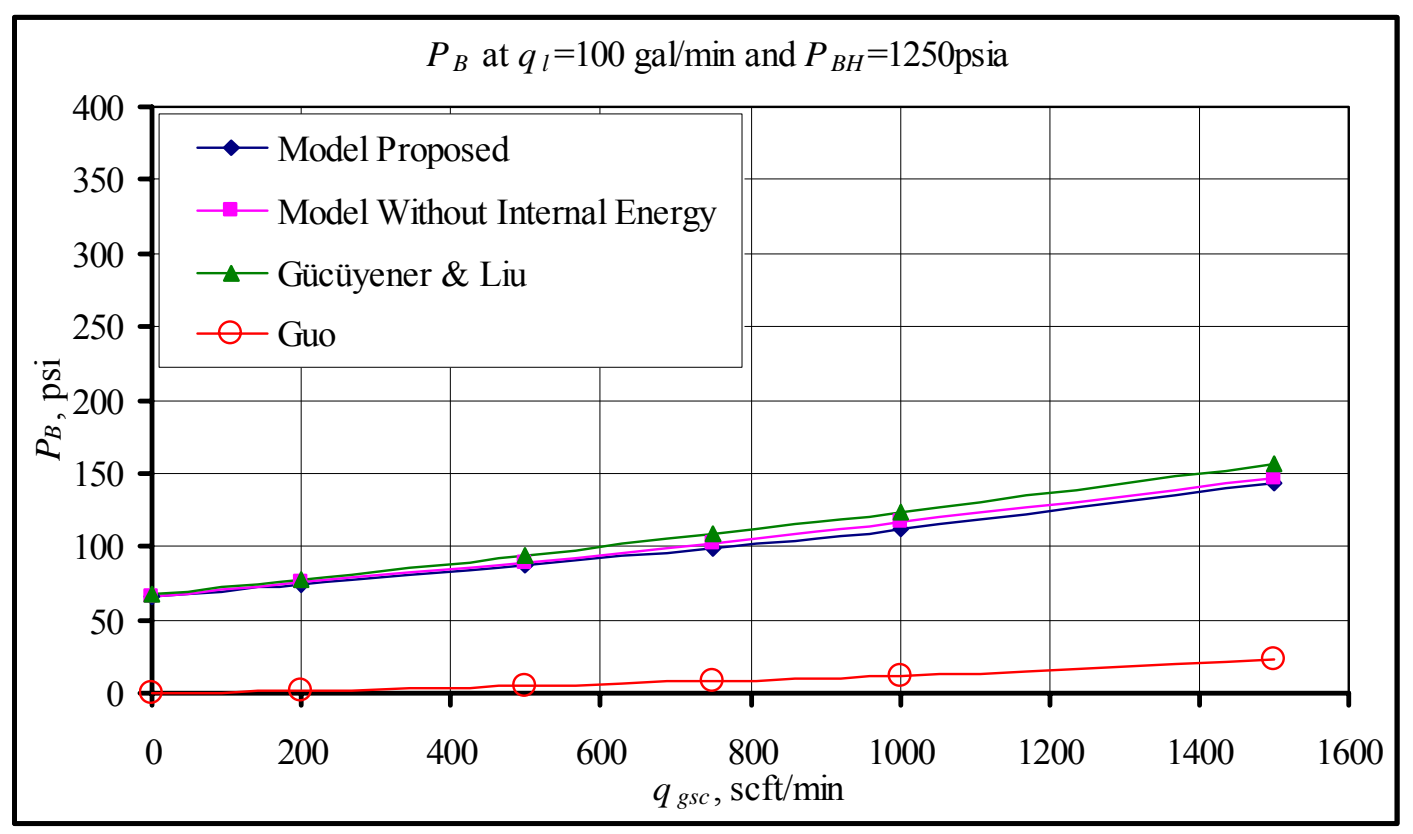

Figure $18 P_{B}$ at $q_{l}=100 \mathrm{gal} / \mathrm{min}$ and $P_{B H}=1250 \mathrm{psia}$ 


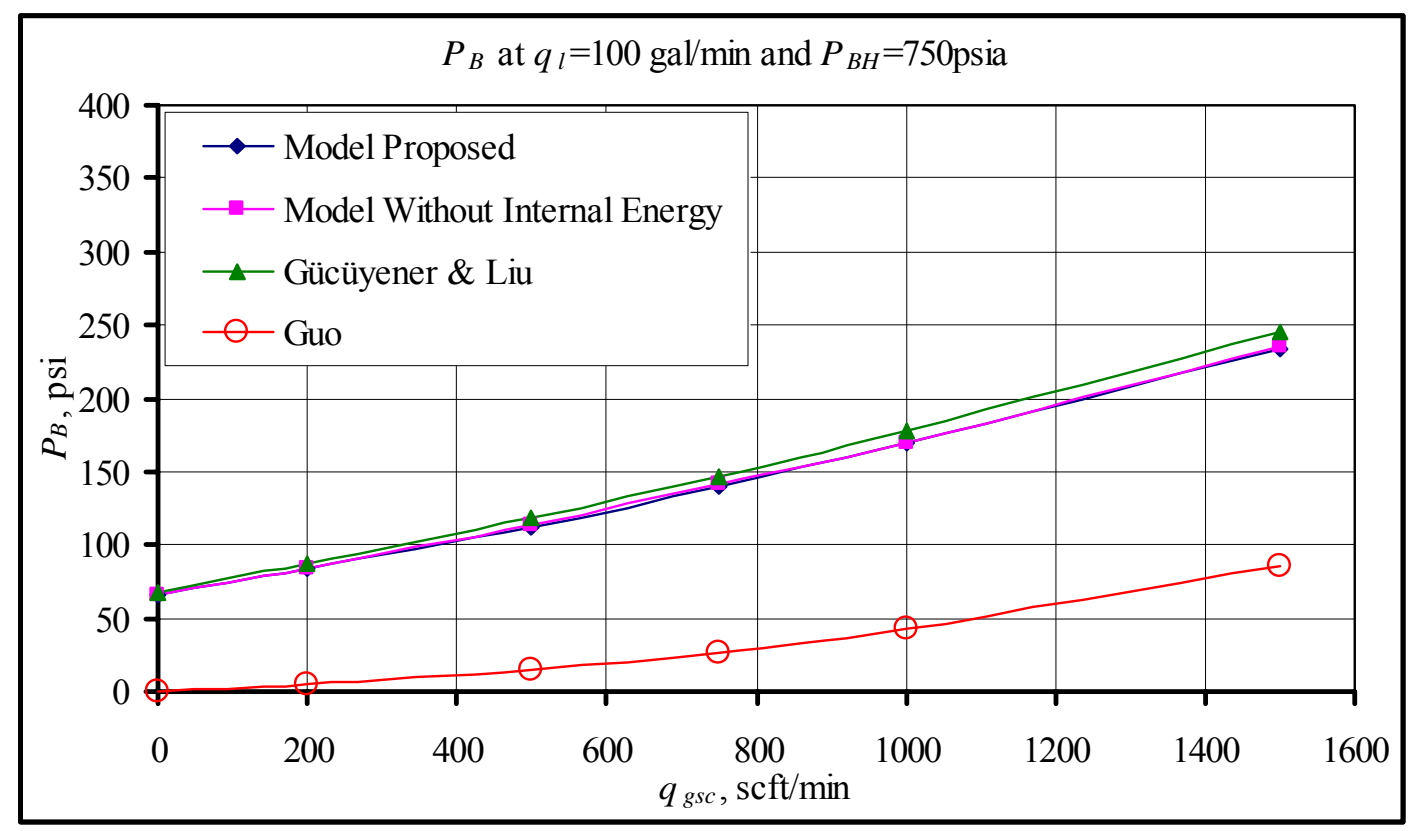

Figure $19 P_{B}$ at $q_{l}=100 \mathrm{gal} / \mathrm{min}$ and $P_{B H}=750 \mathrm{psia}$

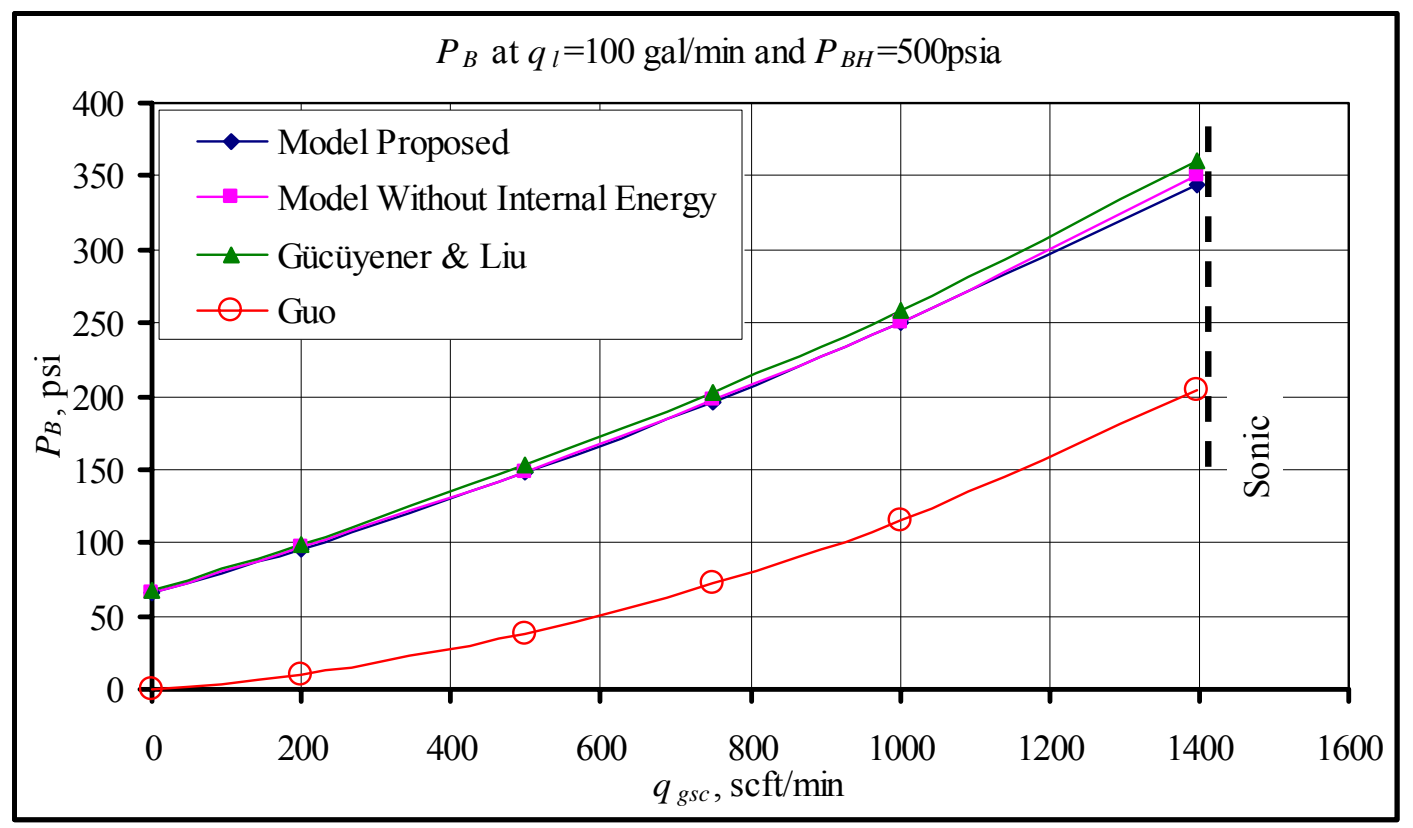

Figure $20 \quad P_{B}$ at $q_{l}=100 \mathrm{gal} / \mathrm{min}$ and $P_{B H}=500 \mathrm{psia}$ 


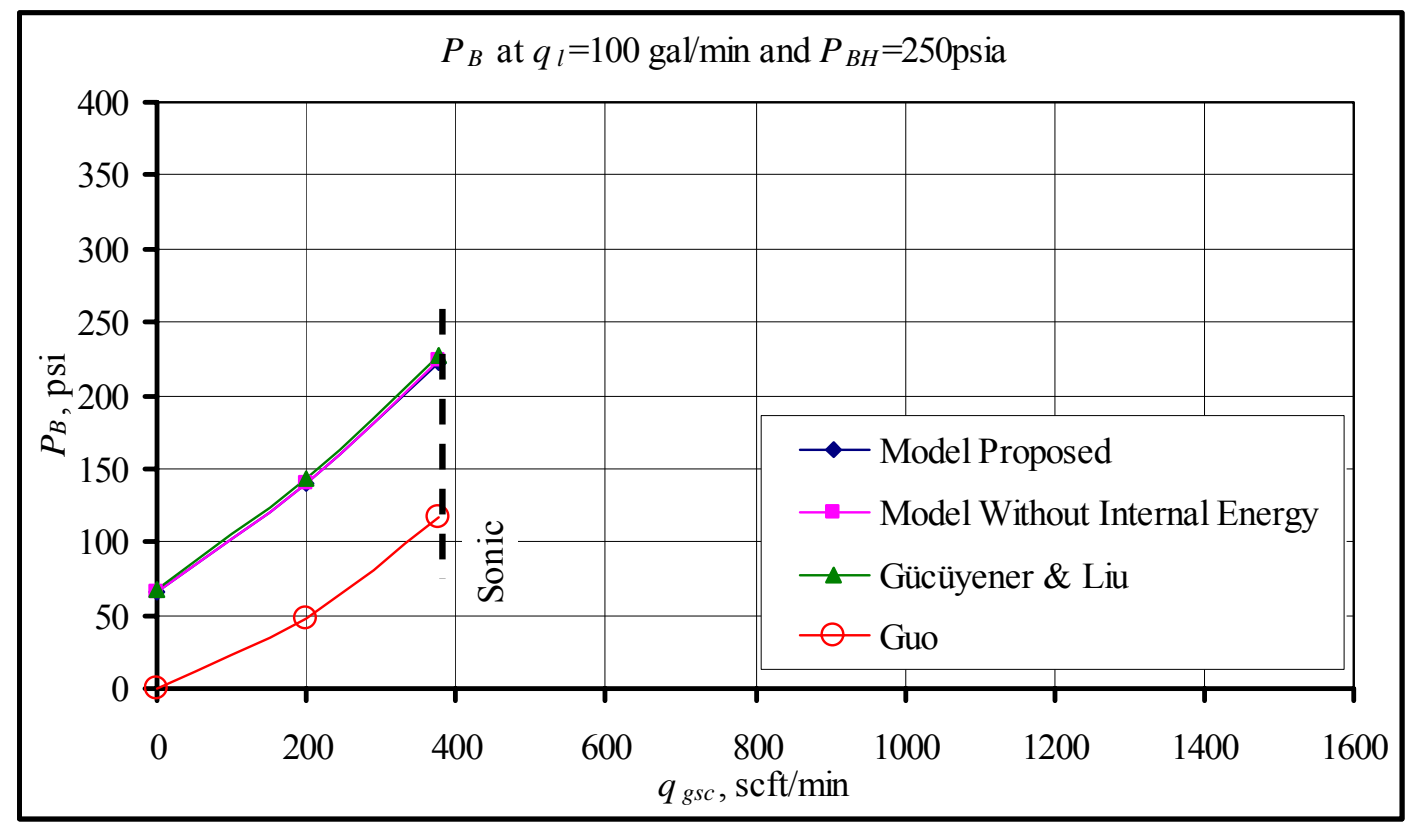

Figure $21 \quad P_{B}$ at $q_{l}=100 \mathrm{gal} / \mathrm{min}$ and $P_{B H}=250 \mathrm{psia}$

\subsubsection{Effect of Liquid Flow Rate on Pressure Drop}

The influence of the liquid flow rate on bit pressure drop has been discussed in the previous sections. In Figures 22 and 23, the effects of bit pressure drop varying liquid rates at constant bottom hole pressure on bit pressure drop are examined. The increase in the liquid flow rate results an increase in the bit pressure drop values, as presented in Figure 22 and Figure 23. 


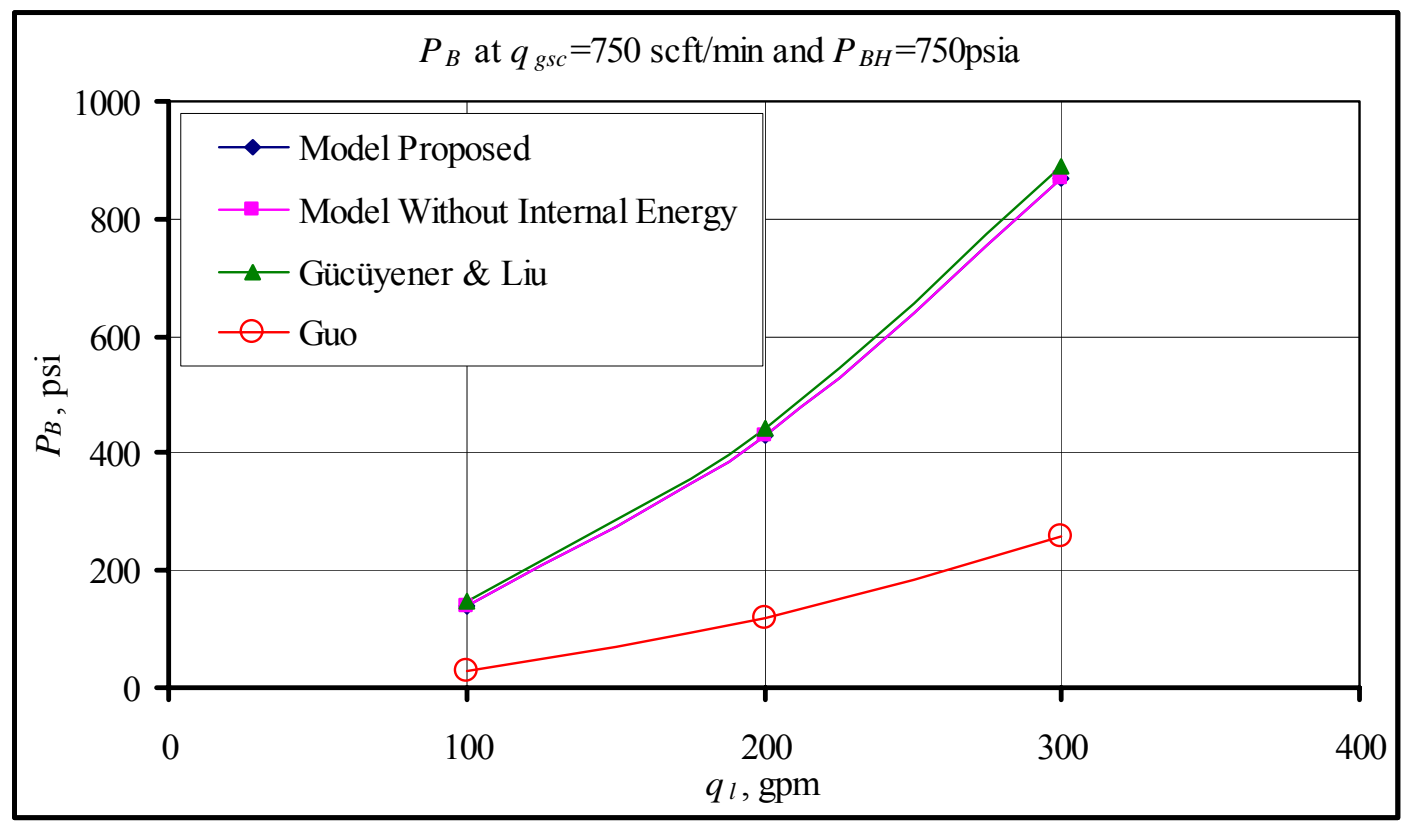

Figure $22 P_{B}$ Values at $q_{g s c}=750 \mathrm{scft} / \mathrm{min}$ and $P_{B H}=750 \mathrm{psia}$

The curves in Figure 22 are approaching to each other except curve of Guo [15] model. The results of Gücüyener [17] and Liu [18] and the proposed model are close to each other. But, although the quantity is small, the variation increases with an increase in liquid flow rate. Moreover, the internal energy effect on pressure drop does not have a significant effect, as seen in Figure 22. But in Figure 23, the existence of internal energy in the proposed model has a small effect on pressure drop values. In fact, the bottom hole pressure is higher in Figure 23 than in Figure 22. 


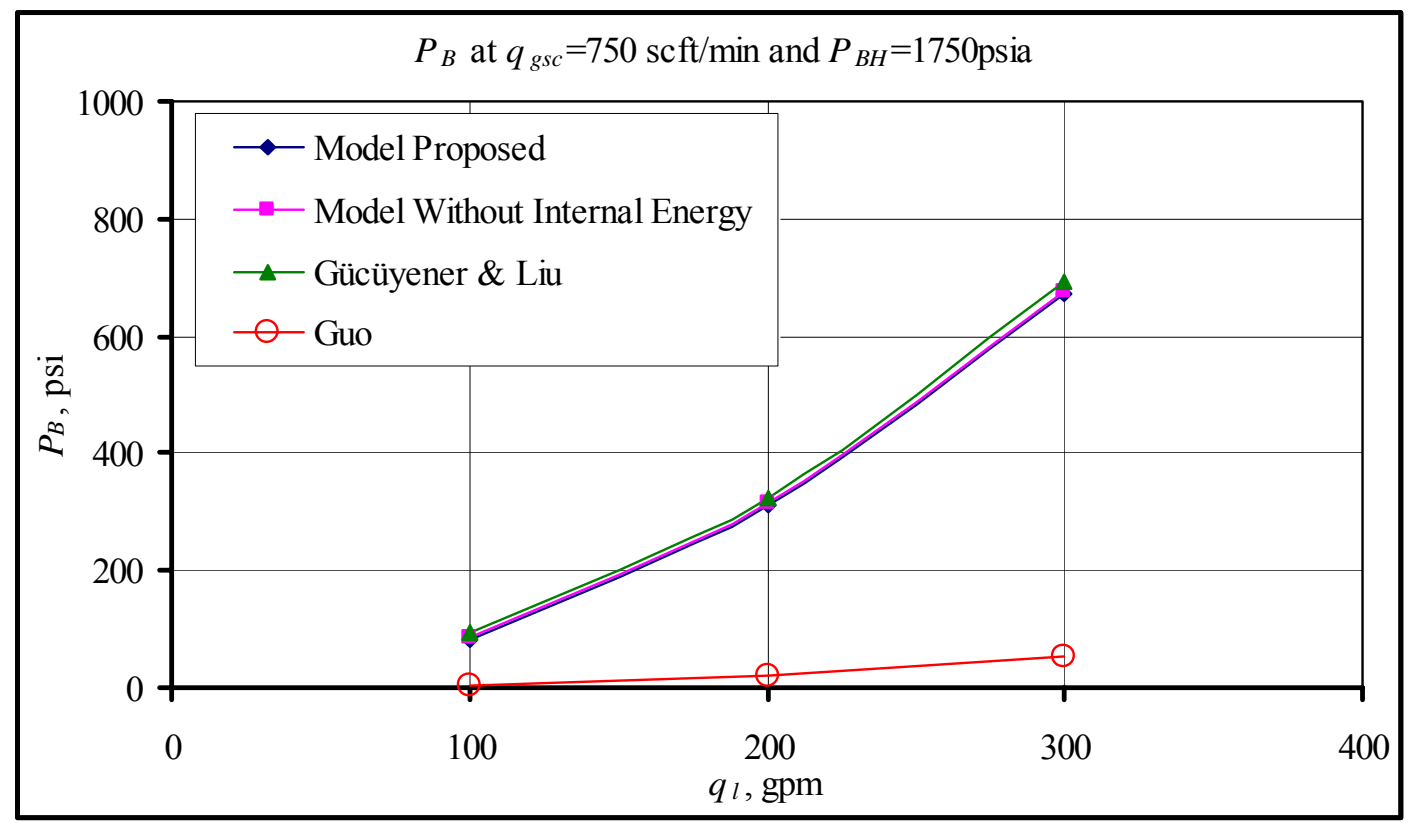

Figure $23 P_{B}$ Values at $q_{g s c}=750 \mathrm{scft} / \mathrm{min}$ and $P_{B H}=1750 \mathrm{psia}$ 


\section{CHAPTER 6}

\section{CONCLUSIONS}

In this study, a mathematical model has been developed for calculating bit pressure drop across a nozzle for two phase drilling fluids. The general energy equation and the sound wave transmission concept are developing the basis of the proposed model. Developed model is valid for both sonic and subsonic flow. Air water mixture, have been used for testing the performance of the proposed model. The obtained conclusions are listed below:

1. It is a general assumption that flow pattern is disperse bubbly through the bit nozzles. In this study, it has been proved that this assumption is valid.

2. The assumptions of all components are moving with the same velocity for a particular arbitrary point, and no slippage between the phases at the nozzle throat, are verified.

3. Since the sonic flow through the nozzle is not desired in drilling operations, the model calculates the pressure drop at the bit for subsonic conditions. If the flow 
is sonic, the model changes the liquid and gas flow rates to achieve subsonic conditions.

4. A sensitivity analysis is conducted for investigating the effects of bottom hole pressure, liquid and gas flow rates, temperature, nozzle size, and bit size on pressure drop at the bit. The followings are concluded:

i. Bottom hole pressure has a significant effect on bit pressure drop across the nozzles. The bit pressure drop reduces with an increase in bottom hole pressure.

ii. Liquid rate has a noticeable effect on bit pressure drop. The liquid phase in the two-phase fluid mixture is incompressible. The amount of incompressible phase has a great effect on pressure drop through the nozzle.

iii. The influence of gas flow rate on pressure drop across the nozzle is not as significant as the liquid flow rate. However, still an increase in the pressure drop is observed as the gas flow rate increased.

iv. Bottom hole temperature has a very slight effect on bit pressure drop.

v. The nozzle size has a strong influence on bit pressure drop. As the nozzle size is decreased, a significant increase in bit pressure drop is observed. 
vi. The bit size has no effect on bit pressure drop. The hydraulic calculations for pipe and annular flow take the bit size into consideration. However, the hydraulic calculations for pipe and annular flow are out of scope of this study.

5. The proposed model can calculate the bit pressure drop with a reasonable accuracy. The developed model has a maximum $9 \%$ difference with the Gücüyener [17] and Liu [18] model results.

6. The superior part of this proposed model when compared with the other models is to be taken into the internal energy and temperature changes consideration. Taking into consideration of the internal energy improves the accuracy of the bit pressure drop calculations.

7. Most widely used model in the drilling industry, Gou [15] model under estimates the pressure drop at the bit and Gücüyener [17] and Liu [18] model overestimates the pressure drop at the bit.

i. Guo [15] model is valid only for high gas flow rates and high gas concentrations. The results of the Guo [15] model give lower results than the Gücüyener [17] and Liu [18] model and the proposed model. Thus, Therefore Gou [15] model under estimates the pressure drop at the bit. 
ii. Internal energy, compressibility factor, temperature changes and initial kinetic energy term do not have any effect on Gücüyener [17] and Liu [18] model results, because, those factors are not included in Gücüyener [17] and Liu [18] model. Therefore, absence of those factors result in the pressure drop of the bit, as seen in Gücüyener [17] and Liu [18] model results. Indeed, the elimination of initial kinetic energy term in their model is the major factor of the variation with the proposed model.

8. When internal energy term is ignored, the proposed model gives closer results to Gücüyener [17] and Liu [18] model. The internal energy changes in the proposed model reduce the bit pressure drop values about 3.3\%. Thus, the proposed model is more sensitive. 


\section{CHAPTER 7}

\section{RECOMMENDATIONS}

In this study, a mathematical model has been developed to calculate bit pressure drop across a nozzle for two phase drilling fluids. The general energy equation is used during the development of this model. Air - water mixtures have been used for testing the performance of the proposed model. Some recommendations are listed below.

- The proposed model has been compared with the existing model. However, to verify validity of the proposed model, the results of the model must be compared with experimental results.

- Some calculations have been conducted for air - water mixture. The results are used for verification of the model with existing models. Indeed, it would be better to verify the model for different liquid and gas component than air and water, i.e., different gases such as $\mathrm{CO}_{2}, \mathrm{~N}_{2}$, and different liquids, such as non-Newtonian fluids. 
- The proposed model should be improved for soluble fluids. In this study, it is assumed that, the gas phase of the fluid is not soluble in liquid phase of the fluid. In this study, the solubility effect is not taken into consideration.

- The liquid heat capacity at constant pressure and volume values should be correlated. The heat capacity of liquid is assumed to be constant. Yet, it shows small changes with temperature and pressure. 


\section{CHAPTER 8}

\section{REFERENCES}

[1] Omana, R. et. al.: "Multiphase Flow Through chokes," paper SPE 2682 presented at the 1969 SPE Annual Meeting, Denver, Sept. 28-Oct. 1.

[2] Ros, N.C.J.: "An Analysis of Critical Simultaneous Gas-Liquid Flow Through a Restriction and its-Application To Flow Metering," Applied Sci. Research (1960), 2, Section A, 374.

[3] Ros, N.C.J.: "Theoretical Approach to the Study of Critical Gas-Liquid Flow Through Beans,” Internal Report, (Feb. 1959).

[4] Pilehvari, A.A.: "Experimental Study of Critical Two-Phase Flow Through Wellhead Chokes" U. of Tulsa Fluid Flow Project, June 1981

[5] Osman, M.E. and Dokla, M.E.: "Gas Condensate Flow Through Chokes," SPE Paper 20988, 23 April 1990. 
[6] Osman, M.E. and Dokla, M.E.: "Correlation Predict Gas-Condensate Flow Through Chokes," Oil and Gas J., March 16, 1992, pp. 43-46.

[7] Tangren, R. F., Dodge, C. H., and Seifert, H.S.: “Compressibility Effects in Two-Phase Flow,” J. Appl, Phys. (July 1949) 20,637.

[8] Ashford, F. E.: “An Evaluation of Critical Multiphase Flow Performance Through Wellhead Chokes,” JPT (Aug. 1974) 843.

[9] Ashford, F.E. and Fierce, P. E.: "Determining Multiphase Pressure Drop and Flow Capabilities in Down-Hole Safety valves,", JPT (Sept.1975) 1145.

[10] Sachdeva, R., Schmidt, Z., Brill, J.P. and Blais, R.M.: "Two-Phase Flow Through Chokes," paper SPE 15657 presented at the 1986 SPE Annual Technical Conference and Exhibition, New Orleans, Oct. 5-8.

[11] Fortunati, F.: "Two-Phase Flow Through Wellhead Chokes," paper SPE 3742 presented at the 1972 SPE European Spring Meeting, The Netherlands, May 16-18.

[12] Gould, T. L.: 'Discussion of an Evaluation of Critical Multiphase Flow Performance Through Wellhead chokes," JPT (Aug. 1974) 849. 
[13] Perkins, T.K.: "Critical and Subcritical Flow of Multiphase Mixtures Through Chokes" SPE Drilling \& Completion, December 1993.

[14] Clack, A.R. and Perkins, T.K.: "Wellbore and Near-surface Hydraulics of a Blown-Out Oil Well,” JPT (Nov. 1981) 2181.

[15] Guo, B., Harelend, G., Rajtar, J.: "Computer Simulation Predicts Unfavorable Mud Rate and Optimum Air Injection Rate for Aerated Mud Drilling” paper SPE 26892 presented at the 1993 regional Conference \& Exhibition held in Pittsburgh, PA, Nov. 2-4.

[16] Lynos, W.C., Guo, B. and Seidel, F.A., Air and Gas Drilling Manual, McGraw-Hill, New York (1999).

[17] Gücüyener, İ. H.: "Design of Aerated Mud for Low Pressure Drilling" paper SPE 80491 presented at the 2003 SPE Asia Pacific Oil and Gas Conference and Exhibition held in Jakarta, Indonesia, April 15-17.

[18] Liu, G. and Medley, G.H.: "Foam Computer Model Helps in Analysis of Under balanced Drilling” Oil and Gas J. July 1, 1996, p.114-119

[19] Wood, A. B., A Testbook of Sound, G. Bell and Sons LTD, London (1960).

[20] Kaya, A.S., Sarica, C., Brill, J.P. : “Comprehensive Mechanistic Modeling of Two-Phase Flow in Deviated Wells," paper SPE 56522 prepared for 
presentation at the 1999 SPE Annual Technical Conference and Exhibition held in Houston, Texas, 3-6 Oct. 1999.

[21] Çengel, Y.A., Boles, M.A., Thermodynamics: An Engineering Approach, $2^{\text {nd }}$ edition, McGraw-Hill Book Co., Inc., New York City, (1994) 870

[22] Hodgman, C.D., Holmes, H.N., Handbook of Chemistry and Physics, $25^{\text {th }}$ edition, Chemical Rubber Publishing Co., Cleveland, Ohio, (1941).

[23] Papay, J.: “A Termelestechnologiai Parameterek Voltozaa a Gazle-lepk Muveless Soran," OGIL MUSZ, Tnd, Kuzl., Budapest (1968) 267. 
APPENDIX A

\section{CORRELATION OF AIR PROPERTIES}

\section{A.1. Correlation for Air Heat Capacity at Constant Pressure Values}

The developed computer program based on the proposed model also calculates the heat capacity values measured by Çengel and Bole [21], and Hodgman [22]. The measured values are numerically processed by the computer and the results are obtained at given pressures and temperatures.

Table 2 Constant Pressure Heat Capacity Values

\begin{tabular}{|c|c|c|c|c|}
\cline { 2 - 5 } \multicolumn{1}{c|}{} & \multicolumn{4}{c|}{ Temperature } \\
\hline $\mathbf{P , ~ p s i}$ & $\mathbf{- 5 8}^{\circ} \mathbf{F}$ & $\mathbf{3 2}^{\circ} \mathbf{F}$ & $\mathbf{1 2 2}^{\circ} \mathbf{F}$ & $\mathbf{2 1 2}^{\circ} \mathbf{F}$ \\
\hline $\mathbf{1 4 . 7}$ & 186.7139 & 186.5582 & 186.8687 & 187.5387 \\
\hline $\mathbf{1 4 7}$ & 190.3492 & 189.6079 & 189.5775 & 190.2572 \\
\hline $\mathbf{2 9 4}$ & 196.1764 & 194.3088 & 192.9859 & 192.2077 \\
\hline $\mathbf{5 8 8}$ & 213.2961 & 202.7014 & 197.0065 & 196.2121 \\
\hline $\mathbf{1 0 2 9}$ & 242.8665 & 218.6682 & 204.4515 & 200.2164 \\
\hline $\mathbf{1 4 7 0}$ & 301.3886 & 250.2086 & 211.5842 & 202.3239 \\
\hline $\mathbf{3 2 3 4}$ & & 714.9144 & 230.4158 & 221.0778 \\
\hline & & \multicolumn{4}{c}{$C_{p}, \mathrm{ft}-1 \mathrm{bf} / \mathrm{lbm}^{\circ} \mathrm{F}$} \\
\hline
\end{tabular}




\section{A.2. Gas Compressibility Factor For Air}

In this study, the air compressibility factor, $z$, is estimated using Papay's [23] method, which is given by.

$z=1.0-\left(P_{r} / T_{r}\right)\left[0.36748758-0.04188423\left(P_{r} / T_{r}\right)\right]$

In this equation, the reduced pressure, $P_{r}$, and the reduced temperature, $T_{r}$, of air are given by,

$P_{r}=P / 547$

and

$T_{r}=(T+460) / 239$

respectively. 
APPENDIX B

\section{EXISTING MODELS}

\section{B.1. Gücüyener and Liu Model}

Gücüyener [17] and Liu [18] developed an equation for determination of pressure drop across the nozzle. In their studies, the general energy equation for two-phase flow through the bit nozzles was used for developing the bit pressure drop equation.

$v_{f} d P+\frac{1}{g_{c}} \vartheta_{f} d \vartheta_{f}+d E+\frac{g}{g_{c}} d Z=0$

In their work, it was assumed that the volumetric velocity of the fluid is almost zero at the upstream conditions. Therefore, the upstream velocity of the fluid was assigned to zero. Moreover, the elevation changes and internal energy term in the general energy equation were neglected because of their slight effect on the calculations. Thus, the integration of eq. (A.4) becomes, 


$$
\int_{P_{u p}}^{P_{B H}} v_{f} d P+\frac{1}{g_{c}} \int_{0}^{\vartheta_{\text {nozzle }}} \vartheta_{f} d \vartheta_{f}=0
$$

After integration, eq. (A.5) becomes

$$
1.08 \times 10^{-4}\left(\frac{\vartheta_{\text {nozzle }}}{C_{N}}\right)^{2}+\frac{f_{g}}{\rho_{g}} P_{B H}\left(\ln \frac{P_{B H}}{P_{B H}-P_{B}}\right)-\frac{f_{l}}{\rho_{l}}\left(P_{B}\right)=0
$$

The results of the equation were compared with those of the proposed model. The results of the Gücüyener [17] and Liu [18] equation overestimate the pressure drop of the bit. 


\section{B.2. Bit Pressure Drop Determination Equation By Guo}

Guo, et. al. [15] developed an equation for estimating the pressure drop of a

multiphase fluid flow through a nozzle. From the first law of thermodynamics, the following equation was obtained.

$\frac{d P}{\rho_{f}}+\frac{\vartheta_{f}}{g_{c}} d \vartheta_{f}+\frac{g}{g_{c}} d Z=0$

According to their study, the elevation changes and energy losses caused by friction were neglected. So, eq. (A.7) became

$d P=-\frac{\rho_{f}}{g_{c}} \vartheta_{f} d \vartheta_{f}$

Integration of eq. (A.8) yielded

$P_{\text {upstream }}-P_{\text {downstream }}=\frac{\rho_{m}}{2 g_{c}}\left(\vartheta_{f-\text { downstream }}^{2}-\vartheta_{f-\text { upstream }}^{2}\right)$

The velocity of a fluid can be determined as

$\vartheta_{f}=\frac{\dot{m}_{f}}{\rho_{f} \times A_{\text {nozzle }}}$ 
Thus, substituting eq. (A.10) into eq. (A.9) yields

$$
P_{B}=\left(\frac{\dot{m}_{f}}{A_{\text {nozzle }}}\right)^{2} \frac{1}{g_{c} \times 144}\left(v_{f \text {-downstream }}-v_{f \text {-upstream }}\right)
$$

Equation (A.11) depends on the specific volume of the fluid. For incompressible mixtures or fluids, the specific volume difference in the equation reduced to zero. Therefore, the equation is valid only for compressible fluids. 


\section{APPENDIX C \\ ITERATION ERROR ANALYSIS}

The developed created computer program based on the proposed model is used to calculate the pressure drop through a nozzle. The calculation process contains iterations. After each iteration, the program calculates the difference between the consecutive iterated values and compares the difference with desired error. The desired iteration error value is defined by the user, and assigned to get more accurate results. The iteration error values and obtained result values are listed in Table 3. For higher error values, the computer program gives results in a long period of time, although there is not a significant difference between the results. Therefore, for calculation of the pressure drop values, the error value of $1.0 \times 10^{-6}$ is selected for iteration error.

Table 3 Iteration Error Analysis

\begin{tabular}{|c|c|c|c|c|}
\hline Error & $1.0 \times 10^{-4}$ & $1.0 \times 10^{-5}$ & $1.0 \times 10^{-6}$ & $1.0 \times 10^{-7}$ \\
\hline Calculated $\boldsymbol{P}_{\boldsymbol{B}}$ & 1209.0864745 & 1241.6502137 & 1245.0172463 & 1245.3350807 \\
\hline
\end{tabular}


APPENDIX D

\section{VARIATON ANALYSIS}

The following statistical parameters have been used to compute the accuracy of the investigated correlation.

- Average absolute percent relative deviation:

$$
A P D=(1 / k) \sum_{i=1}^{k} P D_{i}
$$

where

$$
P D_{i}=\left(\left(P_{B o}-P_{B m}\right) / P_{B o}\right) \times 100
$$

$k=1,2,3,4, \ldots$

$P_{B m}$ is bit pressure calculated by the proposed model

$P_{B o}$ is bit pressure calculated by the existing model 
- Standard deviation:

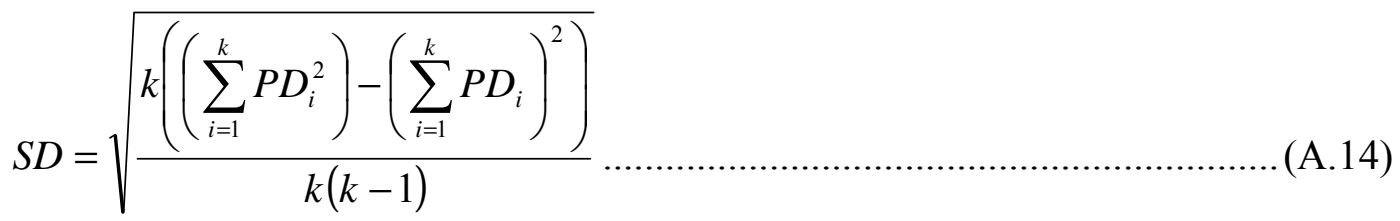


APPENDIX E

\section{CALCULATED PRESSURE DROP VALUES AND VARIATION}

ANALYSIS

The following values, listed in the tables and plotted on the figures, are used to compare the proposed model with the existing models.

Table $4 \quad P_{B}$ values of Case 1 at $q_{l}=100 \mathrm{gal} / \mathrm{min}$ and $P_{B H}=250 \mathrm{psia}$

\begin{tabular}{|c|c|c|c|c|}
\hline $\begin{array}{c}\boldsymbol{Q}_{G S C} \\
\text { scft/min }\end{array}$ & $\begin{array}{c}\text { Proposed } \\
\text { Model }\end{array}$ & $\begin{array}{c}\text { Model without } \\
\text { Internal Energy }\end{array}$ & $\begin{array}{c}\text { Gücüyener } \\
\text { \& Liu }\end{array}$ & Guo \\
\hline 0 & 66.310 & 66.310 & 67.350 & 0.000 \\
\hline 200 & 140.410 & 140.650 & 143.150 & 47.040 \\
\hline 377 & 222.250 & 223.783 & 226.380 & 117.680 \\
\hline
\end{tabular}

\begin{tabular}{|c|c|c|c|c|c|c|}
\hline \multirow{2}{*}{$\begin{array}{c}Q_{G S C} \\
\text { scft } / \text { min }\end{array}$} & \multicolumn{2}{|c|}{$\begin{array}{l}\text { Model without } \\
\text { Internal Energy. }\end{array}$} & \multicolumn{2}{|c|}{$\begin{array}{c}\text { Gücüyener } \\
\text { \& Liu }\end{array}$} & \multicolumn{2}{|c|}{ Guo } \\
\hline & PD & $|\mathbf{P D}|$ & PD & $\mid$ PD| & PD & $|\mathbf{P D}|$ \\
\hline 0 & 0.000 & 0.000 & 1.544 & 1.544 & & \\
\hline 200 & 0.171 & 0.171 & 1.914 & 1.914 & -198.491 & 198.491 \\
\hline 377 & 0.685 & 0.685 & 1.824 & 1.824 & -88.860 & 88.860 \\
\hline Average & 0.285 & 0.285 & 1.761 & 1.761 & -143.675 & 143.675 \\
\hline SD & 0.357 & 0.357 & 0.193 & 0.193 & 77.521 & 77.521 \\
\hline
\end{tabular}


Table $5 \quad P_{B}$ values of Case 1 at $q_{l}=100 \mathrm{gal} / \mathrm{min}$ and $P_{B H}=500 \mathrm{psia}$

\begin{tabular}{|c|c|c|c|c|}
\hline $\begin{array}{c}\boldsymbol{Q}_{G S C} \\
\text { scft/min }\end{array}$ & $\begin{array}{c}\text { Proposed } \\
\text { Model }\end{array}$ & $\begin{array}{c}\text { Model without } \\
\text { Internal Energy }\end{array}$ & $\begin{array}{c}\text { Gücüyener } \\
\text { \& Liu }\end{array}$ & Guo \\
\hline 0 & 66.310 & 66.310 & 67.350 & 0.000 \\
\hline 200 & 96.200 & 96.850 & 99.230 & 10.580 \\
\hline 500 & 147.580 & 148.360 & 152.550 & 38.210 \\
\hline 750 & 196.410 & 196.710 & 202.590 & 72.010 \\
\hline 1000 & 249.720 & 250.400 & 258.400 & 115.490 \\
\hline 1397 & 344.540 & 350.786 & 360.650 & 203.980 \\
\hline
\end{tabular}

\begin{tabular}{|c|c|c|c|c|c|c|}
\hline$Q_{G S C}$ & \multicolumn{2}{|c|}{$\begin{array}{c}\text { Model without } \\
\text { Internal Energy. }\end{array}$} & \multicolumn{2}{|c|}{ Gücüyener \& Liu } & \multicolumn{2}{|c|}{ Guo } \\
\hline scft/min & PD & $|\mathbf{P D}|$ & PD & $\mid$ PD $\mid$ & PD & $\mid$ PD $\mid$ \\
\hline 0 & 0.000 & 0.000 & 1.544 & 1.544 & & \\
\hline 200 & 0.671 & 0.671 & 3.054 & 3.054 & -809.263 & 809.263 \\
\hline 500 & 0.526 & 0.526 & 3.258 & 3.258 & -286.234 & 286.234 \\
\hline 750 & 0.153 & 0.153 & 3.050 & 3.050 & -172.754 & 172.754 \\
\hline 1000 & 0.272 & 0.272 & 3.359 & 3.359 & -116.227 & 116.227 \\
\hline 1397 & 1.781 & 1.781 & 4.467 & 4.467 & -68.909 & 68.909 \\
\hline Average & $\mathbf{0 . 5 6 7}$ & $\mathbf{0 . 5 6 7}$ & $\mathbf{3 . 1 2 2}$ & $\mathbf{3 . 1 2 2}$ & $\mathbf{- 2 9 0 . 6 7 7}$ & $\mathbf{2 9 0 . 6 7 7}$ \\
\hline SD & $\mathbf{0 . 6 4 3}$ & $\mathbf{0 . 6 4 3}$ & $\mathbf{0 . 9 3 6}$ & $\mathbf{0 . 9 3 6}$ & $\mathbf{3 0 1 . 0 2 8}$ & $\mathbf{3 0 1 . 0 2 8}$ \\
\hline
\end{tabular}


Table $6 \quad P_{B}$ values of Case 1 at $q_{l}=100 \mathrm{gal} / \mathrm{min}$ and $P_{B H}=750 \mathrm{psia}$

\begin{tabular}{|c|c|c|c|c|}
\hline $\begin{array}{c}\boldsymbol{Q}_{G S C} \\
\text { sctt/min }\end{array}$ & $\begin{array}{c}\text { Proposed } \\
\text { Model }\end{array}$ & $\begin{array}{c}\text { Model without } \\
\text { InternalEnergy }\end{array}$ & $\begin{array}{c}\text { Gücüyener } \\
\text { \& Liu }\end{array}$ & Guo \\
\hline 0 & 66.310 & 66.310 & 67.350 & 0.000 \\
\hline 200 & 83.420 & 84.390 & 86.910 & 4.380 \\
\hline 500 & 112.530 & 114.150 & 118.410 & 14.700 \\
\hline 750 & 139.540 & 141.190 & 146.750 & 26.940 \\
\hline 1000 & 168.930 & 170.240 & 177.130 & 42.660 \\
\hline 1500 & 234.200 & 234.600 & 244.520 & 85.100 \\
\hline
\end{tabular}

\begin{tabular}{|c|c|c|c|c|c|c|}
\hline $\boldsymbol{Q}_{G S C}$ & \multicolumn{2}{|c|}{$\begin{array}{c}\text { Model without } \\
\text { Internal Energy. }\end{array}$} & \multicolumn{2}{c|}{$\begin{array}{c}\text { Gücüyener } \\
\text { \& Liu }\end{array}$} & \multicolumn{2}{c|}{ Guo } \\
\hline scft/min & PD & $|\mathbf{P D}|$ & PD & $|\mathbf{P D}|$ & PD & $\mid$ PD $\mid$ \\
\hline 0 & 0.000 & 0.000 & 1.544 & 1.544 & & \\
\hline 200 & 1.149 & 1.149 & 4.016 & 4.016 & -1804.566 & 1804.566 \\
\hline 500 & 1.419 & 1.419 & 4.966 & 4.966 & -665.510 & 665.510 \\
\hline 750 & 1.169 & 1.169 & 4.913 & 4.913 & -417.966 & 417.966 \\
\hline 1000 & 0.770 & 0.770 & 4.629 & 4.629 & -295.992 & 295.992 \\
\hline 1500 & 0.171 & 0.171 & 4.221 & 4.221 & -175.206 & 175.206 \\
\hline Average & $\mathbf{0 . 7 8 0}$ & $\mathbf{0 . 7 8 0}$ & $\mathbf{4 . 0 4 8}$ & $\mathbf{4 . 0 4 8}$ & $\mathbf{- 6 7 1 . 8 4 8}$ & $\mathbf{6 7 1 . 8 4 8}$ \\
\hline SD & $\mathbf{0 . 5 7 9}$ & $\mathbf{0 . 5 7 9}$ & $\mathbf{1 . 2 8 3}$ & $\mathbf{1 . 2 8 3}$ & $\mathbf{6 5 8 . 6 8 6}$ & $\mathbf{6 5 8 . 6 8 6}$ \\
\hline
\end{tabular}


Table $7 \quad P_{B}$ values of Case 1 at $q_{l}=100 \mathrm{gal} / \mathrm{min}$ and $P_{B H}=750 \mathrm{psia}$

\begin{tabular}{|c|c|c|c|c|}
\hline $\begin{array}{c}Q_{G S C} \\
\text { scft/min }\end{array}$ & $\begin{array}{c}\text { Proposed } \\
\text { Model }\end{array}$ & $\begin{array}{c}\text { Model without } \\
\text { Internal Energy }\end{array}$ & $\begin{array}{c}\text { Gücüyener } \\
\text { \& Liu }\end{array}$ & Guo \\
\hline 0 & 66.300 & 66.300 & 67.300 & 0.000 \\
\hline 200 & 73.600 & 75.000 & 77.800 & 1.400 \\
\hline 500 & 86.500 & 89.300 & 94.200 & 4.400 \\
\hline 750 & 99.000 & 102.400 & 108.600 & 7.700 \\
\hline 1000 & 112.600 & 116.300 & 123.800 & 11.700 \\
\hline 1500 & 143.000 & 146.500 & 156.200 & 22.400 \\
\hline
\end{tabular}

\begin{tabular}{|c|c|c|c|c|c|c|}
\hline$Q_{G S C}$ & \multicolumn{2}{|c|}{$\begin{array}{c}\text { Model without } \\
\text { Internal Energy. }\end{array}$} & \multicolumn{2}{|c|}{$\begin{array}{c}\text { Gücüyener } \\
\text { \& Liu }\end{array}$} & \multicolumn{2}{|c|}{ Guo } \\
\hline scft/min & PD & $|\mathbf{P D}|$ & PD & $\mid$ PD $\mid$ & PD & $\mid$ PD $\mid$ \\
\hline 0 & 0.000 & 0.000 & 1.486 & 1.486 & & \\
\hline 200 & 1.867 & 1.867 & 5.398 & 5.398 & -5157.143 & 5157.143 \\
\hline 500 & 3.135 & 3.135 & 8.174 & 8.174 & -1865.909 & 1865.909 \\
\hline 750 & 3.320 & 3.320 & 8.840 & 8.840 & -1185.714 & 1185.714 \\
\hline 1000 & 3.181 & 3.181 & 9.047 & 9.047 & -862.393 & 862.393 \\
\hline 1500 & 2.389 & 2.389 & 8.451 & 8.451 & -538.393 & 538.393 \\
\hline Average & $\mathbf{2 . 3 1 5}$ & $\mathbf{2 . 3 1 5}$ & $\mathbf{6 . 8 9 9}$ & $\mathbf{6 . 8 9 9}$ & $\mathbf{- 1 9 2 1 . 9 1 0}$ & $\mathbf{1 9 2 1 . 9 1 0}$ \\
\hline SD & $\mathbf{1 . 2 6 5}$ & $\mathbf{1 . 2 6 5}$ & $\mathbf{2 . 9 6 5}$ & $\mathbf{2 . 9 6 5}$ & $\mathbf{1 8 7 4 . 0 7 0}$ & $\mathbf{1 8 7 4 . 0 7 0}$ \\
\hline
\end{tabular}


Table $8 \quad P_{B}$ values of Case 1 at $q_{l}=100 \mathrm{gal} / \mathrm{min}$ and $P_{B H}=1750 \mathrm{psia}$

\begin{tabular}{|c|c|c|c|c|}
\hline $\begin{array}{c}\boldsymbol{Q}_{G S C} \\
\text { scft/min }\end{array}$ & $\begin{array}{c}\text { Proposed } \\
\text { Model }\end{array}$ & $\begin{array}{c}\text { Model without } \\
\text { Internal Energy }\end{array}$ & $\begin{array}{c}\text { Gücüyener } \\
\text { \& Liu }\end{array}$ & Guo \\
\hline 0 & 66.300 & 66.300 & 67.300 & 0.000 \\
\hline 200 & 69.900 & 71.300 & 74.100 & 0.700 \\
\hline 500 & 76.500 & 79.600 & 84.700 & 2.000 \\
\hline 750 & 83.100 & 87.200 & 93.900 & 3.300 \\
\hline 1000 & 90.800 & 95.500 & 103.500 & 5.000 \\
\hline 1500 & 108.400 & 113.500 & 123.700 & 9.100 \\
\hline
\end{tabular}

\begin{tabular}{|c|c|c|c|c|c|c|}
\hline$Q_{G S C}$ & \multicolumn{2}{|c|}{$\begin{array}{c}\text { Model without } \\
\text { Internal Energy. }\end{array}$} & \multicolumn{2}{|c|}{$\begin{array}{c}\text { Gücüyener } \\
\text { \& Liu }\end{array}$} & \multicolumn{2}{|c|}{ Guo } \\
\hline scft/min & PD & $|\mathbf{P D}|$ & PD & $|\mathbf{P D}|$ & PD & $\mid$ PD $\mid$ \\
\hline 0 & 0.000 & 0.000 & 1.486 & 1.486 & & \\
\hline 200 & 1.964 & 1.964 & 5.668 & 5.668 & -9885.714 & 9885.714 \\
\hline 500 & 3.894 & 3.894 & 9.681 & 9.681 & -3725.000 & 3725.000 \\
\hline 750 & 4.702 & 4.702 & 11.502 & 11.502 & -2418.182 & 2418.182 \\
\hline 1000 & 4.921 & 4.921 & 12.271 & 12.271 & -1716.000 & 1716.000 \\
\hline 1500 & 4.493 & 4.493 & 12.369 & 12.369 & -1091.209 & 1091.209 \\
\hline Average & $\mathbf{3 . 3 2 9}$ & $\mathbf{3 . 3 2 9}$ & $\mathbf{8 . 8 2 9}$ & $\mathbf{8 . 8 2 9}$ & $\mathbf{- 3 7 6 7 . 2 2 1}$ & $\mathbf{3 7 6 7 . 2 2 1}$ \\
\hline SD & $\mathbf{1 . 9 5 2}$ & $\mathbf{1 . 9 5 2}$ & $\mathbf{4 . 3 8 5}$ & $\mathbf{4 . 3 8 5}$ & $\mathbf{3 5 5 7 . 6 0 4}$ & $\mathbf{3 5 5 7 . 6 0 4}$ \\
\hline
\end{tabular}


Table $9 P_{B}$ values of Case 1 at $q_{l}=200 \mathrm{gal} / \mathrm{min}$ and $P_{B H}=500 \mathrm{psia}$

\begin{tabular}{|c|c|c|c|c|}
\hline $\begin{array}{c}\boldsymbol{Q}_{G S C} \\
\text { scft/min }\end{array}$ & $\begin{array}{c}\text { Proposed } \\
\text { Model }\end{array}$ & $\begin{array}{c}\text { Model without } \\
\text { Internal Energy }\end{array}$ & $\begin{array}{c}\text { Gücüyener } \\
\text { \& Liu }\end{array}$ & Guo \\
\hline 0.0 & 265.260 & 265.260 & 269.380 & 0.000 \\
\hline 200 & 334.840 & 335.400 & 341.340 & 51.590 \\
\hline 500 & 452.230 & 453.300 & 462.510 & 154.790 \\
\hline 750 & 563.000 & 564.200 & 576.900 & 261.580 \\
\hline 757.38 & 568.900 & 568.958 & 580.500 & 264.990 \\
\hline
\end{tabular}

\begin{tabular}{|c|c|c|c|c|c|c|}
\hline $\boldsymbol{Q}_{G S C}$ & \multicolumn{2}{|c|}{$\begin{array}{c}\text { Model without } \\
\text { Internal Energy. }\end{array}$} & \multicolumn{2}{c|}{$\begin{array}{c}\text { Gücüyener } \\
\text { \& Liu }\end{array}$} & \multicolumn{2}{|c|}{ Guo } \\
\hline scft/min & PD & $|\mathbf{P D}|$ & $\mathbf{P D}$ & $|\mathbf{P D}|$ & PD & $\mid$ PD $\mid$ \\
\hline 0.0 & 0.000 & 0.000 & 1.529 & 1.529 & & \\
\hline 200 & 0.167 & 0.167 & 1.904 & 1.904 & -549.041 & 549.041 \\
\hline 500 & 0.236 & 0.236 & 2.223 & 2.223 & -192.157 & 192.157 \\
\hline 750 & 0.213 & 0.213 & 2.409 & 2.409 & -115.231 & 115.231 \\
\hline 757.38 & 0.010 & 0.010 & 1.998 & 1.998 & -114.687 & 114.687 \\
\hline Average & $\mathbf{0 . 1 2 5}$ & $\mathbf{0 . 1 2 5}$ & $\mathbf{2 . 0 1 3}$ & $\mathbf{2 . 0 1 3}$ & $\mathbf{- 2 4 2 . 7 7 9}$ & $\mathbf{2 4 2 . 7 7 9}$ \\
\hline SD & $\mathbf{0 . 1 1 2}$ & $\mathbf{0 . 1 1 2}$ & $\mathbf{0 . 3 3 4}$ & $\mathbf{0 . 3 3 4}$ & $\mathbf{2 0 7 . 3 9 2}$ & $\mathbf{2 0 7 . 3 9 2}$ \\
\hline
\end{tabular}


Table $10 P_{B}$ values of Case 1 at $q_{l}=200 \mathrm{gal} / \mathrm{min}$ and $P_{B H}=750 \mathrm{psia}$

\begin{tabular}{|c|c|c|c|c|}
\hline $\begin{array}{c}\boldsymbol{Q}_{G S C} \\
\text { scft/min }\end{array}$ & $\begin{array}{c}\text { Proposed } \\
\text { Model }\end{array}$ & $\begin{array}{c}\text { Model without } \\
\text { Internal Energy }\end{array}$ & $\begin{array}{c}\text { Gücüyener } \\
\text { \& Liu }\end{array}$ & Guo \\
\hline 0 & 265.300 & 265.300 & 269.400 & 0.000 \\
\hline 200 & 305.600 & 306.300 & 312.000 & 24.580 \\
\hline 500 & 370.600 & 372.000 & 380.400 & 71.230 \\
\hline 750 & 429.000 & 430.700 & 441.500 & 118.770 \\
\hline 1000 & 491.400 & 493.200 & 506.800 & 173.920 \\
\hline 1500 & 628.500 & 630.100 & 650.900 & 305.900 \\
\hline
\end{tabular}

\begin{tabular}{|c|c|c|c|c|c|c|}
\hline $\boldsymbol{Q}_{G S C}$ & \multicolumn{2}{|c|}{$\begin{array}{c}\text { Model without } \\
\text { Internal Energy. }\end{array}$} & \multicolumn{2}{c|}{$\begin{array}{c}\text { Gücüyener } \\
\text { \& Liu }\end{array}$} & \multicolumn{2}{|c|}{ Guo } \\
\hline scft/min & PD & $|\mathbf{P D}|$ & PD & $|\mathbf{P D}|$ & PD & $\mid$ PD $\mid$ \\
\hline 0 & 0.000 & 0.000 & 1.522 & 1.522 & & \\
\hline 200 & 0.229 & 0.229 & 2.051 & 2.051 & -1143.287 & 1143.287 \\
\hline 500 & 0.376 & 0.376 & 2.576 & 2.576 & -420.286 & 420.286 \\
\hline 750 & 0.395 & 0.395 & 2.831 & 2.831 & -261.202 & 261.202 \\
\hline 1000 & 0.365 & 0.365 & 3.039 & 3.039 & -182.544 & 182.544 \\
\hline 1500 & 0.254 & 0.254 & 3.441 & 3.441 & -105.459 & 105.459 \\
\hline Average & $\mathbf{0 . 2 7 0}$ & $\mathbf{0 . 2 7 0}$ & $\mathbf{2 . 5 7 7}$ & $\mathbf{2 . 5 7 7}$ & $\mathbf{- 4 2 2 . 5 5 6}$ & $\mathbf{4 2 2 . 5 5 6}$ \\
\hline SD & $\mathbf{0 . 1 4 9}$ & $\mathbf{0 . 1 4 9}$ & $\mathbf{0 . 6 9 5}$ & $\mathbf{0 . 6 9 5}$ & $\mathbf{4 1 9 . 4 1 9}$ & $\mathbf{4 1 9 . 4 1 9}$ \\
\hline
\end{tabular}


Table $11 P_{B}$ values of Case 1 at $q_{l}=200 \mathrm{gal} / \mathrm{min}$ and $P_{B H}=1250 \mathrm{psia}$

\begin{tabular}{|c|c|c|c|c|}
\hline $\begin{array}{c}\boldsymbol{Q}_{G S C} \\
\text { scft/min }\end{array}$ & $\begin{array}{c}\text { Proposed } \\
\text { Model }\end{array}$ & $\begin{array}{c}\text { Model without } \\
\text { Internal Energy }\end{array}$ & $\begin{array}{c}\text { Gücüyener } \\
\text { \& Liu }\end{array}$ & Guo \\
\hline 0 & 265.300 & 265.300 & 269.400 & 0.000 \\
\hline 200 & 284.800 & 285.700 & 291.300 & 9.200 \\
\hline 500 & 315.700 & 317.600 & 325.400 & 25.400 \\
\hline 750 & 343.000 & 345.400 & 355.000 & 41.100 \\
\hline 1000 & 371.500 & 374.200 & 385.600 & 59.000 \\
\hline 1500 & 431.800 & 434.800 & 450.100 & 101.100 \\
\hline
\end{tabular}

\begin{tabular}{|c|c|c|c|c|c|c|}
\hline$Q_{G S C}$ & \multicolumn{2}{|c|}{$\begin{array}{c}\text { Model without } \\
\text { Internal Energy. }\end{array}$} & \multicolumn{2}{c|}{$\begin{array}{c}\text { Gücüyener } \\
\text { \& Liu }\end{array}$} & \multicolumn{2}{|c|}{ Guo } \\
\hline scft/min & PD & $|\mathbf{P D}|$ & PD & $|\mathbf{P D}|$ & PD & $\mid$ PD $\mid$ \\
\hline 0 & 0.000 & 0.000 & 1.522 & 1.522 & & \\
\hline 200 & 0.315 & 0.315 & 2.231 & 2.231 & -2995.652 & 2995.652 \\
\hline 500 & 0.598 & 0.598 & 2.981 & 2.981 & -1142.913 & 1142.913 \\
\hline 750 & 0.695 & 0.695 & 3.380 & 3.380 & -734.550 & 734.550 \\
\hline 1000 & 0.722 & 0.722 & 3.657 & 3.657 & -529.661 & 529.661 \\
\hline 1500 & 0.690 & 0.690 & 4.066 & 4.066 & -327.102 & 327.102 \\
\hline Average & $\mathbf{0 . 5 0 3}$ & $\mathbf{0 . 5 0 3}$ & $\mathbf{2 . 9 7 3}$ & $\mathbf{2 . 9 7 3}$ & $\mathbf{- 1 1 4 5 . 9 7 6}$ & $\mathbf{1 1 4 5 . 9 7 6}$ \\
\hline SD & $\mathbf{0 . 2 8 9}$ & $\mathbf{0 . 2 8 9}$ & $\mathbf{0 . 9 4 7}$ & $\mathbf{0 . 9 4 7}$ & $\mathbf{1 0 7 7 . 1 4 7}$ & $\mathbf{1 0 7 7 . 1 4 7}$ \\
\hline
\end{tabular}


Table $12 P_{B}$ values of Case 1 at $q_{l}=200 \mathrm{gal} / \mathrm{min}$ and $P_{B H}=1750 \mathrm{psia}$

\begin{tabular}{|c|c|c|c|c|}
\hline $\begin{array}{c}\boldsymbol{Q}_{G S C} \\
\text { scft/min }\end{array}$ & $\begin{array}{c}\text { Proposed } \\
\text { Model }\end{array}$ & $\begin{array}{c}\text { Model without } \\
\text { Internal Energy }\end{array}$ & $\begin{array}{c}\text { Gücüyener } \\
\text { \& Liu }\end{array}$ & Guo \\
\hline 0 & 265.300 & 265.300 & 269.400 & 0.000 \\
\hline 200 & 277.000 & 277.900 & 283.400 & 4.600 \\
\hline 500 & 295.600 & 297.500 & 304.900 & 12.400 \\
\hline 750 & 311.800 & 314.400 & 323.300 & 19.800 \\
\hline 1000 & 328.700 & 331.800 & 342.300 & 27.900 \\
\hline 1500 & 364.300 & 368.000 & 381.600 & 46.600 \\
\hline
\end{tabular}

\begin{tabular}{|c|c|c|c|c|c|c|}
\hline$Q_{G S C}$ & \multicolumn{2}{|c|}{$\begin{array}{c}\text { Model without } \\
\text { Internal Energy. }\end{array}$} & \multicolumn{2}{c|}{$\begin{array}{c}\text { Gücüyener } \\
\text { \& Liu }\end{array}$} & \multicolumn{2}{|c|}{ Guo } \\
\hline scft/min & PD & $|\mathbf{P D}|$ & PD & $|\mathbf{P D}|$ & PD & $\mid$ PD $\mid$ \\
\hline 0 & 0.000 & 0.000 & 1.522 & 1.522 & & \\
\hline 200 & 0.324 & 0.324 & 2.258 & 2.258 & -5921.739 & 5921.739 \\
\hline 500 & 0.639 & 0.639 & 3.050 & 3.050 & -2283.871 & 2283.871 \\
\hline 750 & 0.827 & 0.827 & 3.557 & 3.557 & -1474.747 & 1474.747 \\
\hline 1000 & 0.934 & 0.934 & 3.973 & 3.973 & -1078.136 & 1078.136 \\
\hline 1500 & 1.005 & 1.005 & 4.534 & 4.534 & -681.760 & 681.760 \\
\hline Average & $\mathbf{0 . 6 2 2}$ & $\mathbf{0 . 6 2 2}$ & $\mathbf{3 . 1 4 9}$ & $\mathbf{3 . 1 4 9}$ & $\mathbf{- 2 2 8 8 . 0 5 1}$ & $\mathbf{2 2 8 8 . 0 5 1}$ \\
\hline SD & $\mathbf{0 . 3 9 1}$ & $\mathbf{0 . 3 9 1}$ & $\mathbf{1 . 1 1 5}$ & $\mathbf{1 . 1 1 5}$ & $\mathbf{2 1 1 5 . 9 6 5}$ & $\mathbf{2 1 1 5 . 9 6 5}$ \\
\hline
\end{tabular}


Table $13 P_{B}$ values of Case 1 at $q_{l}=300 \mathrm{gal} / \mathrm{min}$ and $P_{B H}=500 \mathrm{psia}$

\begin{tabular}{|c|c|c|c|c|}
\hline $\begin{array}{c}\boldsymbol{Q}_{G S C} \\
\text { scft/min }\end{array}$ & $\begin{array}{c}\text { Proposed } \\
\text { Model }\end{array}$ & $\begin{array}{c}\text { Model without } \\
\text { Internal Energy }\end{array}$ & $\begin{array}{c}\text { Gücüyener } \\
\text { \& Liu }\end{array}$ & Guo \\
\hline 0.0 & 596.800 & 596.800 & 606.100 & 0.000 \\
\hline 200 & 714.300 & 714.900 & 726.400 & 112.910 \\
\hline 500 & 910.900 & 912.500 & 928.100 & 312.580 \\
\hline 512.0 & 921.440 & 921.970 & 936.800 & 321.230 \\
\hline
\end{tabular}

\begin{tabular}{|c|c|c|c|c|c|c|}
\hline $\boldsymbol{Q}_{G S C}$ & \multicolumn{2}{|c|}{$\begin{array}{c}\text { Model without } \\
\text { Internal Energy. }\end{array}$} & \multicolumn{2}{c|}{$\begin{array}{c}\text { Gücüyener } \\
\text { \& Liu }\end{array}$} & \multicolumn{2}{|c|}{ Guo } \\
\hline scft/min & PD & $|\mathbf{P D}|$ & PD & $|\mathbf{P D}|$ & PD & $\mid$ PD $\mid$ \\
\hline 0.0 & 0.000 & 0.000 & 1.534 & 1.534 & & \\
\hline 200 & 0.084 & 0.084 & 1.666 & 1.666 & -532.628 & 532.628 \\
\hline 500 & 0.175 & 0.175 & 1.853 & 1.853 & -191.413 & 191.413 \\
\hline 512.0 & 0.057 & 0.057 & 1.640 & 1.640 & -186.847 & 186.847 \\
\hline Average & $\mathbf{0 . 0 7 9}$ & $\mathbf{0 . 0 7 9}$ & $\mathbf{1 . 6 7 3}$ & $\mathbf{1 . 6 7 3}$ & $\mathbf{- 3 0 3 . 6 3 0}$ & $\mathbf{3 0 3 . 6 3 0}$ \\
\hline SD & $\mathbf{0 . 0 7 3}$ & $\mathbf{0 . 0 7 3}$ & $\mathbf{0 . 1 3 3}$ & $\mathbf{0 . 1 3 3}$ & $\mathbf{1 9 8 . 3 3 1}$ & $\mathbf{1 9 8 . 3 3 1}$ \\
\hline
\end{tabular}


Table $14 P_{B}$ values of Case 1 at $q_{l}=300 \mathrm{gal} / \mathrm{min}$ and $P_{B H}=750 \mathrm{psia}$

\begin{tabular}{|c|c|c|c|c|}
\hline $\begin{array}{c}\boldsymbol{Q}_{G S C} \\
\text { scft/min }\end{array}$ & $\begin{array}{c}\text { Proposed } \\
\text { Model }\end{array}$ & $\begin{array}{c}\text { Model without } \\
\text { Internal Energy }\end{array}$ & $\begin{array}{c}\text { Gücüyener } \\
\text { \& Liu }\end{array}$ & Guo \\
\hline 0 & 596.800 & 596.800 & 606.100 & 0.000 \\
\hline 200 & 664.400 & 665.000 & 676.400 & 59.260 \\
\hline 500 & 772.100 & 773.600 & 788.800 & 161.350 \\
\hline 750 & 868.200 & 870.300 & 889.200 & 257.700 \\
\hline 1000 & 970.100 & 972.800 & 996.000 & 363.400 \\
\hline 1142.1 & 1036.440 & 1036.570 & 1059.800 & 427.400 \\
\hline
\end{tabular}

\begin{tabular}{|c|c|c|c|c|c|c|}
\hline$Q_{G S C}$ & \multicolumn{2}{|c|}{$\begin{array}{c}\text { Model without } \\
\text { Internal Energy. }\end{array}$} & \multicolumn{2}{c|}{$\begin{array}{c}\text { Gücüyener } \\
\text { \& Liu }\end{array}$} & \multicolumn{2}{|c|}{ Guo } \\
\hline scft/min & PD & $|\mathbf{P D}|$ & PD & $|\mathbf{P D}|$ & PD & $\mid$ PD $\mid$ \\
\hline 0 & 0.000 & 0.000 & 1.534 & 1.534 & & \\
\hline 200 & 0.090 & 0.090 & 1.774 & 1.774 & -1021.161 & 1021.161 \\
\hline 500 & 0.194 & 0.194 & 2.117 & 2.117 & -378.525 & 378.525 \\
\hline 750 & 0.241 & 0.241 & 2.362 & 2.362 & -236.903 & 236.903 \\
\hline 1000 & 0.278 & 0.278 & 2.600 & 2.600 & -166.951 & 166.951 \\
\hline 1142.1 & 0.013 & 0.013 & 2.204 & 2.204 & -142.499 & 142.499 \\
\hline Average & $\mathbf{0 . 1 3 6}$ & $\mathbf{0 . 1 3 6}$ & $\mathbf{2 . 0 9 9}$ & $\mathbf{2 . 0 9 9}$ & $\mathbf{- 3 8 9 . 2 0 8}$ & $\mathbf{3 8 9 . 2 0 8}$ \\
\hline SD & $\mathbf{0 . 1 1 9}$ & $\mathbf{0 . 1 1 9}$ & $\mathbf{0 . 3 8 9}$ & $\mathbf{0 . 3 8 9}$ & $\mathbf{3 6 5 . 0 1 3}$ & $\mathbf{3 6 5 . 0 1 3}$ \\
\hline
\end{tabular}


Table $15 P_{B}$ values of Case 1 at $q_{l}=300 \mathrm{gal} / \mathrm{min}$ and $P_{B H}=1250 \mathrm{psia}$

\begin{tabular}{|c|c|c|c|c|}
\hline $\begin{array}{c}\boldsymbol{Q}_{G S C} \\
\text { scft/min }\end{array}$ & $\begin{array}{c}\text { Proposed } \\
\text { Model }\end{array}$ & $\begin{array}{c}\text { Model without } \\
\text { Internal Energy }\end{array}$ & $\begin{array}{c}\text { Gücüyener } \\
\text { \& Liu }\end{array}$ & Guo \\
\hline 0 & 596.800 & 596.800 & 606.100 & 0.000 \\
\hline 200 & 629.600 & 630.300 & 641.400 & 24.500 \\
\hline 500 & 680.400 & 682.000 & 696.000 & 64.900 \\
\hline 750 & 724.400 & 726.600 & 743.100 & 102.100 \\
\hline 1000 & 769.800 & 772.500 & 791.800 & 142.400 \\
\hline 1500 & 865.000 & 868.500 & 894.000 & 232.000 \\
\hline
\end{tabular}

\begin{tabular}{|c|c|c|c|c|c|c|}
\hline$Q_{G S C}$ & \multicolumn{2}{|c|}{$\begin{array}{c}\text { Model without } \\
\text { Internal Energy. }\end{array}$} & \multicolumn{2}{c|}{$\begin{array}{c}\text { Gücüyener } \\
\text { \& Liu }\end{array}$} & \multicolumn{2}{|c|}{ Guo } \\
\hline scft/min & PD & $|\mathbf{P D}|$ & PD & $\mid$ PD $\mid$ & PD & $\mid$ PD $\mid$ \\
\hline 0 & 0.000 & 0.000 & 1.534 & 1.534 & & \\
\hline 200 & 0.111 & 0.111 & 1.840 & 1.840 & -2469.796 & 2469.796 \\
\hline 500 & 0.235 & 0.235 & 2.241 & 2.241 & -948.382 & 948.382 \\
\hline 750 & 0.303 & 0.303 & 2.516 & 2.516 & -609.500 & 609.500 \\
\hline 1000 & 0.350 & 0.350 & 2.778 & 2.778 & -440.590 & 440.590 \\
\hline 1500 & 0.403 & 0.403 & 3.244 & 3.244 & -272.845 & 272.845 \\
\hline Average & $\mathbf{0 . 2 3 3}$ & $\mathbf{0 . 2 3 3}$ & $\mathbf{2 . 3 5 9}$ & $\mathbf{2 . 3 5 9}$ & $\mathbf{- 9 4 8 . 2 2 3}$ & $\mathbf{9 4 8 . 2 2 3}$ \\
\hline SD & $\mathbf{0 . 1 5 3}$ & $\mathbf{0 . 1 5 3}$ & $\mathbf{0 . 6 2 4}$ & $\mathbf{0 . 6 2 4}$ & $\mathbf{8 8 6 . 5 3 0}$ & $\mathbf{8 8 6 . 5 3 0}$ \\
\hline
\end{tabular}


Table $16 P_{B}$ values of Case 1 at $q_{l}=300 \mathrm{gal} / \mathrm{min}$ and $P_{B H}=1750 \mathrm{psia}$

\begin{tabular}{|c|c|c|c|c|}
\hline $\begin{array}{c}\boldsymbol{Q}_{G S C} \\
\text { scft/min }\end{array}$ & $\begin{array}{c}\text { Proposed } \\
\text { Model }\end{array}$ & $\begin{array}{c}\text { Model without } \\
\text { Internal Energy }\end{array}$ & $\begin{array}{c}\text { Gücüyener } \\
\text { \& Liu }\end{array}$ & Guo \\
\hline 0 & 596.800 & 596.800 & 606.100 & 0.000 \\
\hline 200 & 616.800 & 617.400 & 628.200 & 12.900 \\
\hline 500 & 647.200 & 648.800 & 662.000 & 33.800 \\
\hline 750 & 673.500 & 675.700 & 690.900 & 52.600 \\
\hline 1000 & 700.400 & 703.100 & 720.400 & 72.600 \\
\hline 1500 & 756.100 & 759.600 & 781.300 & 116.500 \\
\hline
\end{tabular}

\begin{tabular}{|c|c|c|c|c|c|c|}
\hline$Q_{G S C}$ & \multicolumn{2}{|c|}{$\begin{array}{c}\text { Model without } \\
\text { Internal Energy. }\end{array}$} & \multicolumn{2}{c|}{$\begin{array}{c}\text { Gücüyener } \\
\text { \& Liu }\end{array}$} & \multicolumn{2}{|c|}{ Guo } \\
\hline scft/min & PD & $|\mathbf{P D}|$ & PD & $|\mathbf{P D}|$ & PD & $\mid$ PD $\mid$ \\
\hline 0 & 0.000 & 0.000 & 1.534 & 1.534 & & \\
\hline 200 & 0.097 & 0.097 & 1.815 & 1.815 & -4681.395 & 4681.395 \\
\hline 500 & 0.247 & 0.247 & 2.236 & 2.236 & -1814.793 & 1814.793 \\
\hline 750 & 0.326 & 0.326 & 2.518 & 2.518 & -1180.418 & 1180.418 \\
\hline 1000 & 0.384 & 0.384 & 2.776 & 2.776 & -864.738 & 864.738 \\
\hline 1500 & 0.461 & 0.461 & 3.225 & 3.225 & -549.013 & 549.013 \\
\hline Average & $\mathbf{0 . 2 5 2}$ & $\mathbf{0 . 2 5 2}$ & $\mathbf{2 . 3 5 1}$ & $\mathbf{2 . 3 5 1}$ & $\mathbf{- 1 8 1 8 . 0 7 2}$ & $\mathbf{1 8 1 8 . 0 7 2}$ \\
\hline SD & $\mathbf{0 . 1 7 5}$ & $\mathbf{0 . 1 7 5}$ & $\mathbf{0 . 6 2 3}$ & $\mathbf{0 . 6 2 3}$ & $\mathbf{1 6 6 7 . 6 7 7}$ & $\mathbf{1 6 6 7 . 6 7 7}$ \\
\hline
\end{tabular}




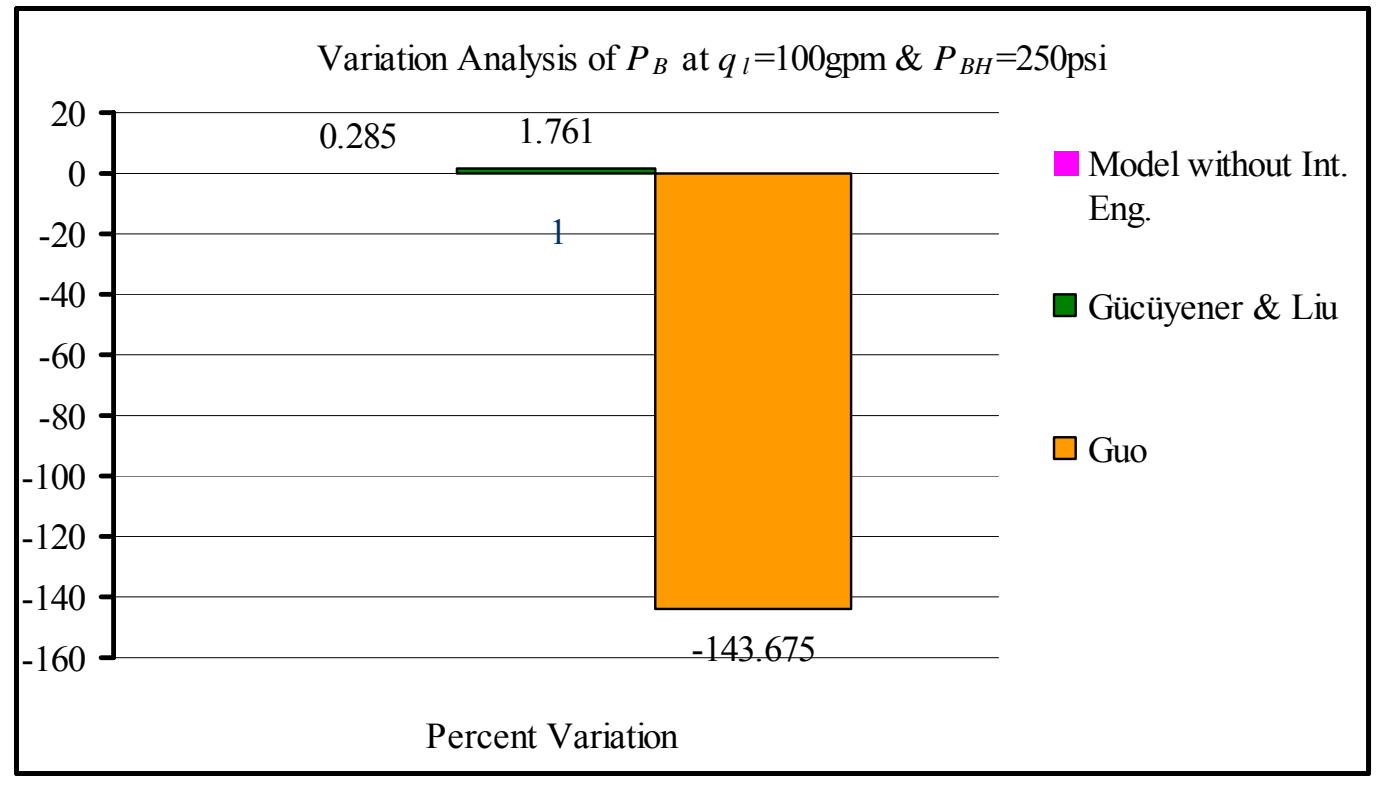

Figure 24 Variation Analysis of $P_{B H}$ at $q_{l}=100 \mathrm{gal} / \mathrm{min}$ and $P_{B H}=250 \mathrm{psi}$

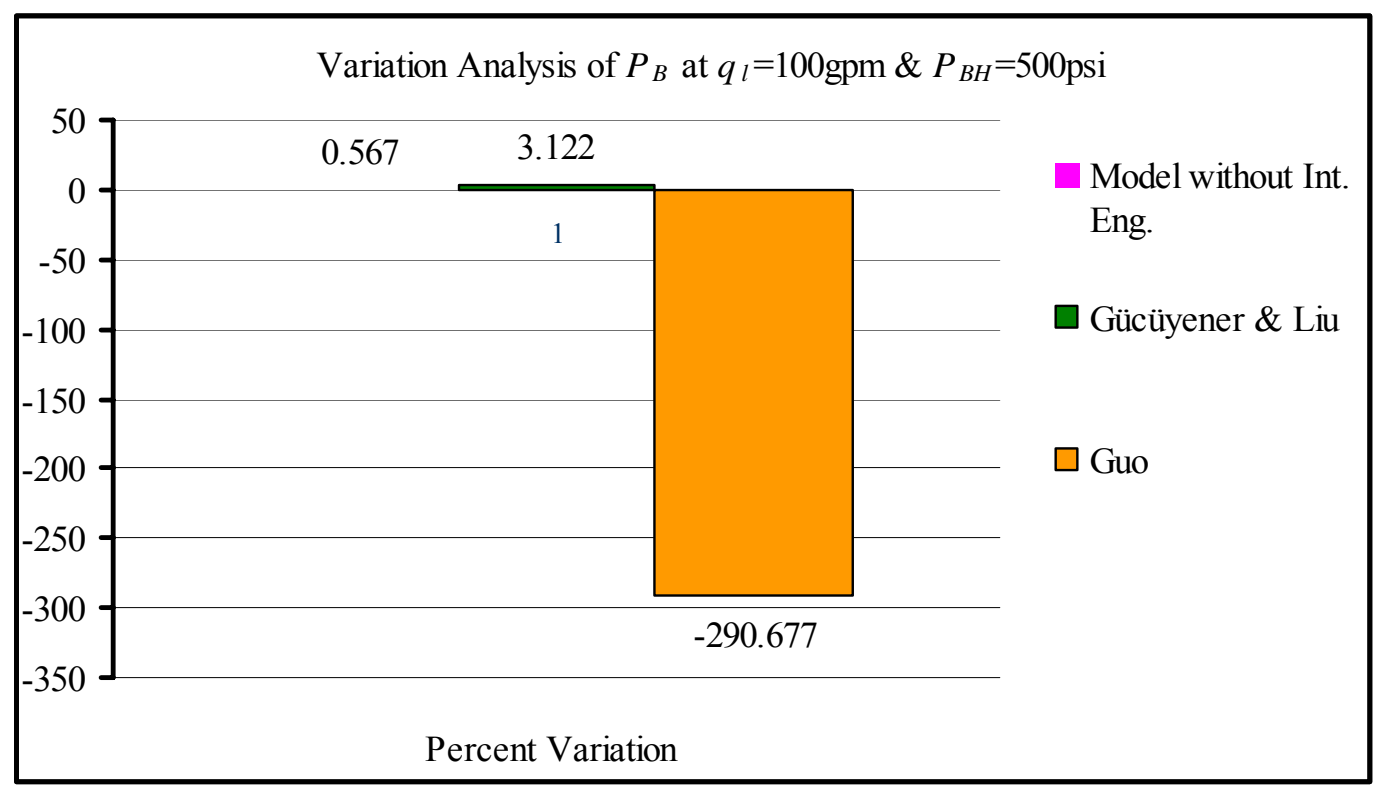

Figure 25 Variation Analysis of $P_{B H}$ at $q_{l}=100 \mathrm{gal} / \mathrm{min}$ and $P_{B H}=500 \mathrm{psi}$ 


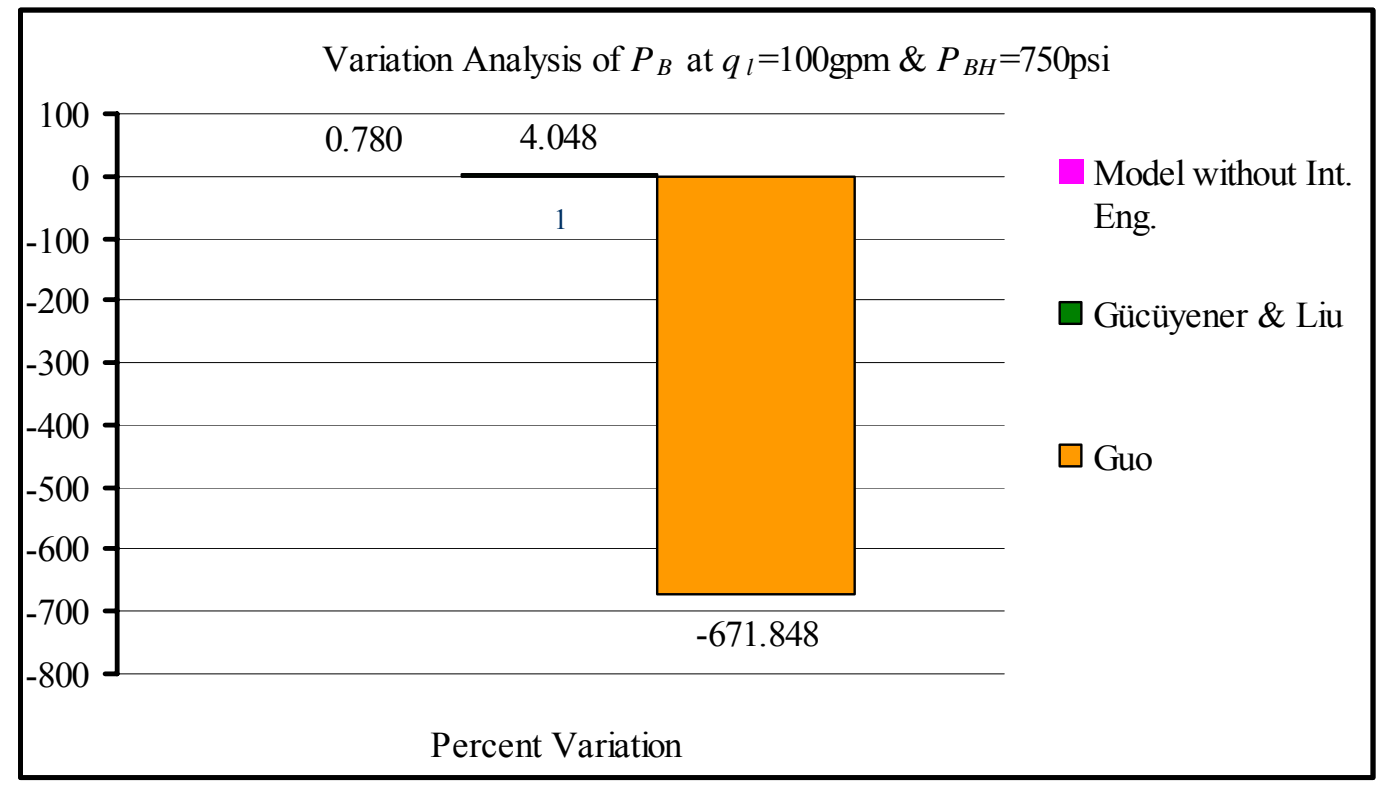

Figure 26 Variation Analysis of $P_{B}$ at $q_{l}=100 \mathrm{gal} / \mathrm{min}$ and $P_{B H}=750 \mathrm{psi}$

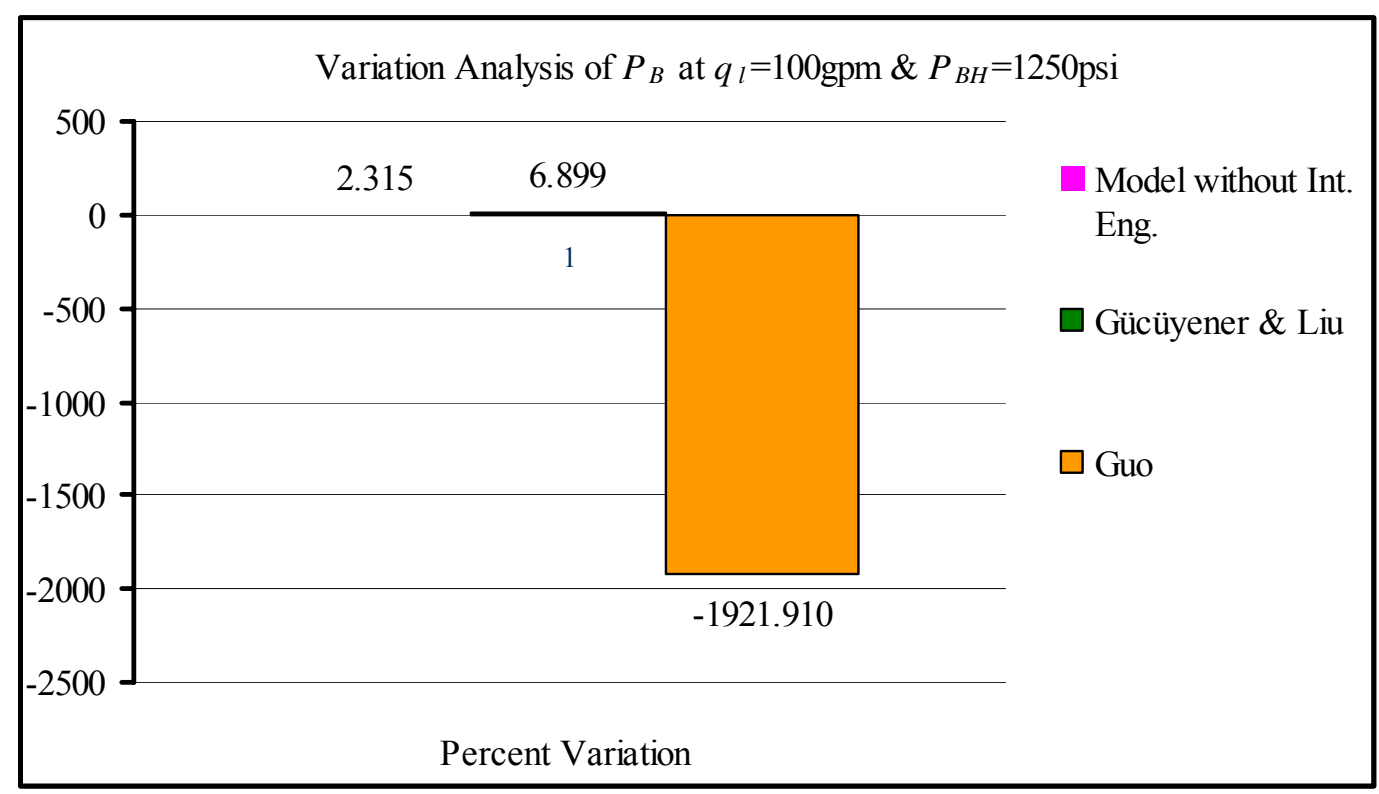

Figure 27 Variation Analysis of $P_{B}$ at $q_{l}=100 \mathrm{gal} / \mathrm{min}$ and $P_{B H}=1250 \mathrm{psi}$ 


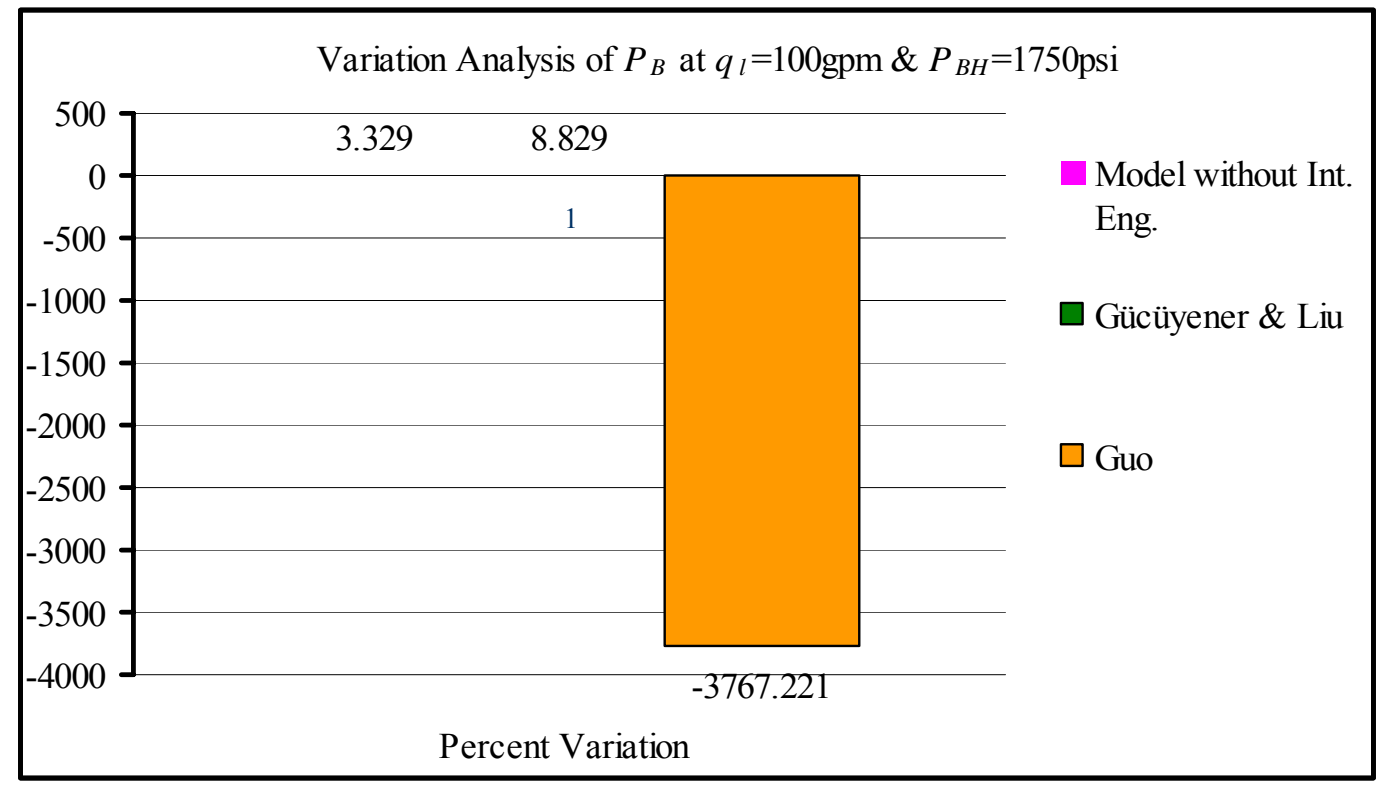

Figure 28 Variation Analysis of $P_{B}$ at $q_{l}=100 \mathrm{gal} / \mathrm{min}$ and $P_{B H}=1750 \mathrm{psi}$

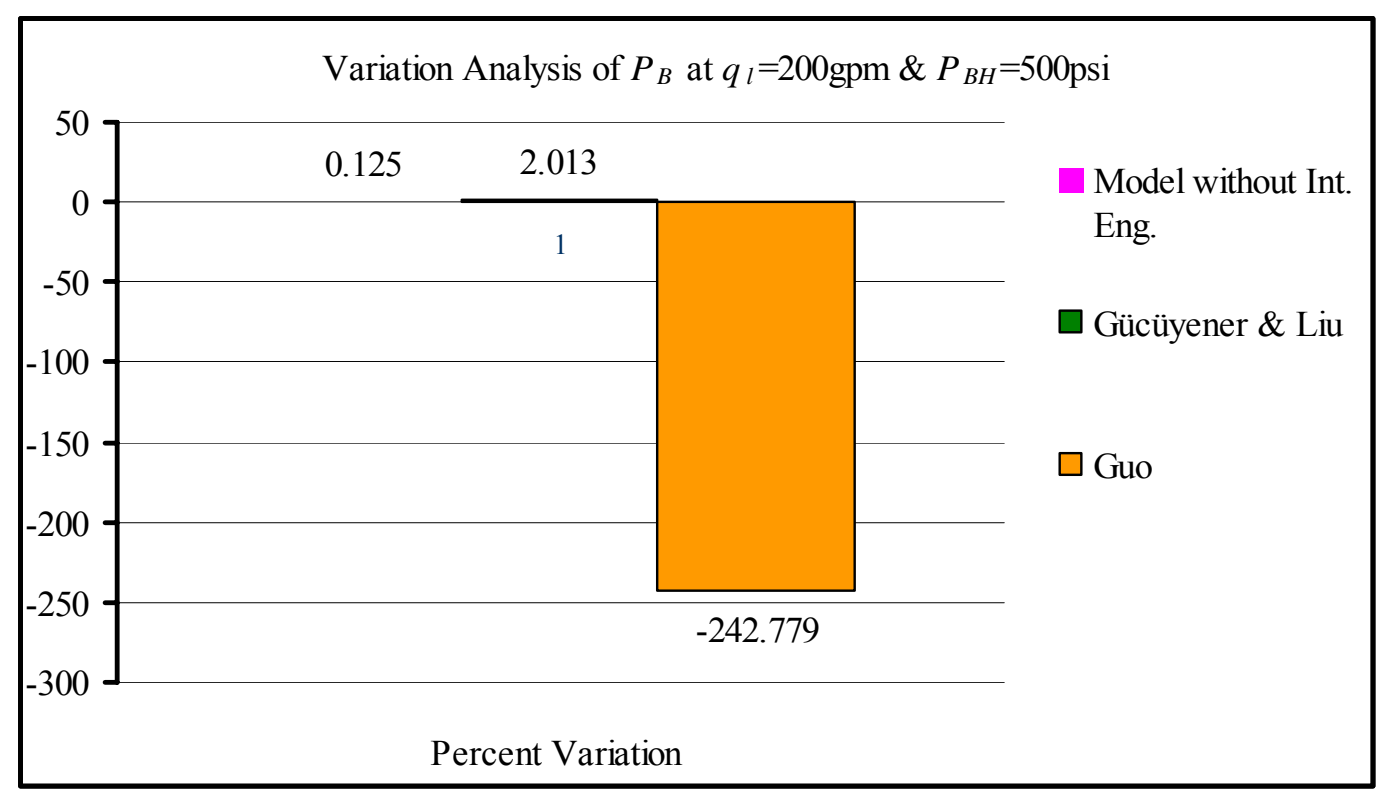

Figure 29 Variation Analysis of $P_{B}$ at $q_{l}=200 \mathrm{gal} / \mathrm{min}$ and $P_{B H}=500 \mathrm{psi}$ 


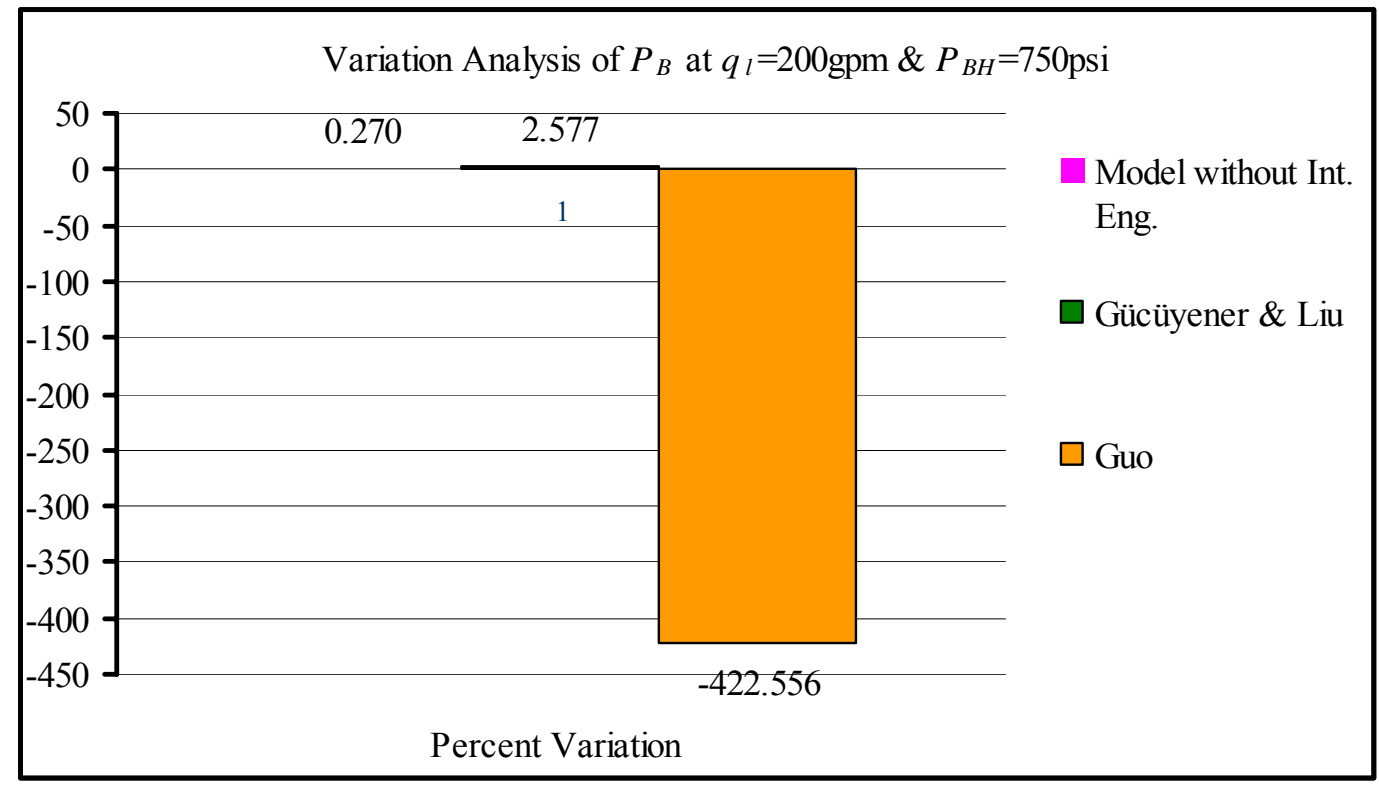

Figure 30 Variation Analysis of $P_{B}$ at $q_{l}=200 \mathrm{gal} / \mathrm{min}$ and $P_{B H}=750 \mathrm{psi}$

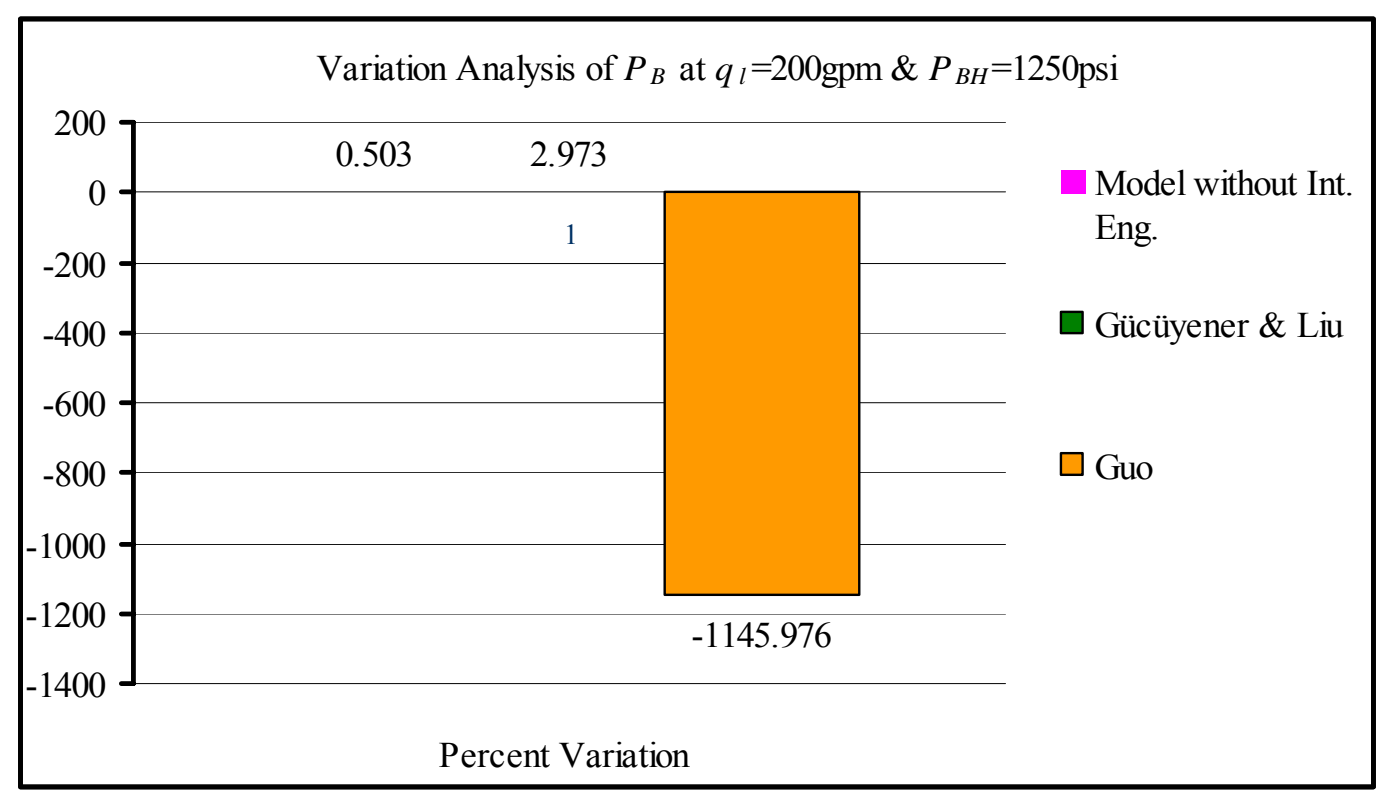

Figure 31 Variation Analysis of $P_{B}$ at $q_{l}=200 \mathrm{gal} / \mathrm{min}$ and $P_{B H}=1250 \mathrm{psi}$ 


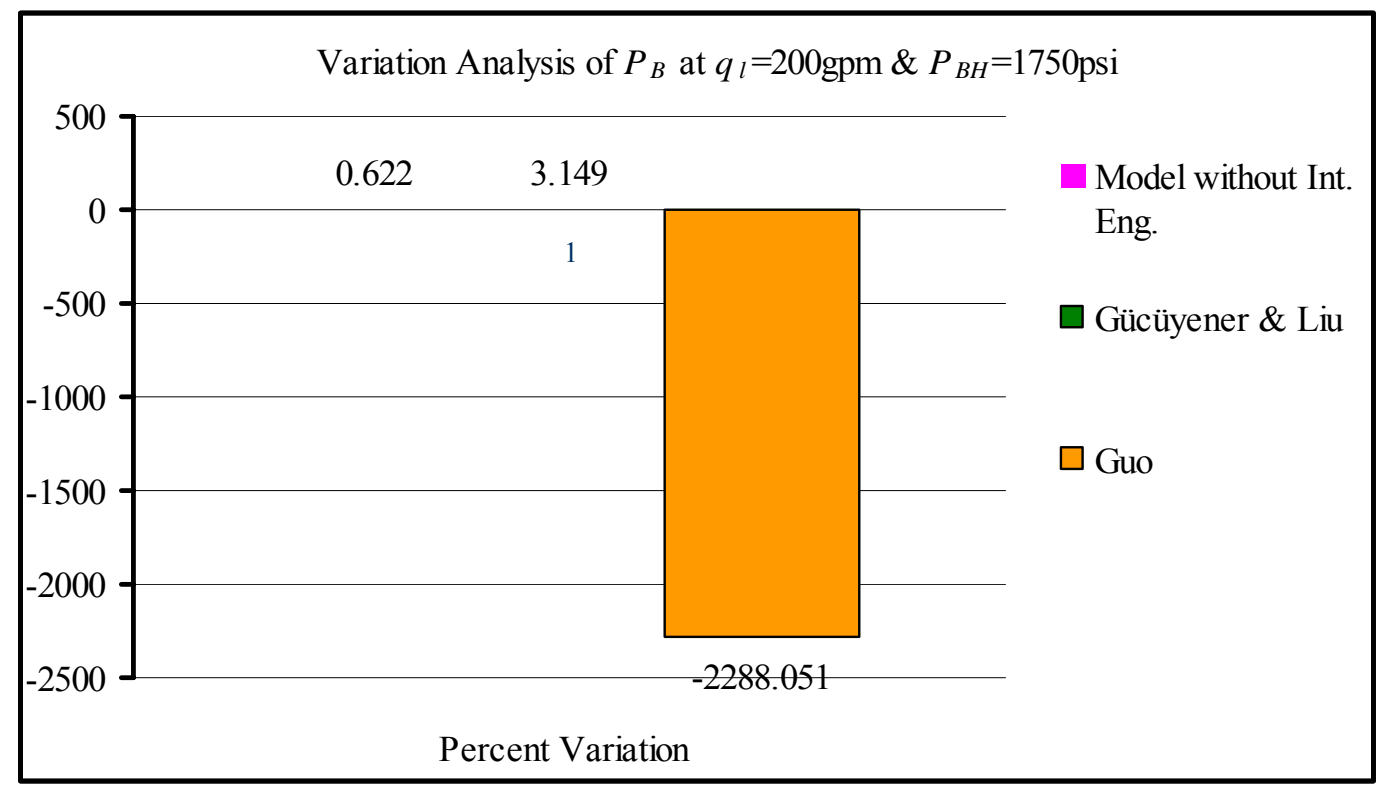

Figure 32 Variation Analysis of $P_{B}$ at $q_{l}=200 \mathrm{gal} / \mathrm{min}$ and $P_{B H}=1750 \mathrm{psi}$

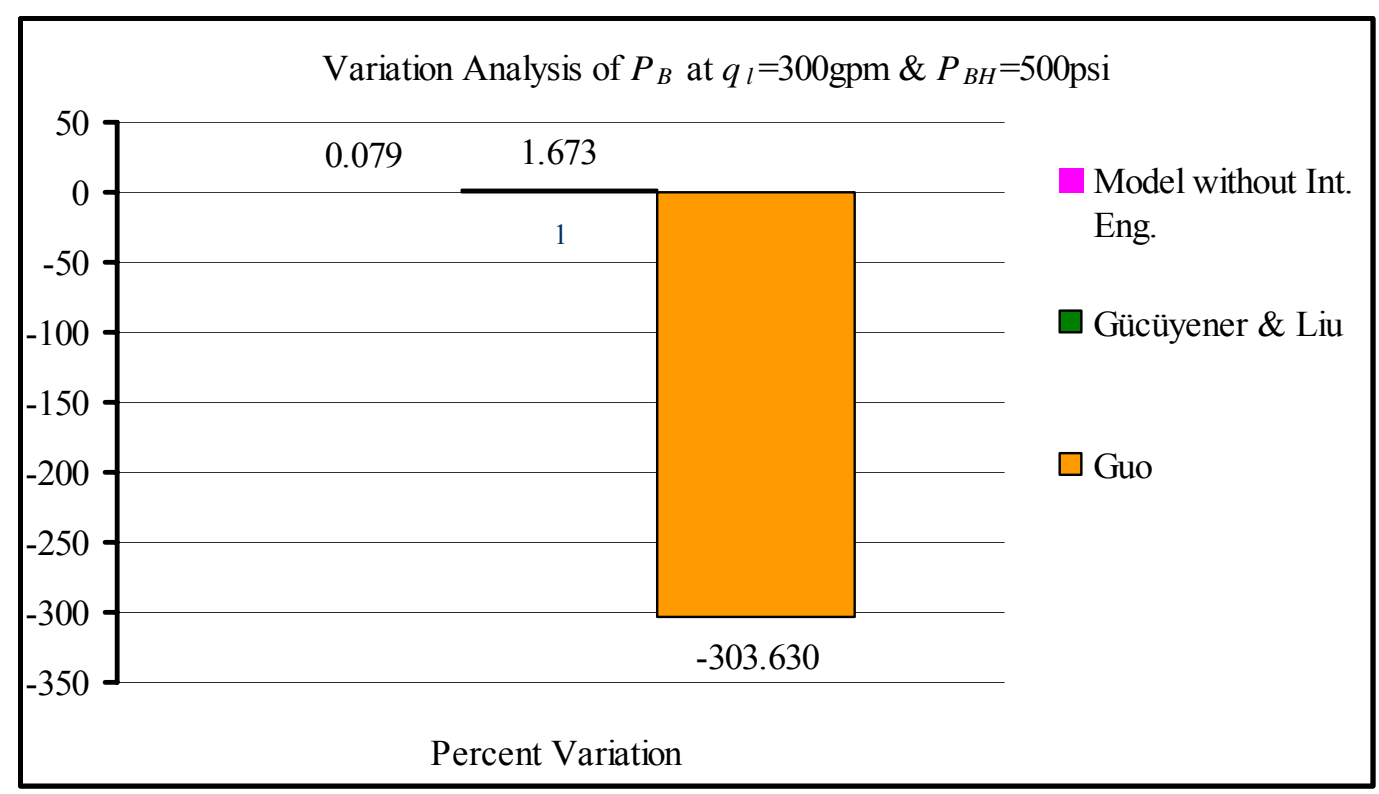

Figure 33 Variation Analysis of $P_{B}$ at $q_{l}=300 \mathrm{gal} / \mathrm{min}$ and $P_{B H}=500 \mathrm{psi}$ 


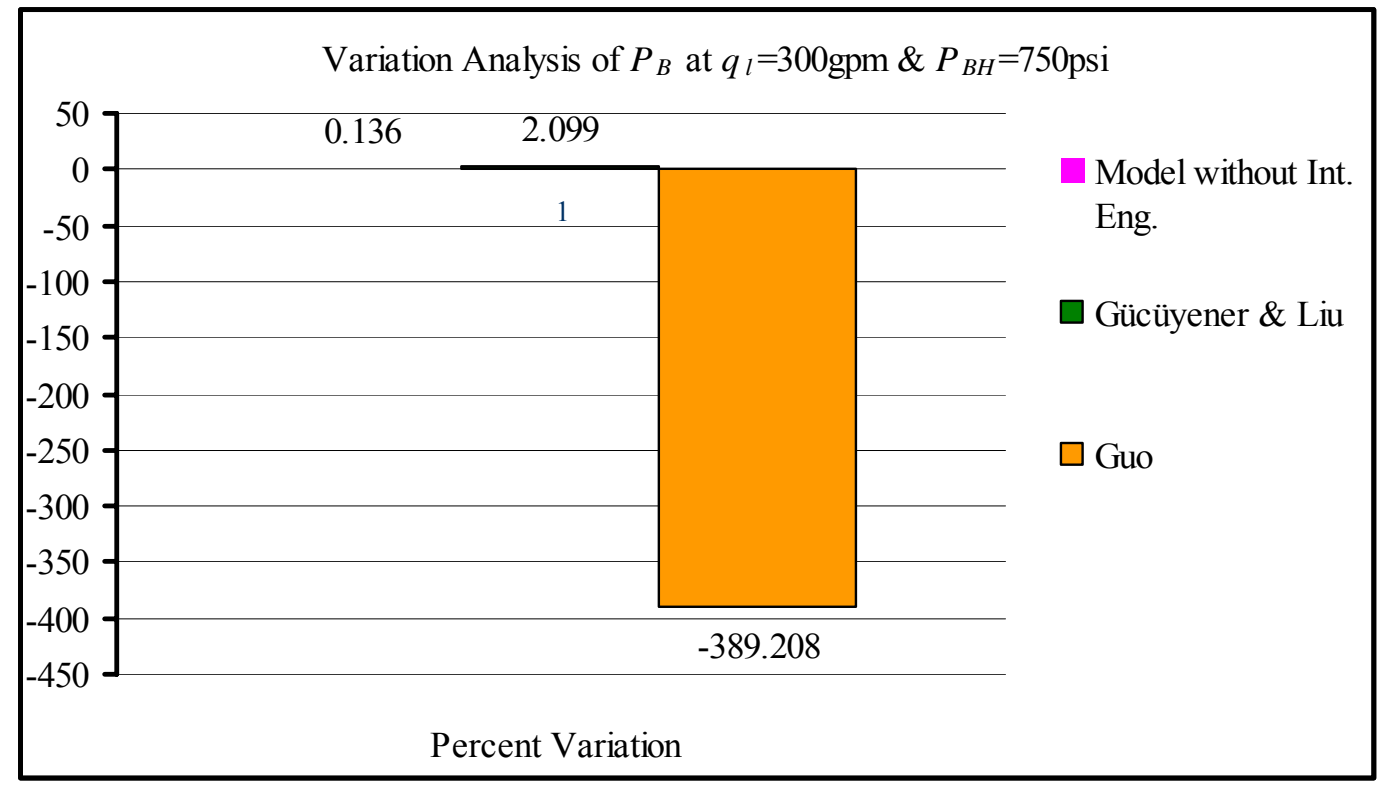

Figure 34 Variation Analysis of $P_{B}$ at $q_{l}=300 \mathrm{gal} / \mathrm{min}$ and $P_{B H}=750 \mathrm{psi}$

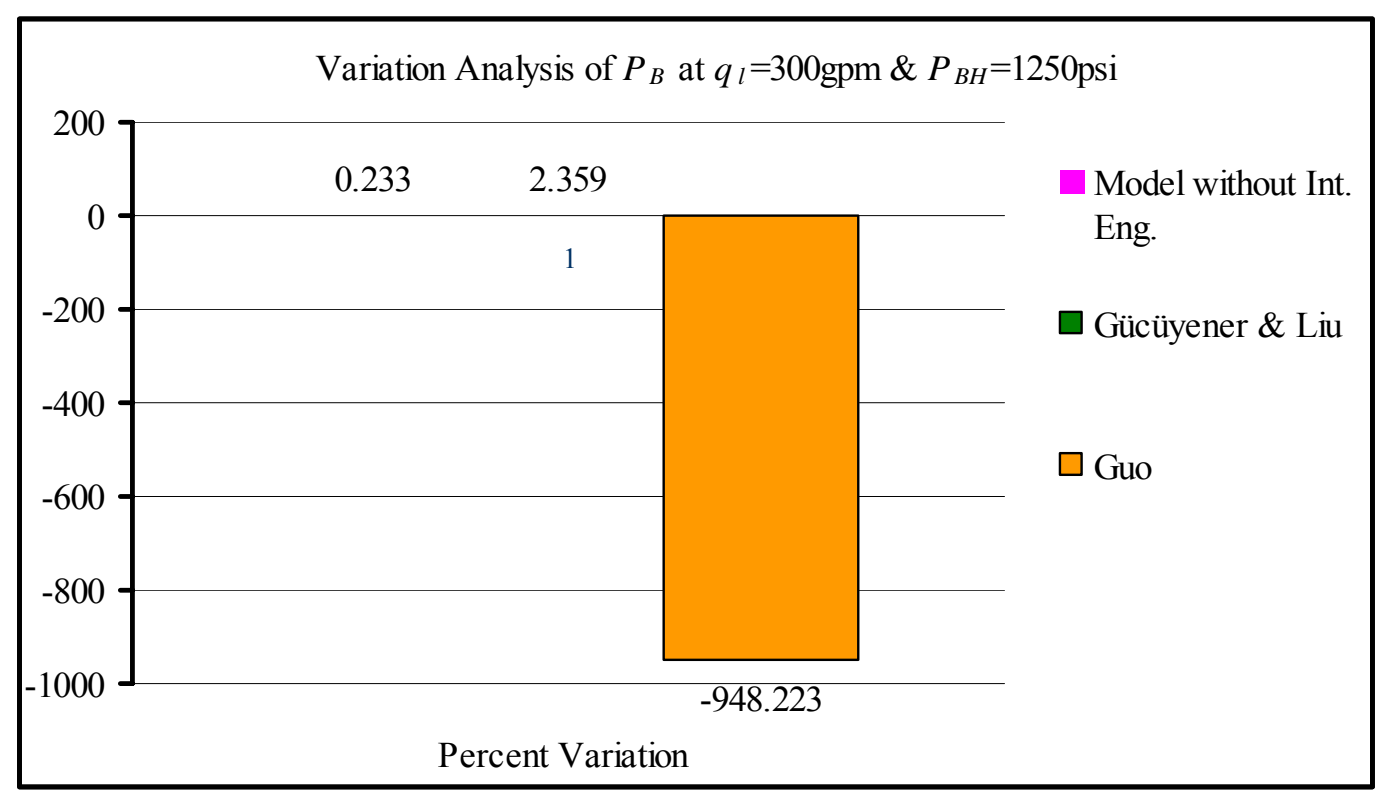

Figure 35 Variation Analysis of $P_{B}$ at $q_{l}=300 \mathrm{gal} / \mathrm{min}$ and $P_{B H}=1250 \mathrm{psi}$ 


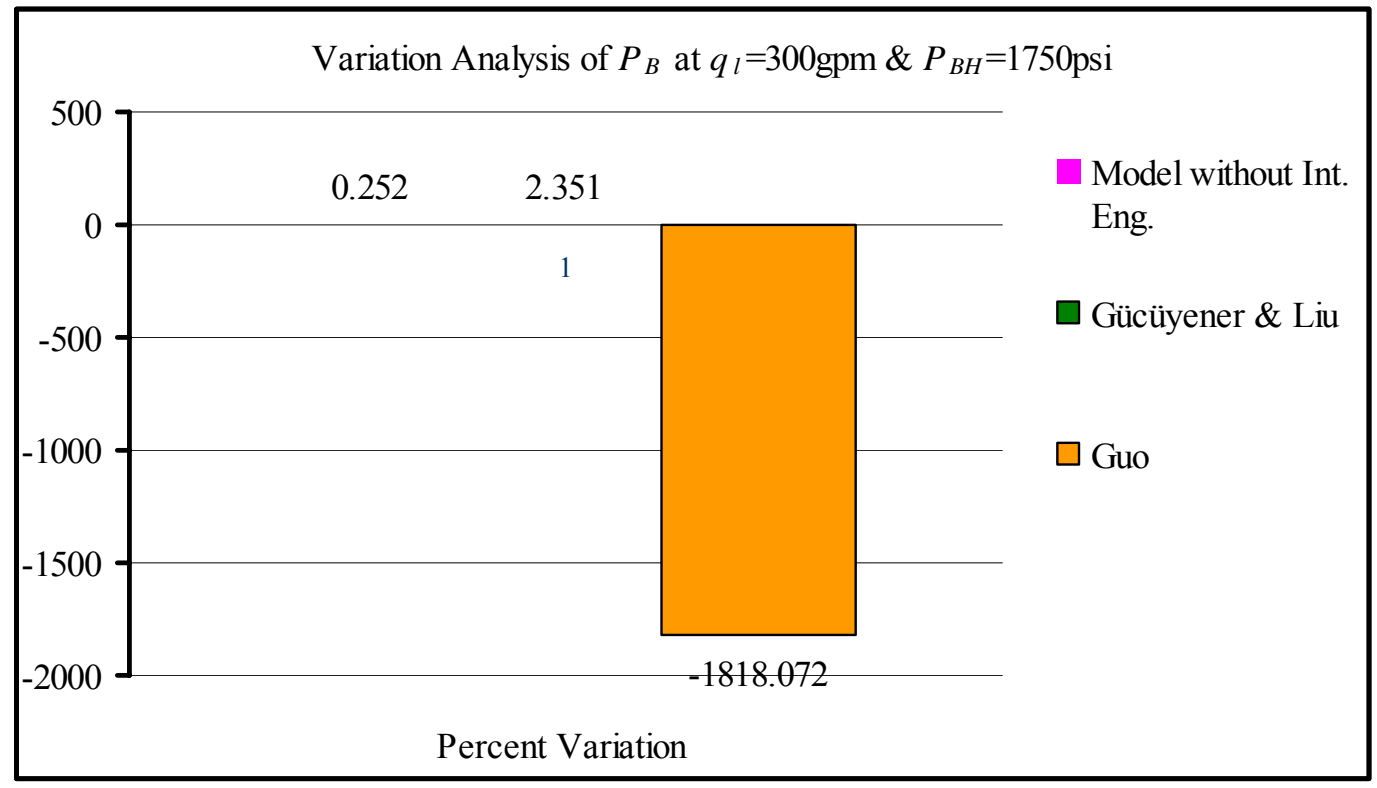

Figure 36 Variation Analysis of $P_{B}$ at $q_{l}=300 \mathrm{gal} / \mathrm{min}$ and $P_{B H}=1750 \mathrm{psi}$ 